Bicycle-Vehicle Interactions at Mid-Sections of Mixed Traffic Streets: Examining Passing Distance and Bicycle Comfort Perception

\author{
by
}

\title{
Peter Apasnore
}

B.Sc. Kwame Nkrumah University of Science and Technology, Ghana

A thesis submitted to the Faculty of Graduate and Postdoctoral Affairs in partial fulfillment of the requirements for the degree of

\author{
Master of Applied Science
}

in

Civil Engineering

Ottawa-Carleton Institute of Civil and Environmental Engineering

\author{
Carleton University \\ Ottawa, Ontario
}

(C) 2016, Peter Apasnore 


\begin{abstract}
This research studies relevant factors in mixed traffic that may impact bicycling comfort in Ottawa, Canada. The observations are: [i] the average position of bicyclists from the curb is $0.57 \mathrm{~m}$, and lesser (i.e. $0.35 \mathrm{~m}$ ) in the presence of parking; [ii] bicyclists ride slightly further from curbs for two lanes in travel direction compared to single lanes; [iii] $90 \%$ of passes exceed $1.23 \mathrm{~m}$; [iv] lateral spacing between bicycles and vehicles (passing distance, PD) is positively correlated to motor vehicle speed, lane width, and bicyclist position from adjacent curb edge line, whiles inversely correlated to ambient traffic density and bicycle speed; [v] motor speed has the highest prediction of PD variability. Two linear regression models for PD and Comfort perception were developed, both exhibiting limited predictive power similar to Love et al. (2012) and Stewart and McHale (2014). Residual plots and significance of included variables are however indicative of correct model assumptions.
\end{abstract}




\section{Acknowledgements}

The foremost appreciation and gratitude goes to the almighty God for the strength, good health, and fitness of the mind to successfully complete this thesis.

Next, I want to sincerely express my deep felt thankfulness to my research supervisor Professor Karim Ismail, without whom this thesis will not have been possible. I thank him for his belief in me, his unwavering and professional support, guidance, encouragement, constructive criticism and friendly approach to issues over the past two years of this research. I also want to thank the examiners Professor Ata Khan, Professor Steven Prus and Professor Jeffrey Erochko for taking time off their busy schedules to review my thesis, partake in the examination and provide me constructive feedback.

In addition, I am grateful to Dr. Ali Kassim for assisting me with effective advices and sharing some of his video data with me. I also want to thank my friends Fayez Alamry, Mahad Musse, Jonathan Tsikata and all the people who helped me throughout this research especially in the data collection, experiments and measurements. I appreciate the participation of all the individuals who submitted evaluations on bicycling comfort as well as the bicycle clubs who did lend me a helping hand.

Finally, but not the least, I am very grateful to my family - my father, Alex; my mother, Felicia; and my sisters, Abigail, Hannah and Esther. Their unconditional love, prayers, encouragement, and support all through my life, especially the past two years has been immense. 


\section{Table of Contents}

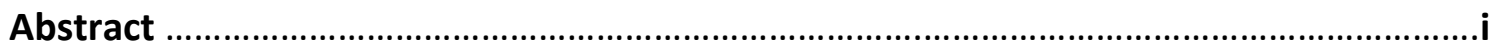

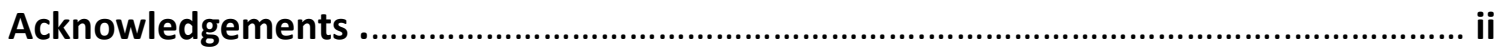

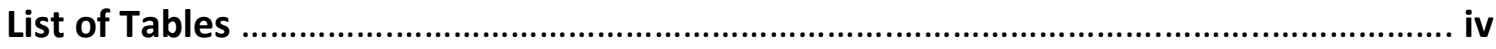

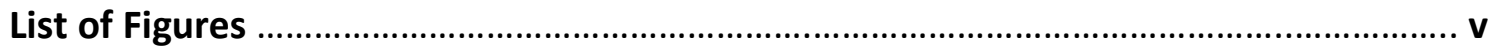

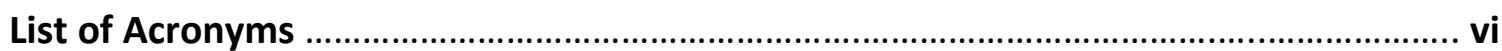

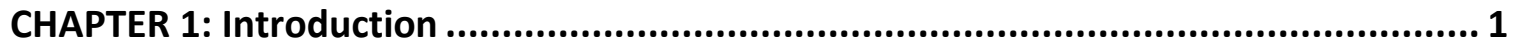

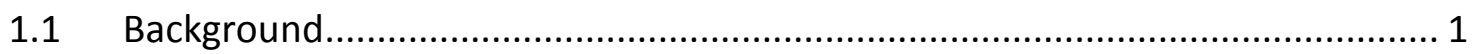

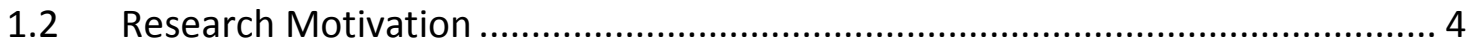

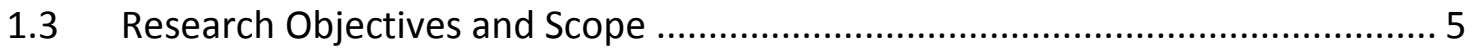

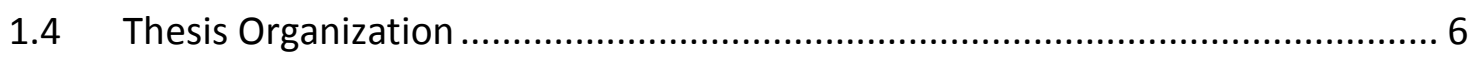

CHAPTER 2: Literature Review .............................................................................. 7

2.1 Background

2.2 Mixed Traffic Interactions or Road Sharing .................................................. 8

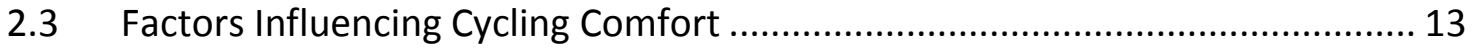

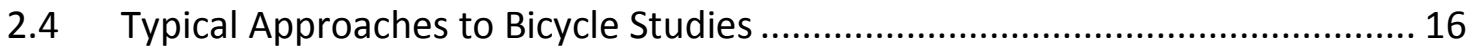

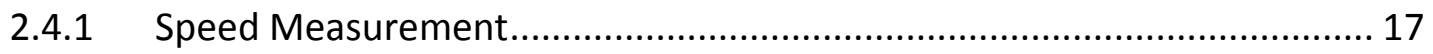

2.4.2 Lateral Distance measurement (Passing Distance) ................................... 19

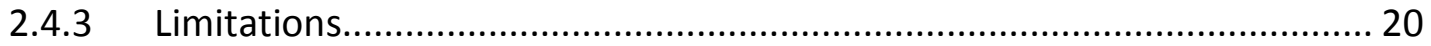

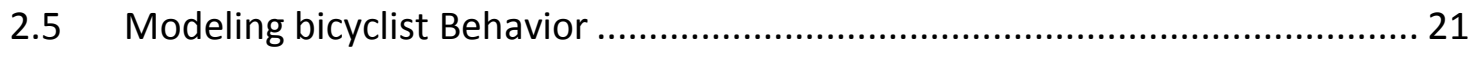

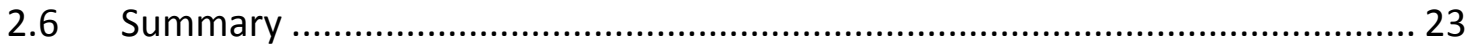

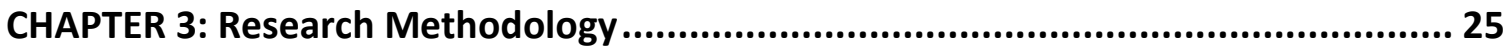

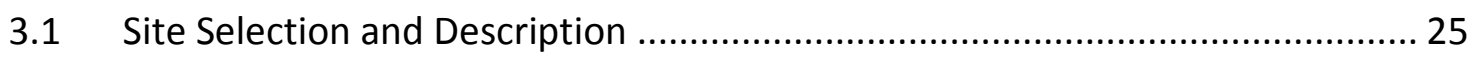

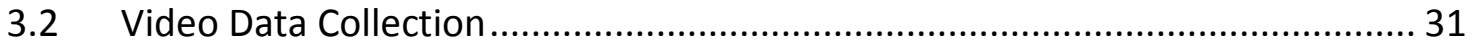

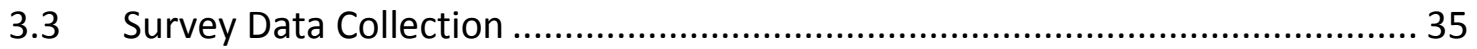

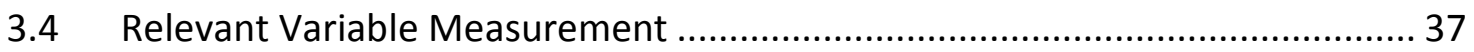

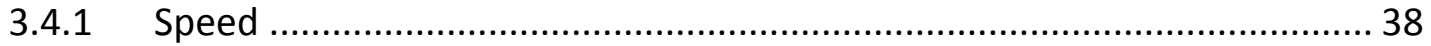

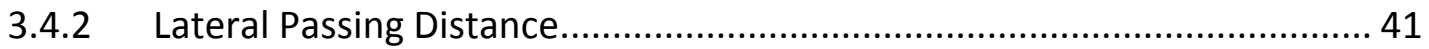

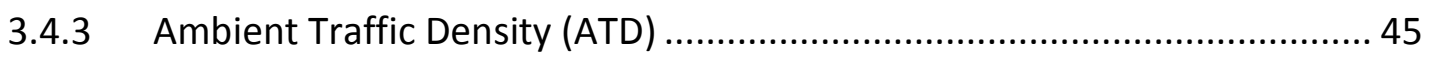

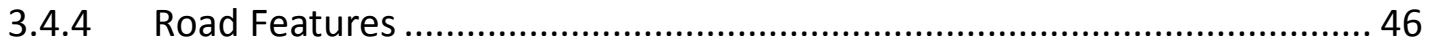




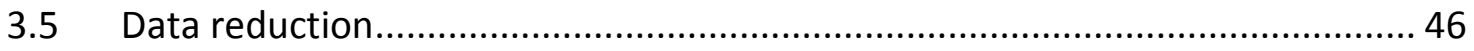

3.6 Statistical Analysis and Model Development............................................... 47

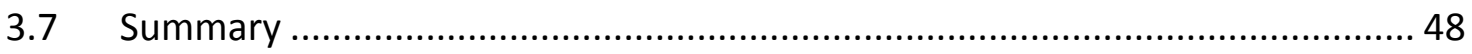

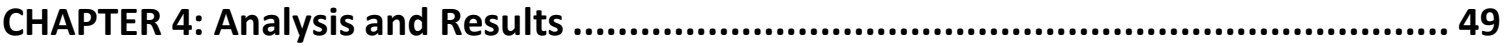

4.1 Variable comparisons and tests of Hypothesis ............................................. 50

4.1.1 Effects of Parking, Grade and number of Lanes on Road Sharing ............... 50

4.1.2 Effect of Lane width and ATD on Road Sharing .................................... 52

4.1.3 Effect of Bicyclist position, Vehicle and Bicycle Speeds on Road Sharing .. 54

4.1.4 Effect of variables on Comfort Perception of Road Sharing ....................... 57

4.1.5 Summary and Other investigation .................................................... 57

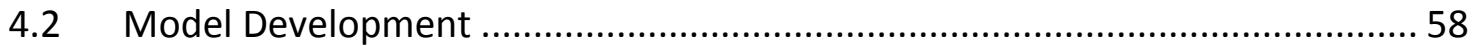

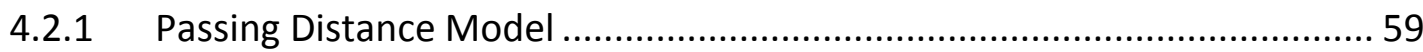

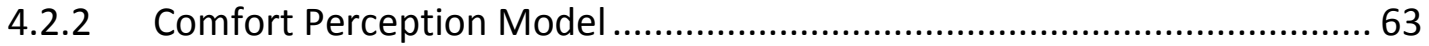

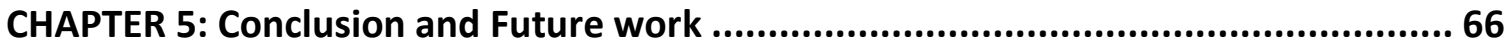

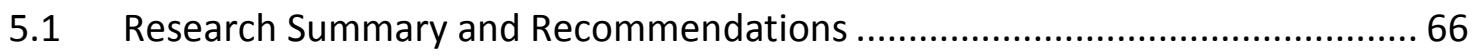

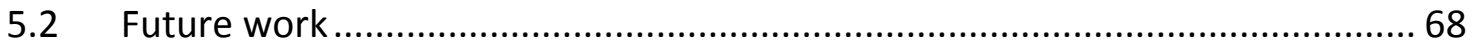

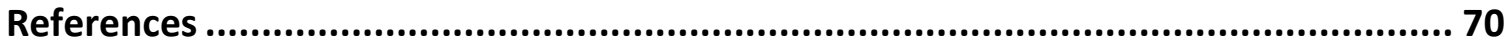

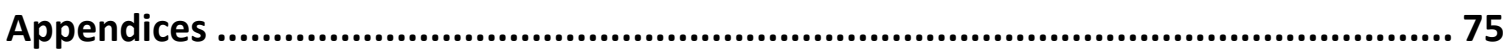

Appendix A: Summary of Comfort Evaluation Responses ....................................... 75

Appendix B: Sample Survey Responses............................................................... 80

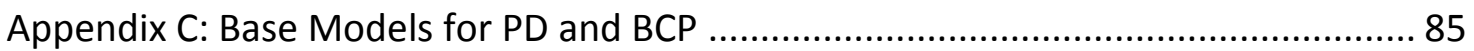

\section{List of Tables}

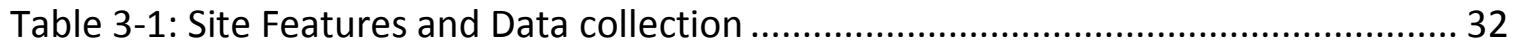

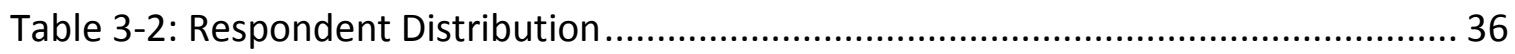

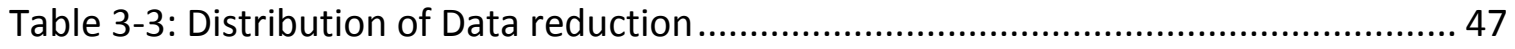

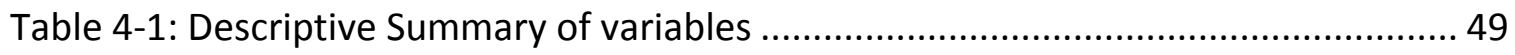

Table 4-2: Co-linearity test by variance inflation factor (VIF) ...................................... 59

Table 4-3: Summary Statistics of the Linear Regression Model for Passing Distance...... 60

Table 4-4: Summary Statistics of the Linear Regression Model for Comfort Perception. 64 


\section{List of Figures}

Figure 3-1: A slide from Strava Heat map showing cycling concentration on routes in

Ottawa (descending bicycle concentration in order: Green, yellow, red) ...................... 26

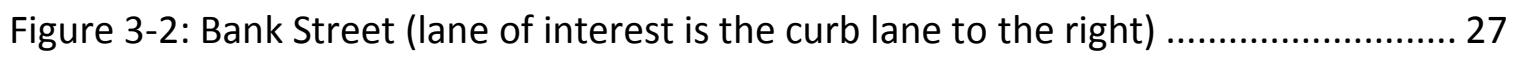

Figure 3-3: St Patrick Street (both lanes and edges considered) ................................. 28

Figure 3-4: Gladstone Avenue (both lanes or edges and directions considered) ............ 29

Figure 3-5: Pleasant Park Road (both lanes or edges and directions considered) ........... 29

Figure 3-6: Preston Street (both lanes or edges and directions considered) .................. 30

Figure 3-7: Wellington Street (both lanes or edges and directions considered) ............. 30

Figure 3-8: Camera setup at St Patrick Street and Preston Street ............................... 33

Figure 3-9: Camera setup at Bank Street and Gladstone Street................................. 34

Figure 3-10: Edge 1 and 2 used as markers for speed estimation on Bank Street........... 39

Figure 3-11: Transparent plot for day1 of Bank Street ............................................ 40

Figure 3-12: Using Perpendicular line plot to locate starting point frame for speed

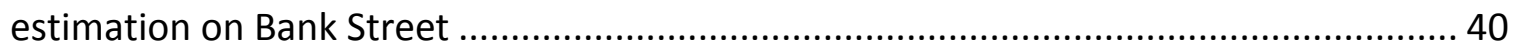

Figure 3-13: Measuring Width of an OC Transpo bus using the Matlab script and

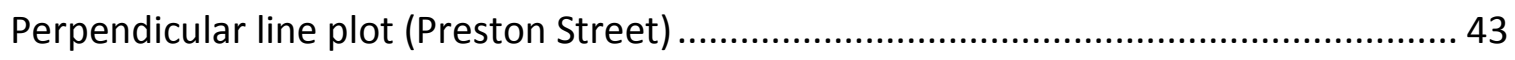

Figure 3-14: Measuring lateral distance on Wellington Street .................................. 43

Figure 3-15: Transparent plot for day 1 of Gladstone Avenue .................................... 44

Figure 3-16: Using Perpendicular line plot to locate frame with properly aligned bicyclist and motor vehicle on Gladstone Avenue .......................................................... 44

Figure 4-1: Comparing Distances by number of lanes and Parking .............................. 51 
Figure 4-2: Comparing Distances by Lane Width

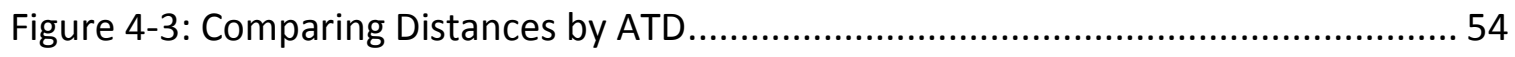

Figure 4-4: Scatter Plots of Passing Distance with Speeds and Bicycle Position .............. 56

Figure 4-5: Cumulative distribution plot for Passing distance.................................... 57

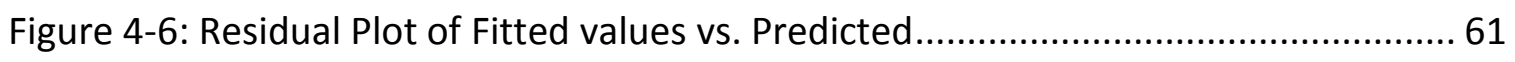

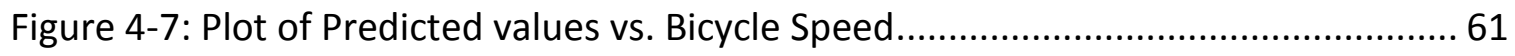

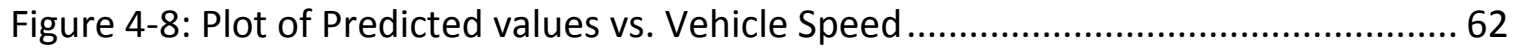

Figure 4-9: Plots of Residuals for the comfort Perception Model ................................. 65

\section{List of Acronyms}

$\begin{array}{lll}\text { ADT } & - & \text { Average Daily Traffic } \\ \text { ANOVA } & - & \text { Analysis of Variance } \\ \text { ATD } & - & \text { Ambient Traffic Density } \\ \text { B.C } & - & \text { British Columbia } \\ \text { BCP } & - & \text { Bicycle Comfort Perception } \\ \text { BSIR } & - & \text { Bicycle Safety Index Rating } \\ \text { GLM } & - & \text { Generalized Linear Model } \\ \text { GPS } & - & \text { Global Positioning System } \\ \text { OLS } & - & \text { Ordinary Least Square } \\ \text { PD } & - & \text { Passing Distance } \\ \text { VIF } & - & \text { Variance Inflation Factor }\end{array}$




\section{CHAPTER 1: INTRODUCTION}

\subsection{Background}

After centuries of the bicycle's invention, it is still an efficient mode of transport that can compete with many modern modes of transport. A great proportion of commuter trips in most urban areas like in Canada and the US are less than 5 miles, which is reasonable and convenient for completion by bicycle (Dill and Gliebe 2008). Moreover, biking makes efficient use of limited roadway capacity, improves health, while being a more pleasurable, low-cost, low-polluting alternative transport mode to several more modern modes like the motor vehicles (Handy, Xing, and Buehler 2010; M. Li and Faghri 2014; Pucher and Buehler 2008; Shackel and Parkin 2014). For example, bicycling is proven to be strongly associated with improved health. It ensures riders have a level of physical activity that reduces the risk of high level obesity and many other diseases such as coronary heart disease, stroke and hypertension, Type-two diabetes, some types of cancer, and depression (M. Li and Faghri 2014; Pucher, Dill, and Handy 2010). The congestion and high pollution in most urban cities associated with escalating use of motor vehicles may be resolved by converting some of these car trips to bicycling (Pucher and Buehler 2008). In addition, a bicycle can be afforded, used, and maintained by the financially average person, providing an equal platform to own and use. Aside from being affordable to the individual, it cost's far less than both the private car and public transport with regards to public infrastructure costs (McKibbin 2011). Heinen, Van Wee, and Maat (2010) also notes that bicycling provides riders more room to view, feel and exchange 
with their neighbourhood and nature, as one is able to access more corners, parks and interact with people.

In short, commuting by bicycle generates several benefits to the bicyclist and to the community as a whole. That notwithstanding, there are still low rates of biking relative to other transport modes even for short trips within biking distance, especially in North America (Pucher, Komanoff, and Schimek 1999). Literature indicates that, among all the deterrents to bicycling, number one is comfort or safety risk, while many of the other factors are to some extent safety implied or comfort related (Chataway et al. 2014; Hull and O'Holleran 2014). Efforts are being made by transportation departments and academic researchers to understand and to improve important drivers of bicycling such as safety, comfort, infrastructure and its continuity, road sharing, traffic speed etc. in order to increase ridership (Hull and O'Holleran 2014; Pucher and Buehler 2008).

Winters et al. (2010) confirmed the desire of bicycle commuters to use the shortest route for their trips as 75 percent of bicycle trips were within 10 percent of the shortest possible distance along the road network, while 90 percent were within 25 percent for non-recreational bicyclists during a study in Vancouver, B.C. This indicates that bicyclists who find a single link within their path to be too dangerous or stressful are likely to avoid the route and if they are unable to find another route that is short enough, may boycott riding altogether. Furthermore, the perception bicyclists and potential riders make of safety on a road is key to their decision to cycle. This perception is shown by many survey studies to be highly and positively dependent on the existence of bicycle facilities even though objective studies find bicycle facilities not to be the safest option 
for all conditions (Harkey, Stewart, and Rodgman 1997; Parkin and Meyers 2010). The perception of less safety in the absence of bicycle facilities can be postulated as due to bicycle interaction with vehicular traffic. However, it is difficult to avoid mixed traffic situations due to frequent discontinuity in on-street bicycle facilities and limited right of way situations. In sum, there is a need to seek understanding of bicyclists' behavior regarding road sharing with vehicles since such situations tend to be the weakest link for most bicycle commuters. In order to encourage utilitarian bicycling, a low stress bicycle network is essential. In other words, a road network that is well-connected with lowstress cycling, such that the routes between user origins and destinations do not require bicyclists to use links that exceed their tolerance for traffic stress or require excessive detours (Mekuria, Furth, and Nixon 2012).

This study was carried out in the City of Ottawa, Ontario. According to Ottawa's Cycling Master Plan for 2013, the City is the only designated Gold-level Bicycle Friendly Community in Ontario and has seen significant growth in bicycling share for morning peak period by $41 \%$ between 2005 and 2011. Ottawa's cycling master plan is aimed at providing a city wide connected network of bicycling facilities that will be actively used by all types and ages of bicyclists to meet their transportation needs ("Ottawa Cycling Master Plan" 2013). The city's cycling master plan shows the use of a vehicle operating speed and Average Daily Traffic (ADT) nomograph for determining the type of bicycle facility to be selected for a road section. Combination of speeds less than $60 \mathrm{Km} / \mathrm{h}$ and ADT less than 5,000 (for all lanes in both directions) may result in a mixed traffic facility (see Exhibit 4.7 
- Page 44 of the Ottawa Cycling Master Plan). This means mixed traffic and hence interactions between bicycles and vehicles are expected to exist in Ottawa into the future.

\subsection{Research Motivation}

The key to improving bicycling and reaping its numerous benefits is by providing conditions necessary to encourage bicycling. This begins with building knowledge and gaining understanding regarding bicyclist behavior, expectations and comfort thresholds. There is high discontinuity in bicycle facilities and also limited space in urban areas makes bicycle lanes difficult to implement. Hence, bicycles and vehicles must appropriately and safely share the road (most likely the right-most lane). However, most studies regarding bicycling are either focused on roads with marked lanes for bicycling or concern conflict and safety issues at intersections. As such this study is aimed at building understanding of the interactions at mid-sections on roads without bicycle lanes (segregated or painted), where vehicles and bicycles are required to co-operatively share the road. This is a step towards improving riding conditions and providing efficient and safer bicycling on mixed traffic roads. Studying the various elements that influence the bicyclist's perception of bicycle and motor vehicle interactions is valuable, and a statistical model in that regard will encompass a wide range of potential utilitarian riders. The motivation is to provide a foundation for building microscopic traffic simulation models which involve bicyclists being modelled with adequate representation of their attributes and behavior. A 
statistical model can further be beneficial in ranking mixed traffic facilities, planning and management of bicycle trips.

\subsection{Research Objectives and Scope}

This research has two main objectives: [i] to study the various elements that are important to bicyclists in their interaction with motor vehicles on shared roads and [ii] to fit statistical models to lateral vehicle passing distance and the comfort perception that potential and mixed traffic bicyclists hold on biking with vehicles. The variables are obtained from actual, live and natural interactions between bicycles and vehicles captured in video data. The focus of the interactions are passing events (where both bicycle and vehicle are moving in the same direction) on shared roads with no exclusive bicycle lanes. The term Comfort herein is limited to the experience during the event of an interaction between a bicyclist and an adjacent motor vehicle moving in the same direction. It does not capture the pavement surface texture or vibration index. Factors such as the speeds of bicycle and motor vehicle, lateral passing distance (PD), bicycle distance to the adjacent curb edge line, ambient traffic density (ATD), lane width, grade status, presence or absence of parking and number of lanes are considered. 


\subsection{Thesis Organization}

This chapter has highlighted the benefits of bicycling and introduced the focus of the study. Succeeding chapters include a review of literature on previous work done on the subject of bicycle and vehicle interactions, factors relevant to bicycling comfort perceptions, some typical bicycling data collection and measurement approaches, and modeling bicyclist behavior in the vicinity of motor vehicle traffic. The research methodology and procedures adopted in the collection and measurement of relevant data for the study are discussed in the third chapter. In chapter four, an analysis of the resulting data is presented and a discussion is made regarding the relevant elements. Also, development of the statistical models for bicycling comfort perception and Passing are discussed. Finally, conclusion and a highlight of potential future work. 


\section{CHAPTER 2: LITERATURE REVIEW}

\subsection{Background}

Safety and comfort are the most important considerations for most individuals when deciding to bike, aside from directness of route in order to save time and effort (Rahimi, Kojima, and Kubota 2013). Due to the vulnerability of bicyclists, they are 12 times more likely to be killed compared to motorists per kilometer traveled in the US (Pucher and Dijkstra 2003). Responses to Heinen, Van Wee, and Maat (2010) survey indicates that many people believe that cycling is less safe than walking, driving a car or using public transport. It has been established that while people in urban communities do not cycle because they have a car, 11 to $17 \%$ feel it is too dangerous and 7 to $16 \%$ believe that the amount of vehicular traffic put them off cycling (Hull and O'Holleran 2014). It is not surprising that many people perceive cycling as too dangerous to undertake, as bicyclevehicle interactions in urban communities frequently experience near-miss incidents, aggressive driver behavior, less driver awareness of bicyclists, close passing by vehicles and high vehicle speeds. Hence in these environments, the fear of vehicular traffic interactions and the fear of injury results in a lot of non-frequent riders and recreational cycling, while other bicyclists may avoid cycling altogether or use longer routes to escape the traffic (Chataway et al. 2014). Definitely, if a risky perception of cycling in mixed traffic exist within a society, even constructing bicycle facilities along those routes may do little, as the presence of such facilities will even raise the perception that a hazardous situation exist (J. Parkin, Wardman, and Page 2007). 
Analysis of biking comfort can be done from several perspectives. The Pavement surface texture, interactions with other road users, level of social acceptance, and road cycling network connectivity all come to play in improving biking comfort. For instance, vibrations generated by a road's surface defects and debris are transmitted by the bicycle to the hands and the buttocks of a bicyclist and can be a significant source of discomfort, fatigue and a disincentive to ride. Furthermore, a perception of biking to be associated to poverty and a lack of regard for bicyclists on roads are all sources of discomfort to a bicyclist. However, the focus of the reviews herein will be studies related to comfort perception of cycling in mixed traffic and the influencing factors of such perceptions. The rest of this chapter is a review of previous bicycle studies under the topics: road sharing, factors relevant to comfortable cycling, typical methods and approaches to bicycle studies, and modeling bicycle-vehicle interactions.

\subsection{Mixed Traffic Interactions or Road Sharing}

In 1987, Davis' model was the first step into studying bicycle and motorised vehicle interactions. The model was initially meant to make crash predictions using Annual Average Daily Traffic (AADT), number of through travel lanes, pavement condition and location factors. First Davis developed a roadway segment index (RSI) and an intersection evaluation index (IEI), which were combined to create a bicycle safety index rating (BSIR). Lower RSI, IEI and BSIR were related to better conditions and BSIR could be classified as poor, fair, good or excellent. Davis however did not meet the initial goal of predicting 
bicycle accidents as a result of a low correlation between accident rate and BSIR. This was conjectured to be due to the absence of a term for exposure to risk of a bicycle collision in his model. The model was also found to be inadequate on account of the subjective methodology for selecting location and pavement factors. These two factors happen to account for 30 to as high as 53 percent of the roadway segment index (RSI) value. Nevertheless the study provided a worthwhile insight into the hazards in mixed traffic interaction from the bicyclist's perspective, while also stimulating similar studies. Similar to the Davis model were the initial Broward County Bicycle Facilities Network Plan roadway condition index (RCI) and the Florida Bicycle Coordinator's consensus developed segment condition index (SCI) models in 1991 and 1993 respectively. These were slight alterations to the Davis model. They had adjustment to the coefficients and multiplication of some terms to place a greater weight on segments with narrow lane widths and high vehicle speeds while reducing the effect of location and pavement factors. The two models were also limited by a subjective methodology in the assignment of values for the pavement condition and location factors (Epperson 1994; Landis 1994).

Sorton and Walsh (1994) sought to create a bicycle compatibility model for evaluating the stress experiences of bicyclists on shared roads in the city of Madison, Wisconsin. Bicyclists were categorized into four groups: Child (recreation or play, primary school), Youth (secondary school), Casual (recreation, utility, shopping, etc.) and Experienced (commuting, touring and recreation). They considered three elements as relevant to the study, these include: traffic volume in the curb lane, curb lane width and traffic speed. A Likert scale of 1 to 5 (where 1 - very low stress due to reasonable safety 
for all bicycle groups and 5 - very high stress due to dangerous conditions for all biking groups ) was used to relate each variable to stress experience. A peak hourly volume for curb lane was considered, while configuring the Likert scale as: 1 for 50 vehicles per hour per lane (v/hr/l) or less, 2 for 51 to 150,3 for 151 to 250,4 for 251 to 350 and 5 for 450 $\mathrm{v} / \mathrm{hr} / \mathrm{l}$ or more. Curb lane width consisted the distance from the joint between the curb and gutter and the first full travel lane adjacent to it (including paved shoulders and excluding parking width if present). The Likert scale for lane width was: 1 for $4.6 \mathrm{~m}$ or greater, 2 for $4.3 \mathrm{~m}, 3$ for $4.0 \mathrm{~m}, 4$ for $3.7 \mathrm{~m}$ and 5 for $3.3 \mathrm{~m}$ or less. Traffic speed adopted was the actual $85^{\text {th }}$ percentile speed regardless of speed limit and the Likert scale was established as: 1 for $40 \mathrm{kph}$ or less, 2 for $50 \mathrm{kph}, 3$ for $60 \mathrm{kph}, 4$ for $65 \mathrm{kph}$ and 5 for $75 \mathrm{kph}$ or higher. The average Likert scale value obtained from a combination of the three variables was then considered the stress experience level. The procedure was validated by a survey involving 51 participants (of varying cycling experience, age, gender etc.) who rated videos taken from 24 segments on the basis of each of the three variables. Their results indicated that: [i] a good correlation exist between each selected variable and stress experienced while biking, and [ii] different levels of biking experience does impact the perception of stress.

Landis in 1994 created a hazard rating model called the Interaction Hazard Score (IHS) by modifying the Epperson-Davis version of the Road Condition Index (RCI) model. The IHS model comprises elements such as: Average Daily Traffic (ADT), Speed limit (S), Proportion of Heavy vehicles (HV), total number of through lanes (L), usable width of 
outside through lane $(W)$, land use intensity adjoining the road segment $(L U)^{1}$, Curb cut or Street Parking frequency (CCF) and pavement factor (PF) ${ }^{2}$. The model was established as shown in equation 2-1. The calibration resulted in $0.01,0.01$ and 0.02 for the coefficient $a_{1}, a_{2}$ and $a_{3}$ respectively (Landis 1994). A lower value of the IHS shows better quality or less hazard and the value may further be converted to a categorical level of service (i.e., A, B, C, D, E, and F).

$$
\mathrm{IHS}=\frac{1}{10}\left\{\frac{\mathrm{ADT}}{\mathrm{L}} \times\left(\frac{14}{\mathrm{~W}}\right)^{2} \times\left[\mathrm{a}_{1} \frac{\mathrm{s}}{30} \times(1+\% \mathrm{HV})^{2}+\mathrm{a}_{2} \mathrm{PF}\right]+\mathrm{a}_{3} \mathrm{LU} \times \mathrm{CCF}\right\} \quad \text { Equation 2-1 }
$$

Harkey, Stewart, and Rodgman (1997) investigated the effectiveness of three different types of bicycle and vehicle shared facilities such as roads with paved shoulders, roads with cycle lanes, and wide curb lane roads in Florida. A sum of 1,583 passing interactions were studied on all the three types of facilities and variables considered in the study were: passing distance, distance of bicycle to the edge of the road, change in lateral position of vehicle and vehicle encroachment into adjacent lane during passing. It was found that the average passing distances were $6.4 \mathrm{ft}, 6.2 \mathrm{ft}$ and $5.9 \mathrm{ft}$ for wide curb lane, paved shoulders and bicycle lane facilities respectively. However, bicyclists on wide curb facilities tend to be closer to the edge of the road (1.4ft average) compared to the other facilities (2.6ft average). The conclusion was that, passing distance is not significantly affected by the type of facility, while bicyclists are more likely to ride closer

\footnotetext{
${ }^{1}$ Land use has two scores; commercial score $=15$ and non-commercial score $=1$

2 Pavement Factor is taken as the reciprocal of FHWA Highway Performance Monitoring System's (HPMS)

"PAVECON" factor. Where FHWA - Federal Highway Administration ; PAVECON - pavement condition
} 
to the curb on wide curb lanes. Another inferred conclusion is that, passing distance may be shorter ridding further away from the road edge.

In a study to investigate the effect of the presence of cycle lanes on the proximity of overtaking distance, Parkin and Meyers (2010) collected passing distance data on three roads which all had cycle lane and no cycle lane sections. Site 1 had a speed limit of $80.47 \mathrm{Km} / \mathrm{h}(50 \mathrm{~m} / \mathrm{h})$, the section with a cycle lane had a road width of $9.57 \mathrm{~m}$ and a cycle lane width of $1.45 \mathrm{~m}$, whilst the no cycle lane section was $9.64 \mathrm{~m}$. Site 2 was $64.37 \mathrm{Km} / \mathrm{h}$ $(40 \mathrm{~m} / \mathrm{h})$, the cycle lane section had a road width of $9.57 \mathrm{~m}$ and a cycle lane of $1.45 \mathrm{~m}$, whilst the no cycle lane section was $9.37 \mathrm{~m}$. Site 3 was $48.28 \mathrm{Km} / \mathrm{h}(30 \mathrm{~m} / \mathrm{h})$, the cycle lane section had a road width of $9.45 \mathrm{~m}$ and a cycle lane of $1.3 \mathrm{~m}$, whilst the no cycle lane section was $9.49 \mathrm{~m}$. They found that vehicles passed at closer proximities on sections with cycle lanes for site 1 and 2 where cycle lanes were $1.45 \mathrm{~m}$, while no significant difference was found on site 3 where cycle lane width was $1.3 \mathrm{~m}$. Their explanation for this was that, drivers on site 3 probably do not make overtaking decisions beforehand due to their slower speed and narrower road condition. They concluded that cycle lanes do not provide the best passing proximity in all conditions. Hence, the absence of cycle lanes may be better for bicyclists riding condition on streets with speeds of $64.37 \mathrm{Km} / \mathrm{h}(40 \mathrm{~m} / \mathrm{h})$ or higher and insufficient cycle lane width (i.e., less than $2 \mathrm{~m}$ ).

In a study to determine the effects of road markings, lane width and driver behavior on passing distance and speed of motor vehicles, Shackel and Parkin (2014) used an instrumented bicycle to measure the speeds and lateral distances of passing vehicles. Instruments included: an ultrasonic distance sensor attached to the rear rack for 
measuring passing distance, a video camera to provide footage for vehicle identification and speed estimation and a laser pointer to assist riders stay a meter from the curb. They found lane width to be insignificant to both motor vehicle speed and passing distance on $32.19 \mathrm{Km} / \mathrm{h}(20 \mathrm{~m} / \mathrm{h})$ roads, while higher passing vehicle speeds were found on more spacious lanes (i.e., width of $3.75 \mathrm{~m}$ or greater) on $48.28 \mathrm{Km} / \mathrm{h}(30 \mathrm{~m} / \mathrm{h})$ streets. Higher passing distances were observed on dual lanes, while closer passing was associated with the presence of opposing traffic. They established that the presence of cycle lanes may be associated with higher passing speeds though not particularly significant. Stewart and McHale (2014) also used an instrumented bicycle in a similar study and found that the factors most relevant to the passing distance between motor vehicles and bicycles was the absolute road width, presence of nearside parking and presence of an opposing vehicle during the passing event. They established that, the road width positively affects the passing distance while width restricting conditions such as nearside parking and an opposing vehicle reduced the passing distance given by vehicles.

\subsection{Factors Influencing Cycling Comfort}

Winters et al. (2011) did a survey study of 1,402 current and potential bicyclists in Metro Vancouver (Canada) to establish the major motivators and deterrents to cycling. Participants were contacted via telephone interviews or email, and they were required to rank 73 factors which had been grouped into 15 categories. The factors most likely to influence bicycling were obtained based on a weighted mean score for all respondents, 
where $+1=$ much more likely to cycle,$+0.5=$ more likely to cycle, $0=$ neutral, $-0.5=$ less likely to cycle, and $-1=$ much less likely to cycle. The top influencing factors were found to include: high traffic volume (-0.83), high traffic speed i.e., beyond $50 \mathrm{Km} / \mathrm{hr}(-0.76)$, route with glass or debris $(-0.76)$, unsafe driving while near bicyclists $(-0.73)$, potholes and uneven pavement $(-0.55)$, long steep sections on route $(-0.5)$ etc. Clearly, most of the top influencing factors on the willingness to cycle are indirectly comfort and safety related, especially when considering bicycle motor vehicle interactions. Perhaps the questionnaire would have been more objective by supporting questions with pictures and videos, however this may seem difficult considering the large expanse of the survey. In addition, as in every bicycling survey, there is the limitation of how close an opinion is to respondents' actual actions. In a similar survey study by Kirner and Penha (2011) within two medium sized Brazilian cities, 447 respondents completed a survey to help establish the most relevant factors to cycling promotion. It was found that, the two most important factors to consider in a road's quality evaluation for comfortable, safe and a resulting improvement in cycling were lane width and motor vehicle speed. Traffic volume was less significant even compared to on street parking and grade. The latter result may be due to a limitation on the manner in which the survey was carried out. For example, asking questions like "it is better to ride a bicycle in wider streets" and "When the vehicles are too fast, bicyclists are in risk of accidents" will obviously be expected to receive more agreement responses on the Likert scale than "Bicyclists ride calmly along streets with heavy volume of vehicles". If the question for traffic volume was framed as done for lane width, a different result will probably be obtained. 
To determine the influencing factors on bicyclists' perception of comfort, Li et al. (2012) studied 29 separated bicycle facilities and 14 on-street facilities in the metropolitan area of Nanjing, one of the biggest cities in China. In their study 1074 (730 on separated and 344 on on-street facilities) participants were selected randomly at the traffic stop and interviewed to give their perception on how comfortable it was riding on selected sections of the facilities. A model was then established to predict the perceived comfort using a plethora of explanatory variables considered relevant to cycling comfort. Upon establishing two probit models for the two types of facilities, the following variables were found to be significant in the on-street cycling model: width of the bicycle lane, width of the curb lane, presence of slope, presence of a bus stop, amount of occupied car parking spaces, bicycle flow rate, motor vehicle flow rate, and rate of use of electric bicycles. The separated facilities are significantly influenced by the presence of slope, physical separation from pedestrian, path width, presence of bus stop, residential, commercial and office land uses, and bicycle flow rate. Most factors appear in both models and are consistent, however, the general observation was that, the separated facilities are more comfortable than on-street ones. On the contrary, on-street facilities tend to have an increasing comfort with rising bicycle traffic, hence their conclusion that, on-street facilities may be more effective for heavy cycling traffic.

Calvey et al. (2015) employed a combination of a survey and an instrumented bicycle (instruments includes accelerometers, GPS, sound meter, gyroscopic sensors and data loggers) to study biking comfort based on road surface ride-ability conditions. The survey involved seventy five respondents comprising of 48 males, 27 females and of 
varying ages, fitness level and frequency of cycling. They were asked to rank 24 factors on their influence on riding comfort based on a Likert scale rating were; 5 -Vey comfortable; 4 - Comfortable; 3 - Average; 2 - Uncomfortable; and 1-Very Uncomfortable. The most relevant road surface factors likely to influence biking comfort were found to be the presence of debris and defects. In addition, twenty four volunteers were made to ride the instrumented bicycles on three selected routes to obtain vibration data which was subsequently correlated with the riders' perception data in an attempt to create a rating scale for cycle path surface quality assessment. The three routes used were such that: Route 1 - new smooth surface; Route 2 - old rough/smooth surface with hazards; Route 3 - older rough surface with defects (ruts and bumps). The Pearson correlation coefficient for rider responses and vibration logger feedback were $0.516,0.772$, and 0.390 for the three routes respectively. The study is limited by sample bias, considering that the respondents are largely university students and staff, rather than regular commuters. Furthermore, the respondents are consciously aware of the study and with the choice of the specified three routes, they are likely to form responses for each route beforehand. Haplessly, for studies of this sort, where the consent of an actively involved participant is required, little can be done about the shortcoming.

\subsection{Typical Approaches to Bicycle Studies}

As observed in some of the studies in the previous section, most bicycle data are often collected manually using participants or through surveys. Recent breakthrough in 
computer based studies means, studies are shifting towards automated methods of data collection and measurement. The rest of this section will highlight some methods adopted in literature for the measurement of some parameters relevant to this study.

\subsubsection{Speed Measurement}

Several methods comprising, manual to automated techniques have been employed in measuring speed for both bicycles and motor vehicles in literature. Devices such as the stop watch, radar gun, pneumatic tubes, GPS, and video cameras can be used for the measurement of speed. The use of a particular device may usually depend on the degree of accuracy required, the sample size and budget of the study. For instance, in a study to evaluate the validity of self-reported speeds, Thompson et al. (1997) used radar guns to determine the speed of 150 bicyclists aged 4 to 80 along a recreational pathway. They validated their measurements by recording the times taken for a sample of the riders to cover a $91.4 \mathrm{~m}$ (100 yards) section, and then estimating their speeds. The radar gun readings were within $4 \%$ (i.e., about $11.27 \mathrm{Km} / \mathrm{h}$ ) of the stopwatch estimations. The study concluded that both children and parents are able to accurately estimate children's riding speeds, but teens and adults slightly overestimate their speed.

Dill and Gliebe (2008) used a GPS to track the riding location of 164 bicyclists in Portland, Oregon. The study aimed to answer several questions regarding the travel and route choices of bicyclists. The devices were Garmin iQue (a personal digital assistant with GPS) which could be attached to the handle of the bicycle and the participants could make origin, destination and weather selections each time they ride. The data was then downloaded by the authors at the end of each day for analysis. Speeds, travel times, 
distances, trip trajectories and so on could be extracted from the data. The GPS points were not however accurate as they were mostly a few feet adjacent to the actual streets and the authors had to take steps to correct them. Hunter, Srinivasan, and Martell (2009) adopted pneumatic tubes called Metro-Count 5,600 in a study to determine the effect of newly created cycle lanes on the volume and speed of bicyclists. They had the tubes placed 200 to 300 feet downstream of intersections along two streets named the 31st and 37th streets in St. Petersburg, Florida. A total of 38 locations was selected on both streets and in both directions for data collection. Counts and speed data were recorded with the tubes for periods before and after cycle lane installation. The counts were validated with manual counts from recorded video data at two selected locations. Their results showed a $17.1 \%$ increase in bicycle volume per day after bicycle lane creation, while the average speed of bicyclists was $11-12 \mathrm{mph}$ in both periods.

Zhiwei, Yuanyuan, and Xueyi (2007) presented several methods of estimating vehicle speeds from video data. Most of the methods involved first detecting the vehicle either by the background subtraction method, edge information method or by the frame difference. The distance and time elapse by the tracked moving vehicle over a shot period are then noted for speed estimation. One method however involved tracking the front position of the vehicle from frame to frame over a given distance and using the frame difference to calculate the time and then estimating the speed. The latter method may well be feasible for bicyclists. Zaki, Sayed, and Cheung (2013) used screen lines to obtain counts and average speeds of bicyclists from video data collected at a roundabout. First they adopted a computer vision technique called Kanade-Lucas-Tomasi (see Shi and 
Tomasi 1994) to detect and track bicyclist movement. Subsequently, screen lines were placed on four legs of the roundabout to automatically detect and count bicycles as they pass the screen lines. The counts were validated with manual counts and the results showed an average count accuracy of $90.5 \%$ and worst count was above $85 \%$ accuracy. The average speed of a bicyclist was determined using two screen lines placed a known physical distance of $14 \mathrm{~m}$ apart on a straight sidewalk. The time taken to tracked vehicles to cross both screen lines is recorded automatically and speed is determined by dividing distance by time. To validate the speeds, the time elapsed for a total of seventy bicyclists crossing the screen lines was recorded manually using the video's time and speeds from these were compared with the automatic speeds. For the same set of bicyclists the average speeds were $14.1 \mathrm{Kph}$ and $13.41 \mathrm{Kph}$ for manual and automated respectively (i.e., RMSE $=0.374 \mathrm{~m} / \mathrm{s}$ and $\left.\mathrm{R}^{2}=0.8647\right)$.

\subsubsection{Lateral Distance measurement (Passing Distance)}

Harkey, Stewart, and Rodgman (1997) investigated the effectiveness of three different types of shared facilities for bicycles and motor vehicles by estimating lateral distances of passing vehicles from video data. Video footage and slide shots of passing interactions when vehicle and bicycle rears are even were obtained with the aid of cameras setup in a moving van. The van followed vehicles at selected catching points on 13 sites to capture the events. The slides were projected onto a wall and the lateral distance measurements were extracted by first fitting the slide to a pre-established scale where the constant was always the $1 \mathrm{ft}$ vehicle license plate. 
Parkin and Meyers (2010) estimated lateral distances of passing vehicles from video footage. An instrumented bicycle was adopted for data collection. The rear rack of a bicycle was attached with a camcorder to feed video images into an Archos 605 MP4 recording device. The camera was placed such that it captured overtaking vehicles and a section to the right of the bicycle. Camera recordings where calibrated by taking video of known markings on the road at 20 to $2200 \mathrm{~mm}$ away from the bicycle. Distances of objects away from the bicycle were measured from video footage using a transparency placed over the screen of the computer to create "screen lines" between them. The same was applied in measuring overtaking distances, using the edge of the adjacent front wheel of the vehicle as a reference point. Shackel and Parkin (2014) used an ultrasonic distance sensor attached to the rear rack of a bicycle for picking passing distances between the bicycle's tire and the edge of the passing vehicle's adjacent tire.

\subsubsection{Limitations}

Using the stop watch for speed data collection may not be appropriate due to its high dependence on the observer's accuracy and does not suit large data collection due to the need for constant human presence. The radar gun is particularly for measuring spot speeds, as such unable to measure speed along a section or help in a comparative speed measurement for bicycle and vehicle interactions. On the other hand, the effectiveness of a GPS measurement depends on satellite signal continuity. The signal can however be impacted in highly dense areas with high rise buildings. Pneumatic tubes are shown to be more accurate with count data than speed measurement and they are inappropriate for interaction study. All the methods aside video camera tend to impact 
the natural behavior of traffic due to the presence of visible measurement. The use of a GPS or an ultrasonic distance sensor requires conscious participation, as the device has to be attached to bicycles or vehicles of consented participants. The video camera technique seem to be a better option for large data collection due to less interference in traffic behavior, less human presence and involvement and several parameters may be extracted. This is however only true if data is collected appropriately and the right technique for a parameter extraction is adopted.

\subsection{Modeling bicyclist Behavior}

Only recently has more attention been given to making roads useful to bicyclists, as they are often considered as secondary users or in the aftermath of road designs. Segregating bicyclists from vehicles has been the norm, hence the topic of modeling bicyclist's behavior in the vicinity of vehicles has rarely been investigated. Another issue contributing to the rarity of such a study is the unpredictable human factors associated with motor vehicle and bicycle interactions. Two studies that tried to model the passing distance between vehicles and bicycles are highlighted here.

Love and colleagues carried out a study to assess the level of compliance of Baltimore motorists to a three-foot $(1 \mathrm{~m})$ spacing law enacted by the state of Maryland. In addition, they attempted fitting a linear model to passing distance. They obtained 10.8hours of video data from 34 sites of which five participants recorded 568 motor vehicle passes for their study. The linear model had an $R^{2}$ of 0.26 , for which the significant 
variables were: lane width $(\mathrm{m})$ (explaining $9 \%$ of the variance in passing distance with $p<$ 0.0001 ), the presence of bicycle lanes (explaining $8 \%$ of the variance in passing distance with $p<0.0001$ ), bicyclist identity (explaining $7 \%$ of the variance in passing distance with $p<0.0001$ ), and Street identity was also significant (explaining $10 \%$ of the variance in passing distance with $p<0.0001$ ). Motor vehicle type was not significant (Love et al. 2012). Their model and findings show that, increasing lane width creates an increase in the passing distance and a driver's behavior in passing is influenced by bicyclist behavior and traits. Evident from the low fit of the vehicle passing distance model, the effect of additional variables like traffic volume, vehicle speeds, bicyclist distance to the curb, and the presence of parking could have been considered.

In an attempt to model the passing distance afforded to bicyclist on urban roads in Edinburgh (UK), Stewart and McHale (2014) developed two GLM models. The models had the passing distance (measured tire to tire) as the dependent variable and the predictor variables included: absolute road width $(\mathrm{m})$, opposing vehicles, vehicle speed $(\mathrm{m} / \mathrm{h})$, relative speed $(\mathrm{m} / \mathrm{h})$, nearside parking, opposite side parking, bicycle speed $(\mathrm{m} / \mathrm{h})$, effective lane width $(m)$, cycle lane width $(m)$, presence of traffic Island, color of lane, presence of a bus and opposing flow (veh/h). They fitted a GLM model to 1,908 measured passing distances and the resulting fit had $R^{2}$ of 0.275 . Their data totaled 2,387 events, however, the passing distance of those in excess of the afore-stated 1,908 were not measured as their passing distances exceeds $2.5 \mathrm{~m}$. The reason being that, their methodology was designed to measure up to $2.5 \mathrm{~m}$. Subsequently, a second GLM was fitted to all the 2,387 events for which the additional data were all assumed to have 
passing distances of $2.51 \mathrm{~m}$. The $\mathrm{R}^{2}$ improved to 0.424 . Even though the second is an improvement, it is still limited. Moreover, the intercepts in both models were more significant than the included variables, even being the most significant in the first model. This implies that some significant variables have been left out. The individual driver behavior may be one of them and this is often difficult to account for due to the complexity of individual human traits and behaviors. Nevertheless, it would have been interesting to see how other variables like the bicyclist position from the near side curb, bicyclist speed, number of lanes and grade will impact the passing distance. In addition, the effect of the visible instrumentation on the bicycle is unknown, while little was said about the methodology used in establishing each predictor variable.

\subsection{Summary}

Earlier researches into bicycle and motorised vehicle interactions concentrated on developing an index for road operational conditions relevant to bicyclists. More recent studies have shifted towards analysing the event of mixed traffic interactions, focusing on factors that influence the perception of road sharing like near miss incidents, aggressive driver behavior, less driver awareness of bicyclists, close passing by vehicles, high vehicle speeds etc. Some studies of mixed traffic presume passing distance as the one key factor important to bicyclists and tend to investigate how the parameter is affected by other elements and mixed traffic facility types. On the other hand, many other elements like passing vehicle speed, lane width, and traffic volume are shown by many other studies to be equally important to bicyclists in mixed traffic interactions. Survey studies also found 
perceived cycling comfort to be influenced by the presence of debris and defects on road surface, presence of parking, grade, lane width, vehicle speed, and vehicle and bicycle volumes.

A plethora of methods involving manual and or automated techniques have been adopted in several past bicycle studies to obtain passing distances and speeds of vehicles and bicycles. Speed may be determined by using a stop watch, radar gun, pneumatic tubes, GPS or video cameras depending on the degree of accuracy required, the sample size and budget of the study. Lateral distances may be obtained using ultrasonic sensors or measured from video data. The video camera technique seem to be a better option for large data collection provided the data is collected appropriately and an accurate technique for a parameter measurement is adopted.

Two studies attempted to model the passing distance between bicycles and motor vehicles using GLM and linear regression methods. Both studies ended with low model fits. The possible causes of the low fits being the absence of some relevant variables, the methodology in obtaining some parameters and the randomness of individual bicyclist and driver behaviours. 


\section{CHAPTER 3: RESEARCH METHODOLOGY}

This chapter presents the methods adopted in the collection of data and the measurement of selected variables. First, the chapter describes the sites and how they were selected. Secondly, a detailed explanation of how the two types of data (i.e., video and survey data) were each obtained for this thesis. Then, the procedures adopted for relevant variable extraction, and finally, data reduction.

\subsection{Site Selection and Description}

The thesis pertains to mixed traffic on shared lane roads, therefore, the sites required for this study are roads that are without bicycle lanes (segregated or painted) and no shoulders. Since bicycle and motor vehicle interaction is the main focus in this thesis, it is also required that the selected roads have high volumes of both bicycles and motor vehicles. To identify roads that satisfy these criteria, an attempt was made to obtain data from the City of Ottawa. However, obtaining the nature of roads required will involve a long and extensive search of the City traffic volume data-base, notwithstanding the issue of missing data at some intersections as mentioned by the City traffic and cycling safety coordinators. A combination of Strava heat maps ${ }^{3}$, Google maps and site visits were used to identify the required sites. First, the Strava heat map was used to identify roads with high bicycling frequency (see Figure 3-1). Google map was then used to check if these

\footnotetext{
${ }^{3}$ Strava is a social network of athletes and the Strava heat maps are created using uploaded frequencies and live routes of members, allowing a map user to identify routes that are mostly used by runners, bicyclists and triathletes (check "Strava Global Heatmap" 2016).
} 
roads meet the physical criteria (i.e., no segregated or painted bicycle lanes). The sites were then visited and traffic observed for thirty minutes at peak hours (i.e., either 7-9am or 4-6pm) of the day to confirm the presence of both bicycles and vehicles.

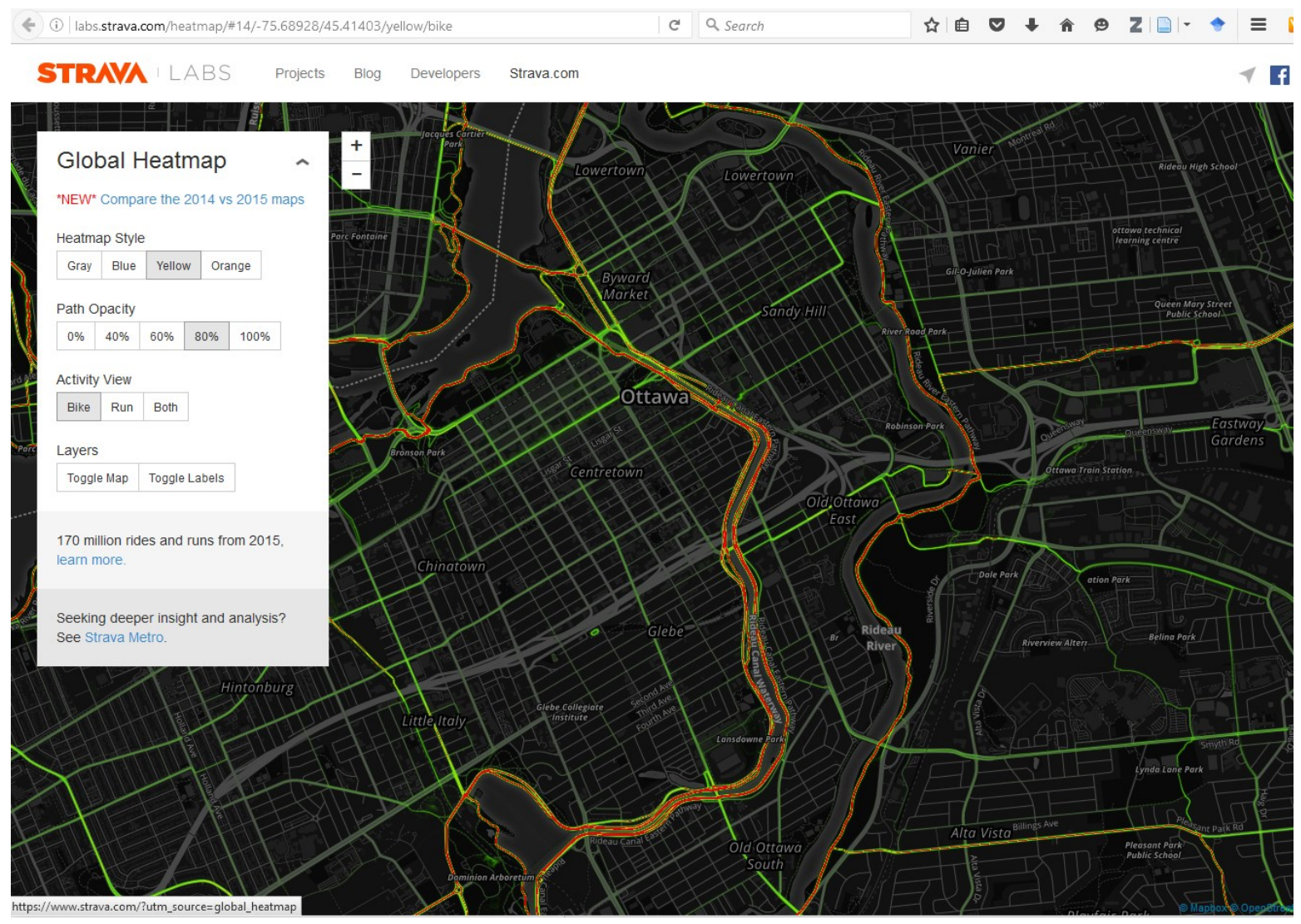

Figure 3-1: A slide from Strava Heat map showing cycling concentration on routes in Ottawa (descending bicycle concentration in order: Green, yellow, red)

The sites selected for the study include Bank Street (section between Wilton Crescent and Echo drive), Wellington Street (between Hinton and Hamilton Avenue), Gladstone Avenue (between Bronson Avenue and Preston Street), Pleasant Park road (between Alta vista drive and Lynda Lane), Preston Street (between Queensway and Carling Avenue) and St Patrick Street (between Sussex and Parent). 
Bank Street has two lanes in each direction, however, only the interactions on the curb lane to the right and moving up the grade were considered (see Figure 3-2). The curb lane in the other direction is not considered due to the temporary block of pedestrians and bicyclists as a result of the adjacent construction activity. The speed limit on this road is $40 \mathrm{Km} / \mathrm{h}$ and sharrows ${ }^{4}$ spaced $27 \mathrm{~m}$ from start edges exist at the center of the $3.6 \mathrm{~m}$ curb lane.

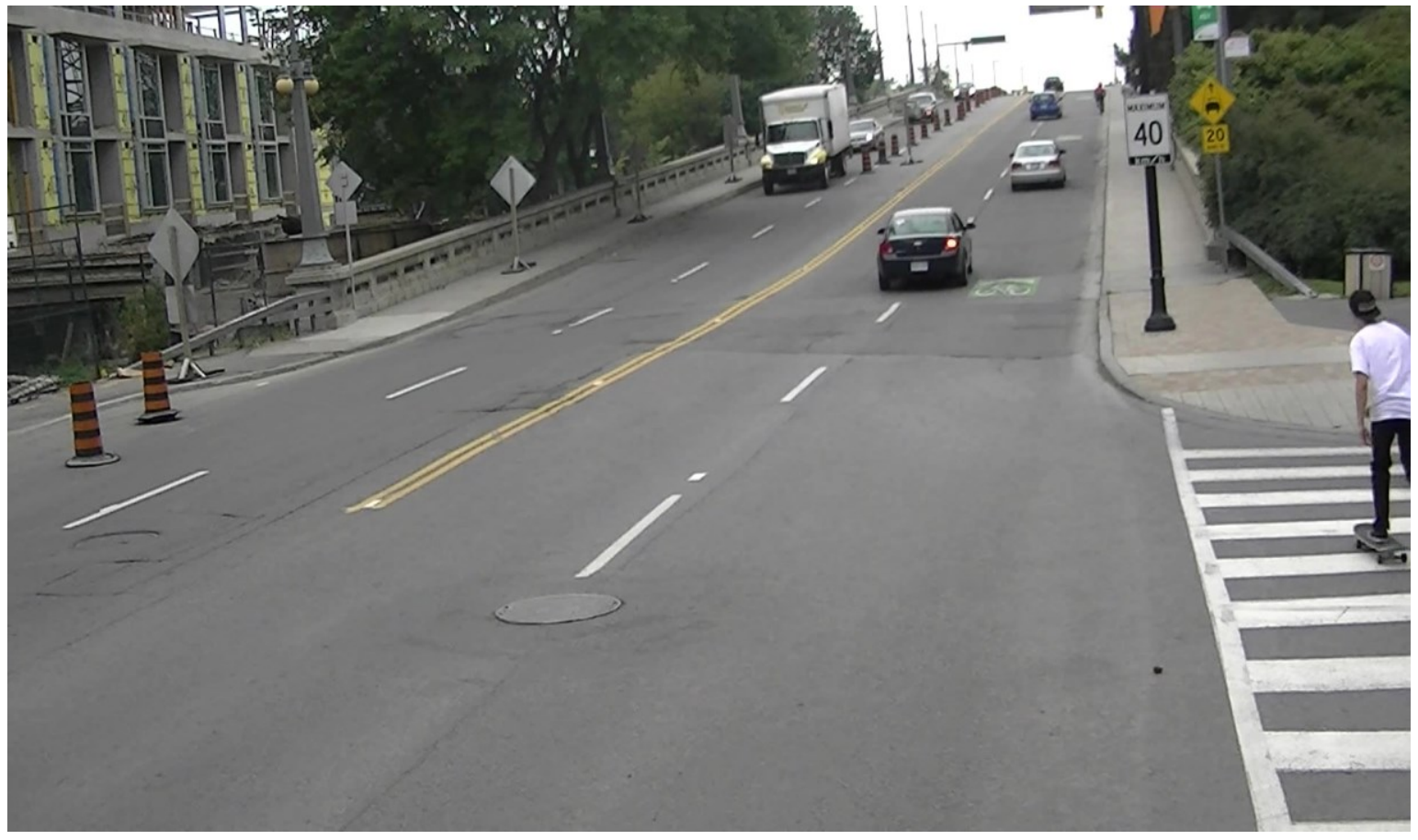

Figure 3-2: Bank Street (lane of interest is the curb lane to the right)

\footnotetext{
${ }^{4}$ Sharrow - a shared lane marking consisting a bicycle and a double chevron at its top, meant to remind motor vehicle drivers to share the road with bicycles
} 
St Patrick Street is a one way street (in the direction from Parent towards Sussex)

with two lanes. Both lanes were considered for bicycle-vehicle interactions moving in the same direction (see Figure 3-3). The speed limit on this road is $40 \mathrm{Km} / \mathrm{h}$.

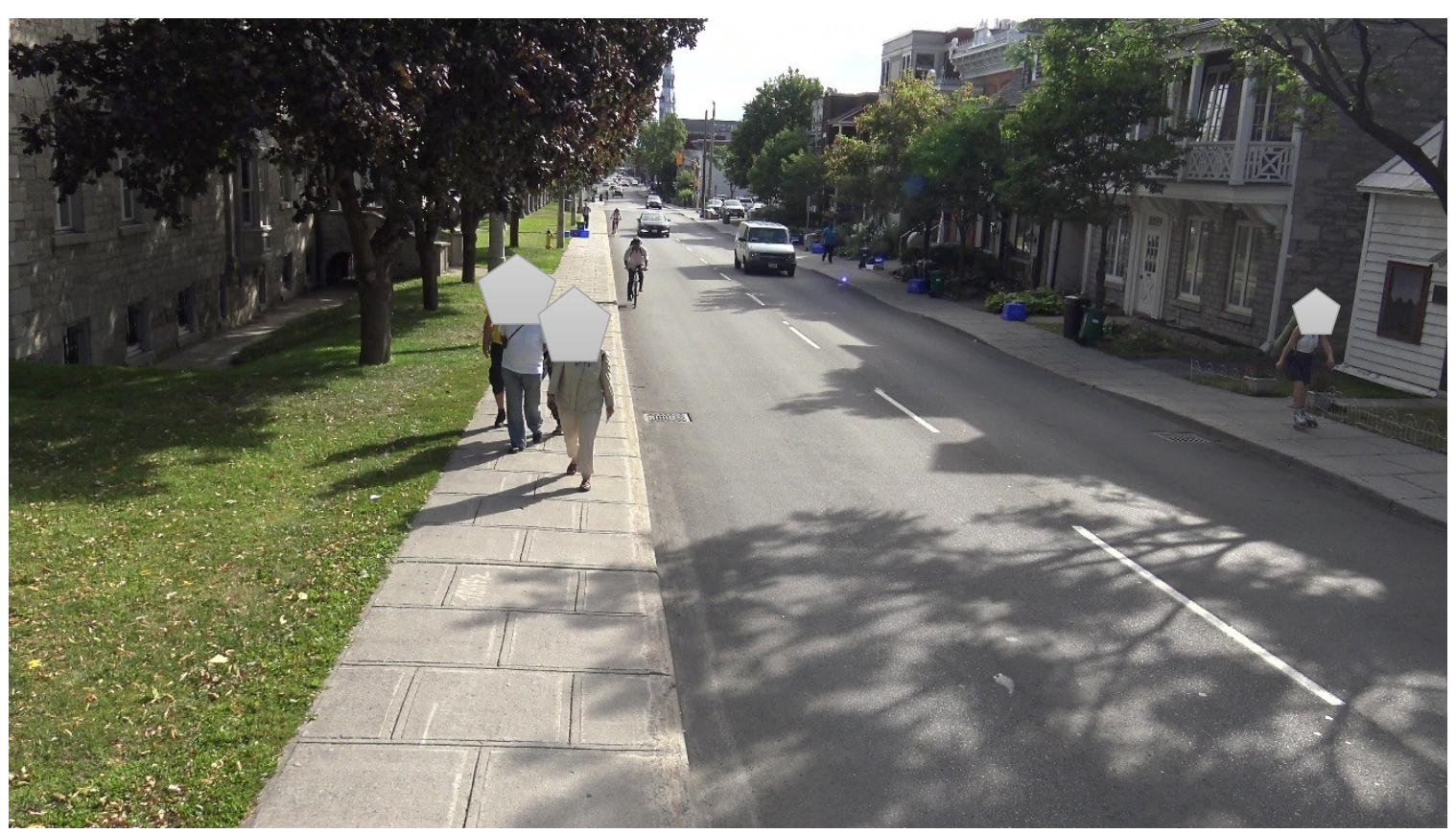

Figure 3-3: St Patrick Street (both lanes and edges considered)

The remaining sites all have two lanes, one in each direction. Both lanes will be considered for bicycle-vehicle interactions moving in the same direction. Each of the remaining sites are presented in Figures 3-4 to 3-7, and they all have speed limits of $40 \mathrm{Km} / \mathrm{h}$. The presence of high traffic volumes and the position of camera on Wellington Street made it difficult to capture the events on the opposite edge, only the near side edge was therefore considered. 


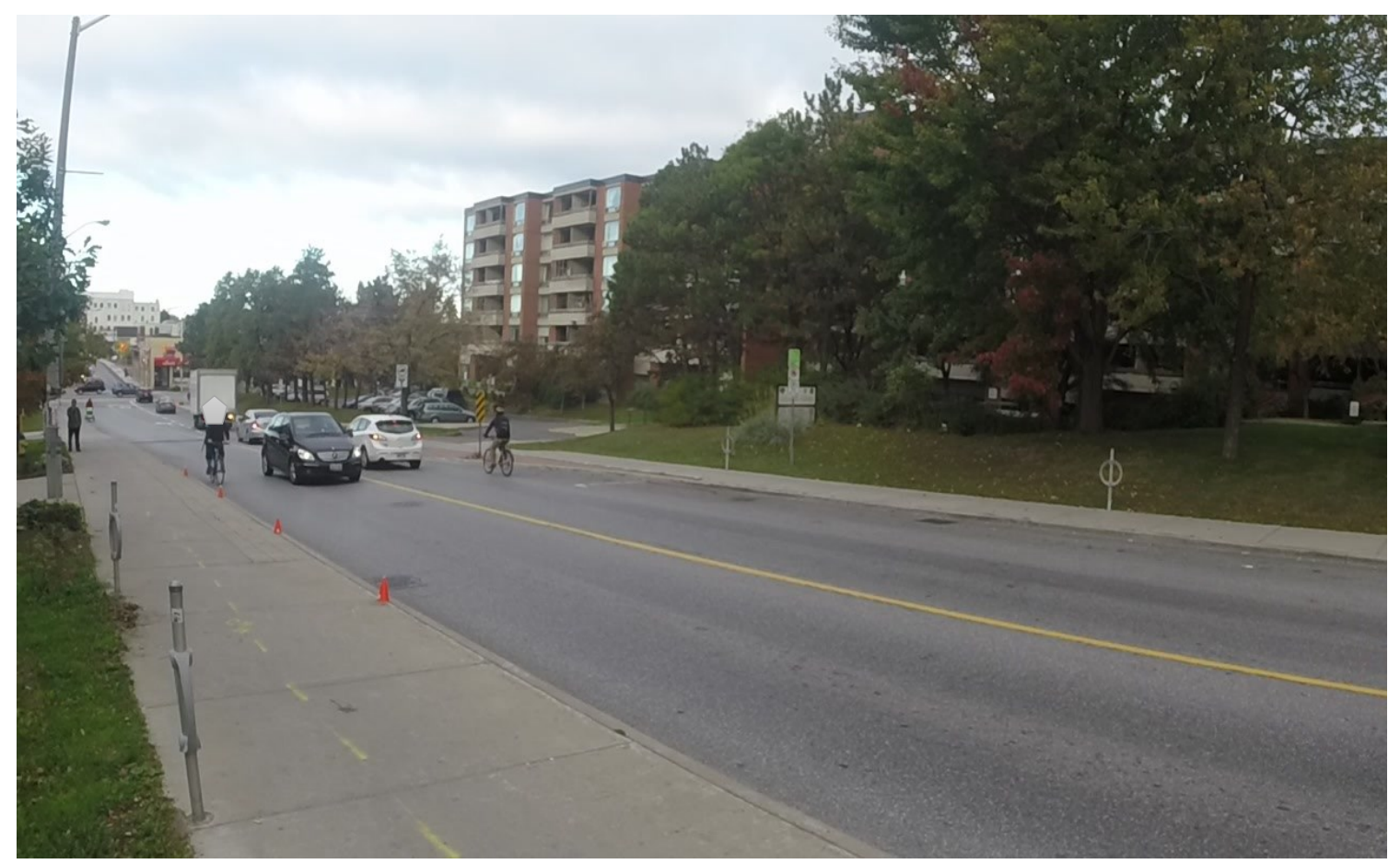

Figure 3-4: Gladstone Avenue (both lanes or edges and directions considered)

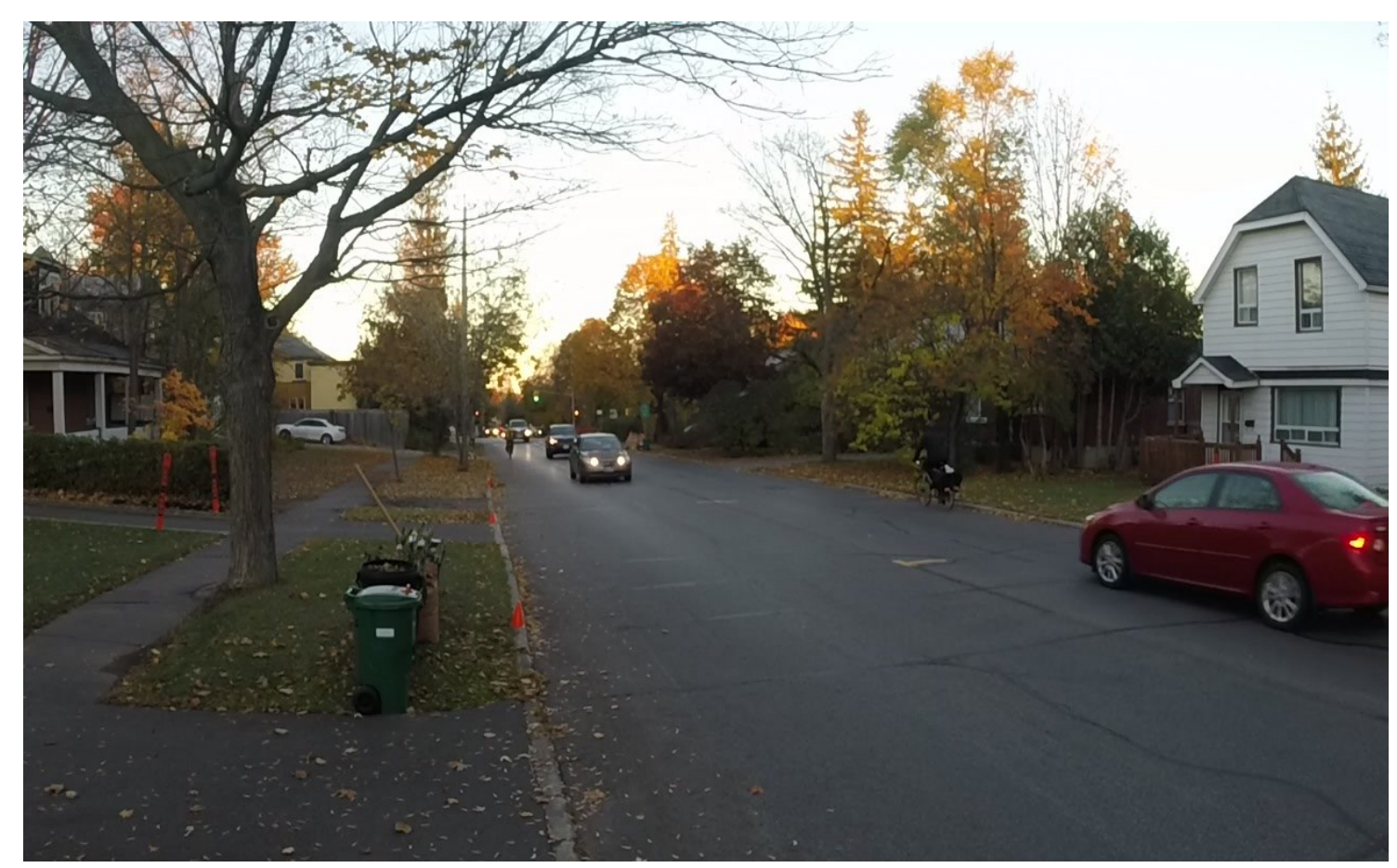

Figure 3-5: Pleasant Park Road (both lanes or edges and directions considered) 


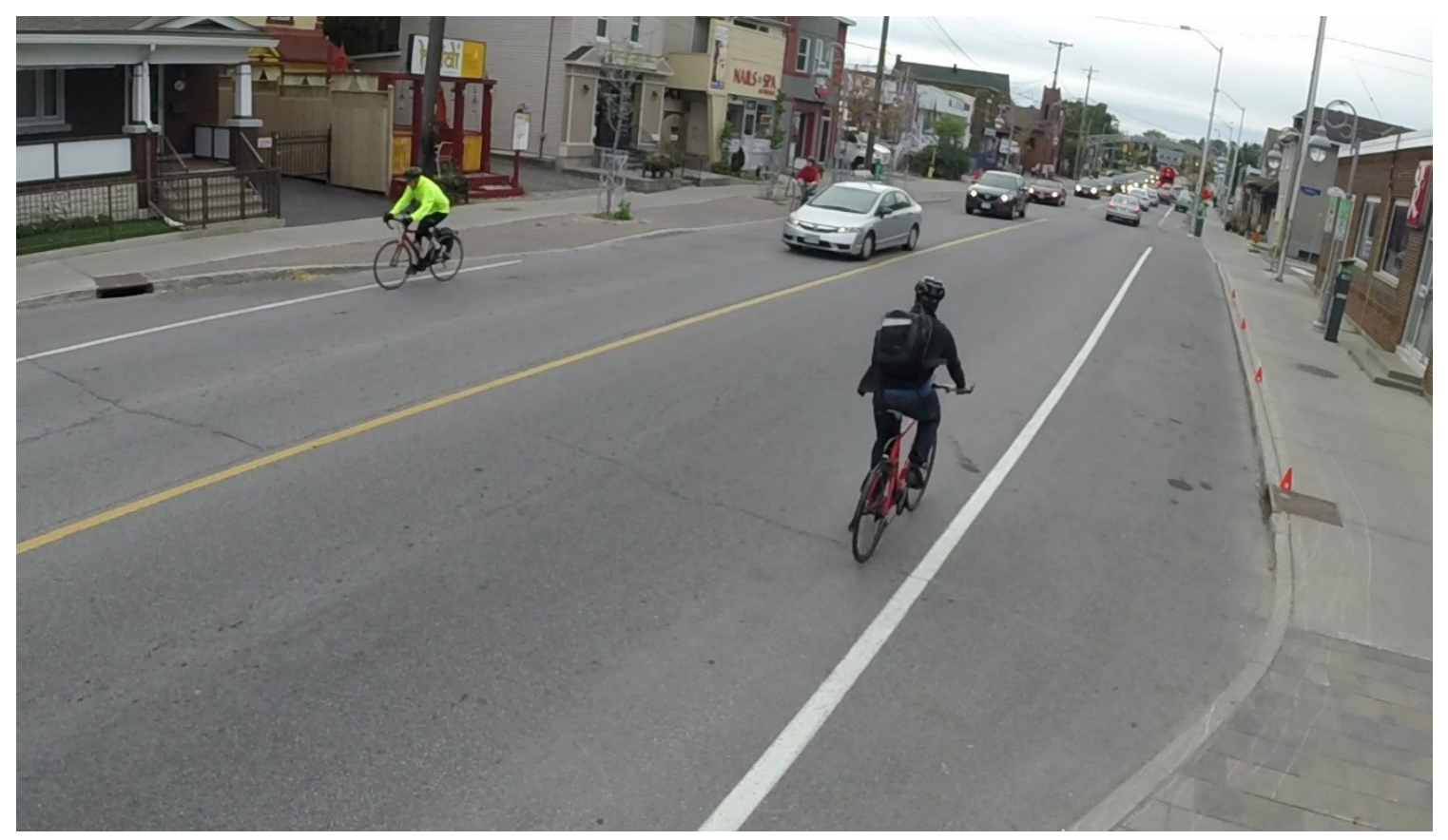

Figure 3-6: Preston Street (both lanes or edges and directions considered)

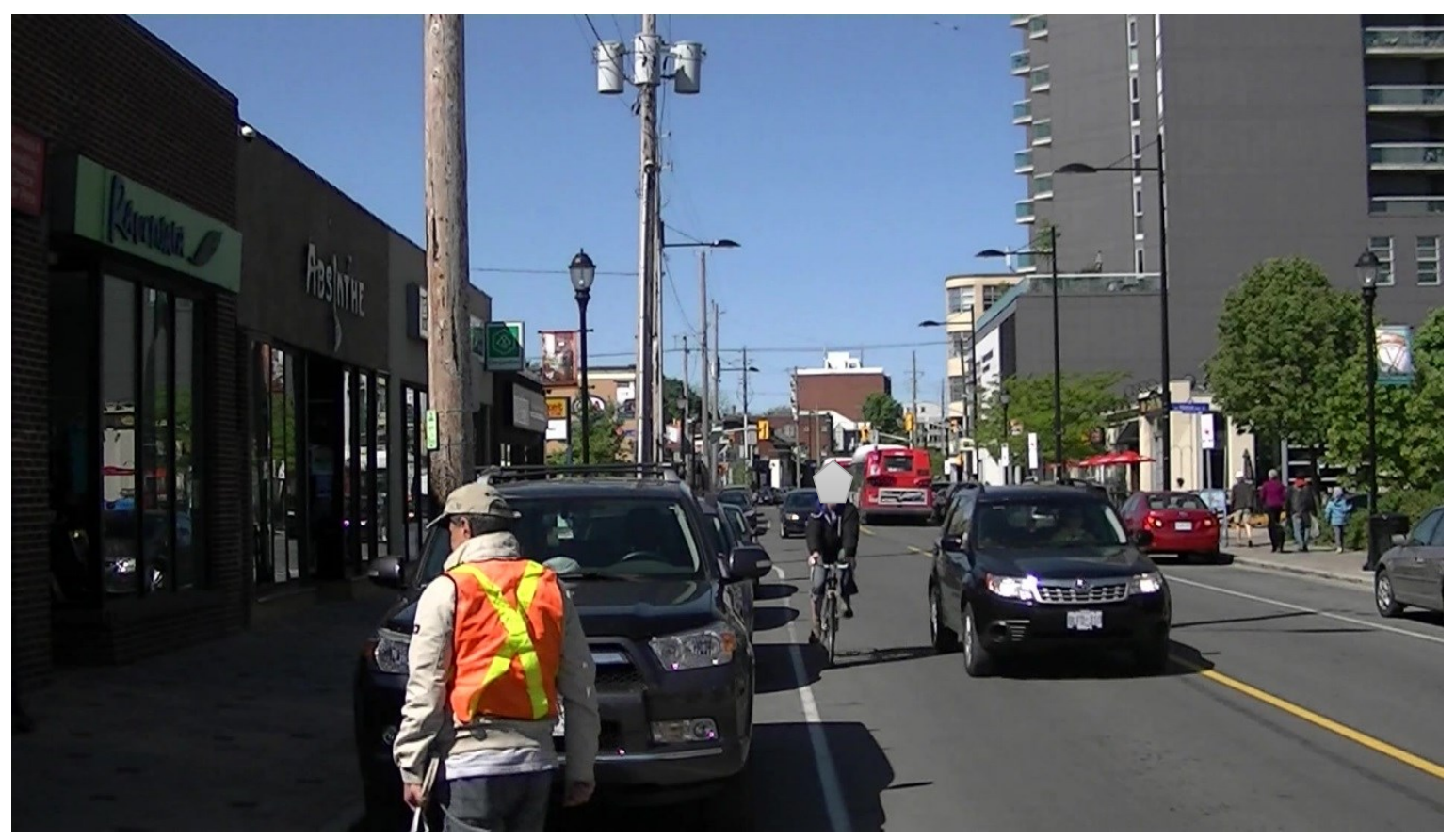

Figure 3-7: Wellington Street (near side lane and edge considered) 


\subsection{Video Data Collection}

Video data totaling 90 hours was collected on the six selected streets (i.e., Bank, Preston, Gladstone, Pleasant Park, St Patrick and Wellington). Data on Bank, Preston, Pleasant Park, Gladstone and St. Patrick were collected in September and October of 2015, while some more on Bank and Wellington had been collected earlier in September, 2014 by Dr. Ali Kassim as part of a previous research work. High-definition Go-Pro cameras were firmly attached to street light poles at about three meters above ground for recording the data. For Pleasant Park and Gladstone however, the cameras were mounted on survey tripods extended to about $2.5 \mathrm{~m}$ above ground. This was due to the absence of street light poles in any adequate position on the two sites. Figures 3-8 and 3-9 shows the camera setup at some of the sites. Data collection, distribution and properties of the study sites are shown in the Table 3-1. Markers (cones or lines) were put in place to make it possible for the measurement of traffic speed. Lane and Road width measurements were taken at three different points along the section of interest on each site with a $30 \mathrm{~m}$ plastic tape measure. The three measurements on each site were always within $2 \mathrm{~cm}$ precision due the absence of any visible changes in road width along selected sections. 
Table 3-1: Site Features and Data collection

\begin{tabular}{|c|c|c|c|c|c|c|c|c|}
\hline \multirow{2}{*}{ Street Name } & \multirow{2}{*}{$\begin{array}{c}\text { \#No. of } \\
\text { Days }\end{array}$} & \multirow{2}{*}{$\begin{array}{c}\text { \#No. of } \\
\text { Edges }\end{array}$} & \multirow{2}{*}{$\begin{array}{c}\text { \#No. of } \\
\text { Hours }\end{array}$} & $\begin{array}{c}\text { Section } \\
\text { Length }(\mathbf{m})\end{array}$ & \multicolumn{2}{|c|}{ Lane Width $(\mathbf{m})$} & \multicolumn{2}{c|}{$\begin{array}{c}\text { Marker } \\
\text { Interval }(\mathbf{m})\end{array}$} \\
\hline Bank & 4 & 1 & 30 & 60 & 3.6 & 3 & 6.6 & 27 \\
\hline Gladstone & 2 & 2 & 10 & 50 & 4.2 & 4.5 & 8.7 & 5 \\
\hline Pleasant Park & 2 & 2 & 10 & 50 & 5.1 & 5.1 & 10.2 & 10 \\
\hline Preston & 2 & 2 & 10 & 50 & 4.6 & 4.6 & 9.2 & 5 \\
\hline Wellington & 2 & 1 & 15 & 50 & 3.3 & 3.3 & 6.6 & 25 \\
\hline St. Patrick & 2 & 2 & 15 & 90 & 4.1 & 4.1 & 8.2 & 15 \\
\hline
\end{tabular}




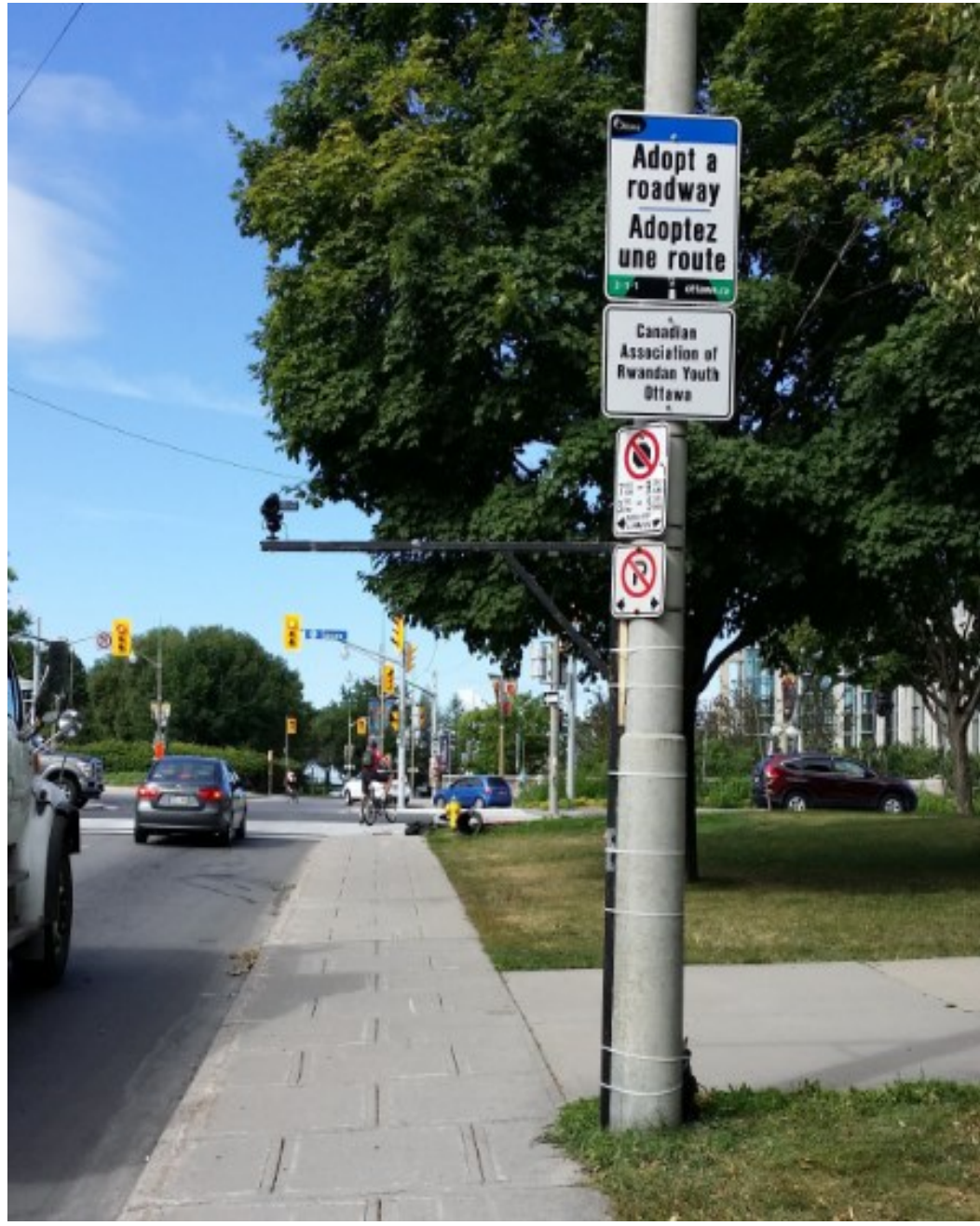

St Patrick Street

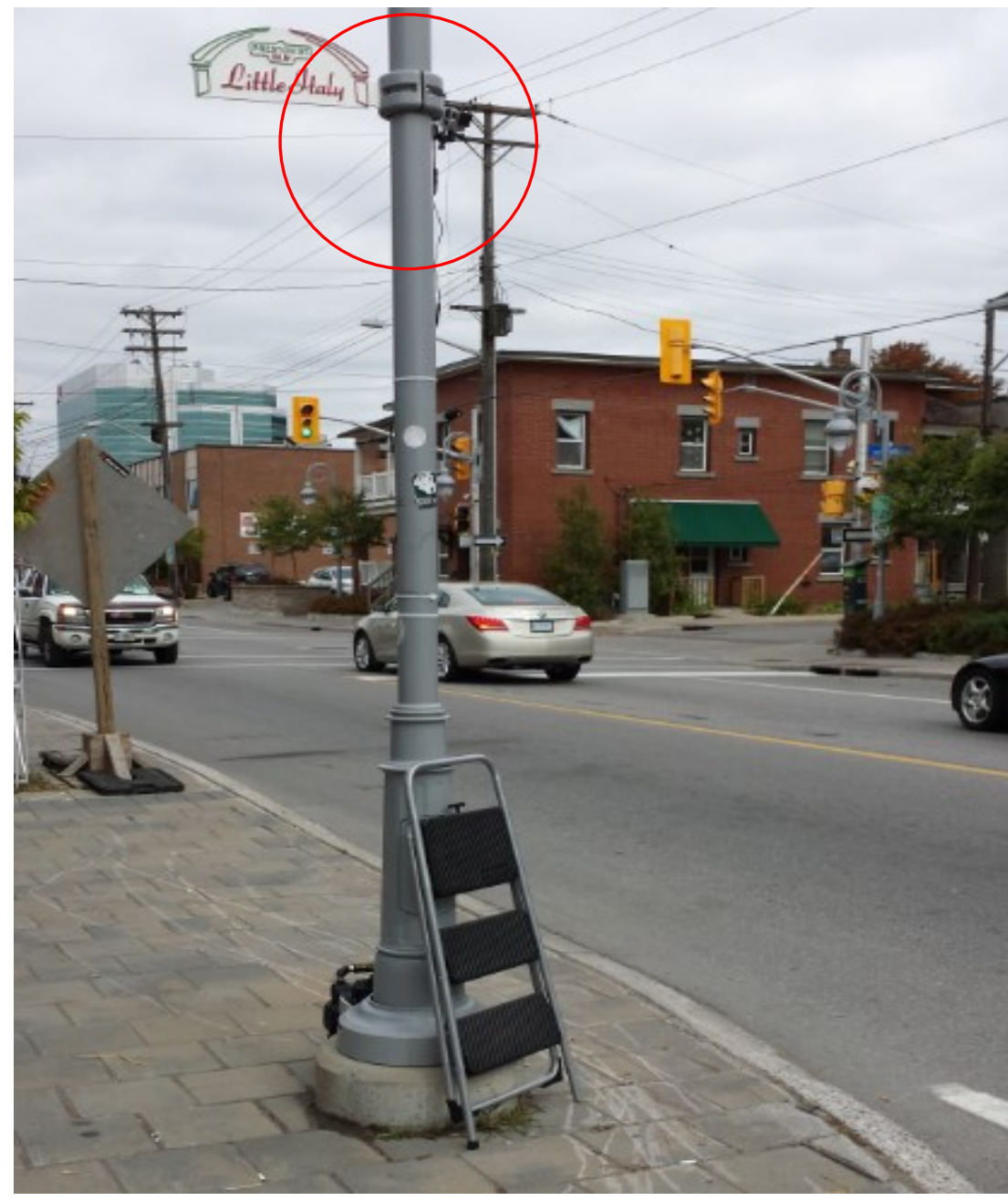

Preston Street

Figure 3-8: Camera setup at St Patrick Street and Preston Street 


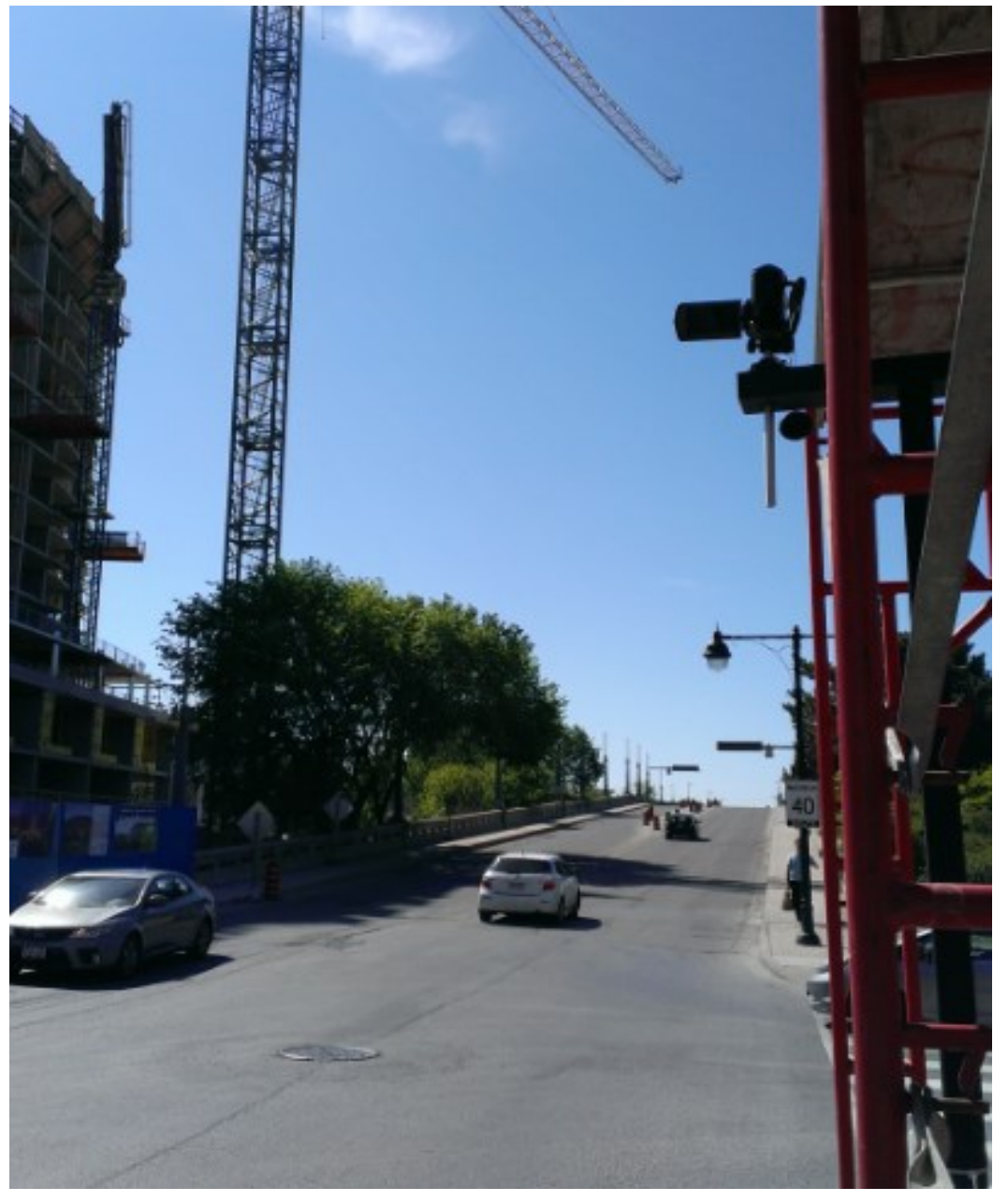

Bank Street

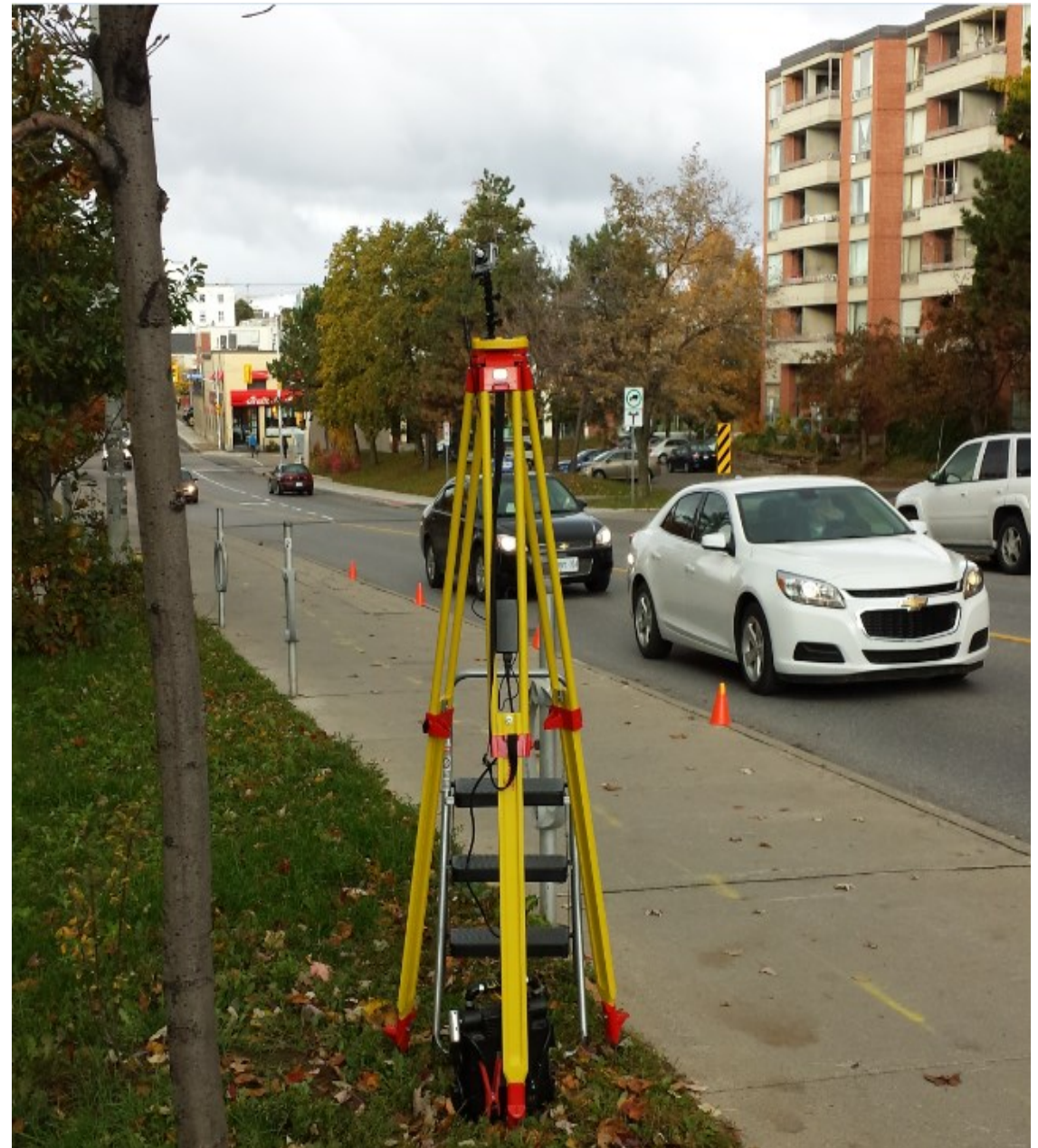

Gladstone Street

Figure 3-9: Camera setup at Bank Street and Gladstone Street 


\subsection{Survey Data Collection}

A total of 108 bicyclists were contacted through self-administered online survey and 56 responses were received. The respondents generally consisted of regular bicyclists, students and bicycle club members in the City of Ottawa. The email addresses of respondents were obtained directly from themselves by direct interviews at nodes of bicycling facilities and a few were obtained by liaising with bicycle club executives. The distribution of the participant population is shown in Table 3-2. The youngest and the oldest respondents were 15 and 70 years respectively. For reliable responses, bicyclists below 13 years were exempted from the survey. Passing Events (described in section 3.4) from the recorded videos for all sites where mixed and grouped into sets of twenty five. A total of 18 sets $^{5}$ were created from 483 of the events ${ }^{6}$ and each set was evaluated by at least three different respondents. Respondents for each set were independent. The respondents viewed the 25 passing events and evaluated them on a comfort Likert scale of 1 (dangerous) to 5 (very comfortable). Sample responses are presented in Appendix B: Exhibit 1 to 5.

The respondents are greatly, a combination of mixed traffic and potential mixed traffic bicyclists, as only $3(5 \%)$ will not consider riding with motor traffic, while the rest either already ride in mixed traffic or will ride if it is safe and tolerable. Moreover, the distribution of scores on experience indicates that the respondents are largely a group

\footnotetext{
${ }^{5} 45$ videos in the sets had 2 or 3 passing events very close in time such that they could not be separated for respondent's evaluation, hence evaluated together.

${ }^{6}$ Time constraints and tardy in receipt of required number of responses per event prevented the use of 80 events, whiles 17 events where exempted due to inability to extract some relevant variables. Hence a reduction from 580 to 483 evaluation responses.
} 
that is experienced enough to bike in traffic but may be concerned with the bicyclist's safety, and vehicle behavior on trafficked routes. The respondent group is considered appropriate as it involves opinions of bicyclists who are representative of the potential viability of promoting mixed traffic cycling.

Table 3-2: Respondent Distribution

\begin{tabular}{|c|c|c|c|c|}
\hline Factor & \multicolumn{4}{|c|}{ Distribution } \\
\hline \multirow{2}{*}{ Gender } & Male & Female & \\
\cline { 2 - 5 } & $39(70 \%)$ & $17(30 \%)$ & \\
\hline \multirow{2}{*}{ Age } & $15-20$ & $21-40$ & $41-60$ & $>60$ \\
\cline { 2 - 5 } & $2(4 \%)$ & $31(55 \%)$ & $16(29 \%)$ & $3(5 \%)$ \\
\hline \multirow{2}{*}{$\begin{array}{c}\text { Experience } \\
\text { Level }\end{array}$} & Novice (1) & Good (2) & Very Good (3) & Expert (4) \\
\cline { 2 - 5 } & $2(4 \%)$ & $3(5 \%)$ & $29(52 \%)$ & $22(39 \%)$ \\
\hline
\end{tabular}




\subsection{Relevant Variable Measurement}

Several parameters have been highlighted in the literature as significant to a comfortable interaction between a bicyclist and a motorist. Passing is one inevitable event in mixed traffic, as such passing distance is very significant in bicycle and vehicle interactions. For this study, motor vehicle speed, traffic volume, presence of parking, bicyclist speed and bicyclist position from the nearest hazard (.i.e., curb or parked vehicles) have also been identified as relevant factors to safe interactions. In addition, road specific features are considered.

The entire video data was viewed by staff to identify and cut passing events for further analysis. A passing event starts when an adjacent vehicle approaches a bicycle with the front bumper aligned with the bicycle's rear tire and ends when the vehicle clears the bicycle's front tire. Vice versa for the bicycle and vehicle is also considered an event. Nevertheless, to enhance measuring all variables from an extracted video, the start and end time boundaries were extended beyond the passing event. Thus, a time at which the bicycle and or vehicle appear in the video without going beyond the starting marker and without the passing event already taking place was recorded in an excel script as the event's start time. Again the time after both the bicycle and vehicle have gone past the end marker and the passing event already occurred is recorded in the script as the end time. The times recorded in the excel script were used to cut the passing events from the entire video footages. The rest of this section explains how the relevant factors aforementioned were obtained from the passing event videos. 


\subsubsection{Speed}

The speed of the passing motor vehicle and that of the passed bicyclist were measured from the passing events. For each passing event (mostly 8 to 20 seconds length), all frames were extracted. Some videos were 60 frames per second ( $f p s)$ and the rest $30 \mathrm{fps}$, with each video producing between 300 to 1200 frames. To measure the speed of the bicyclist or the motor vehicle, two frames are noted. First, the frame showing the bicycle/vehicle aligned with the start marker (i.e., the cones or line) and secondly, the frame indicating an alignment of the bicycle/vehicle with the end marker. In Figure 3-10 for Bank Street events, edge one and two shown are the markers and the length over which speed is estimated is $27 \mathrm{~m}$. The bicycle or vehicle is said to be aligned with a marker when a perpendicular line across the road passes through the marker and simultaneously has the tire of focus sitting on it. The two frame numbers were recorded in excel for every single passing event. For the videos with $60 \mathrm{fps}$, a time factor of $1 / 60$ was multiplied by the difference obtained between the end and start frame numbers. The same was done for $30 \mathrm{fps}$ videos, but using a factor of $1 / 30$. The adopted method will result in a time measurement with precision of 0.0167 and 0.033 seconds for the $60 \mathrm{fps}$ and $30 \mathrm{fps}$ videos respectively. The speeds were subsequently calculated by dividing the distances by the times. The methodology for speed estimation was validated by comparing samples from two staff members. The maximum difference in speed was $0.7 \mathrm{Km} / \mathrm{h}$ and $3 \mathrm{Km} / \mathrm{h}$ for bicycle and motor speed estimation respectively. 


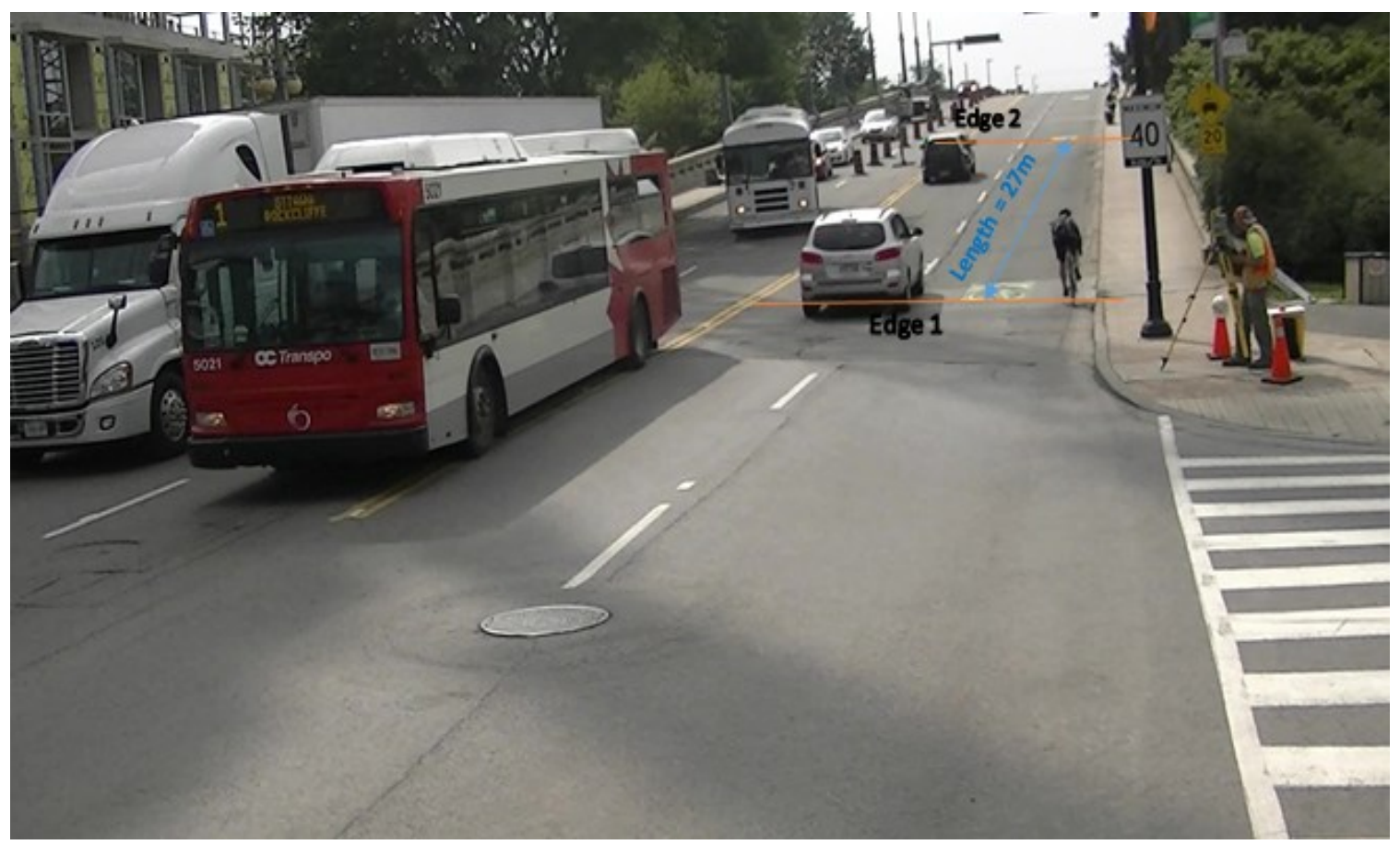

Figure 3-10: Edge 1 and 2 used as markers for speed estimation on Bank Street

The perpendicular line to a lane at a particular point on the road was determined by a graphical method using transparent graphical plots (i.e., plots on a transparent film). The OC Transpo buses (popular transit provider in Ottawa) were used to create the plots. A straight edge close to the base of the bus along the bus's width was used to draw the perpendicular lines. The observation was that, the perpendicular lines tend to have a slightly changing angle as the bus moves away from the camera. As such, a set of perpendicular lines were drawn along the road section appearing in the video scene using frames of the same bus moving along the road. Since the cameras were unmoved for each site and day of recording, then a single plot for each site for each day was considered accurate. Figures 3-11 and 3-12 shows a description of how the transparent line plots look and are used. 


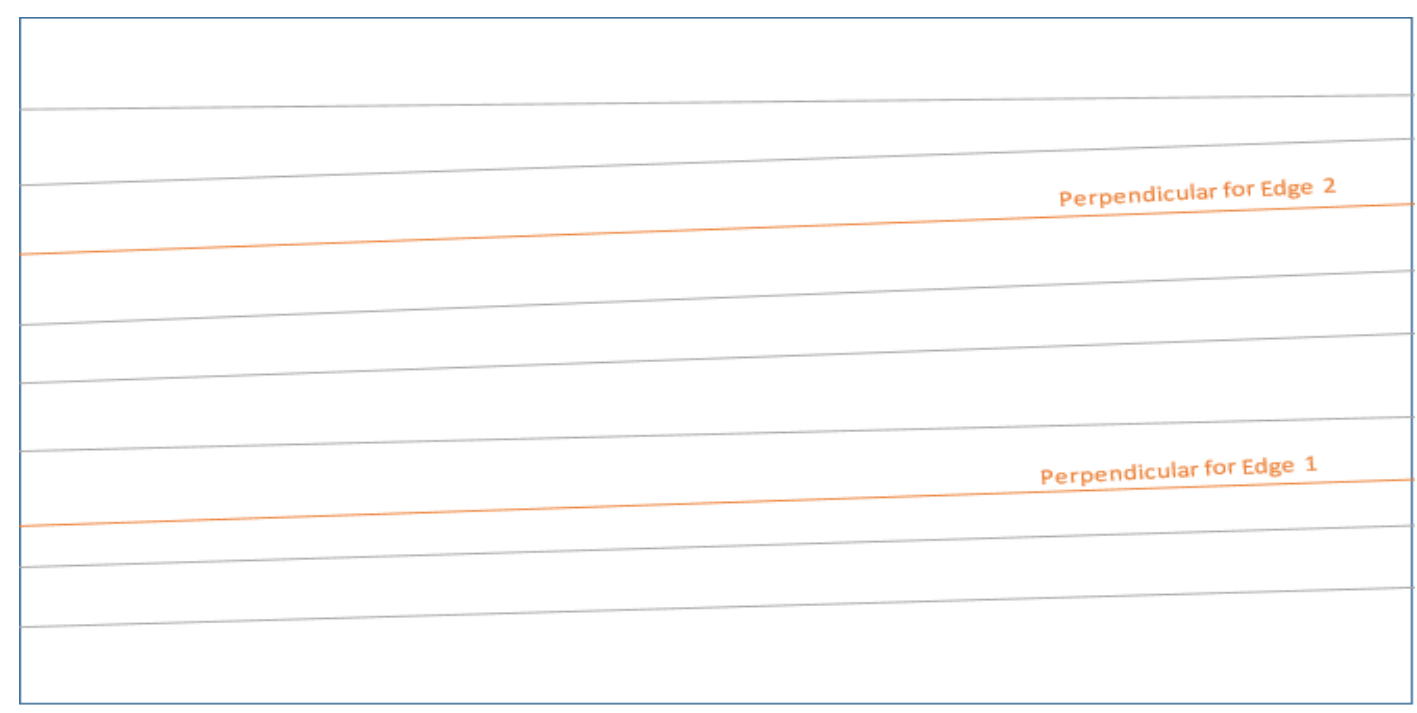

Figure 3-11: Transparent plot for day1 of Bank Street

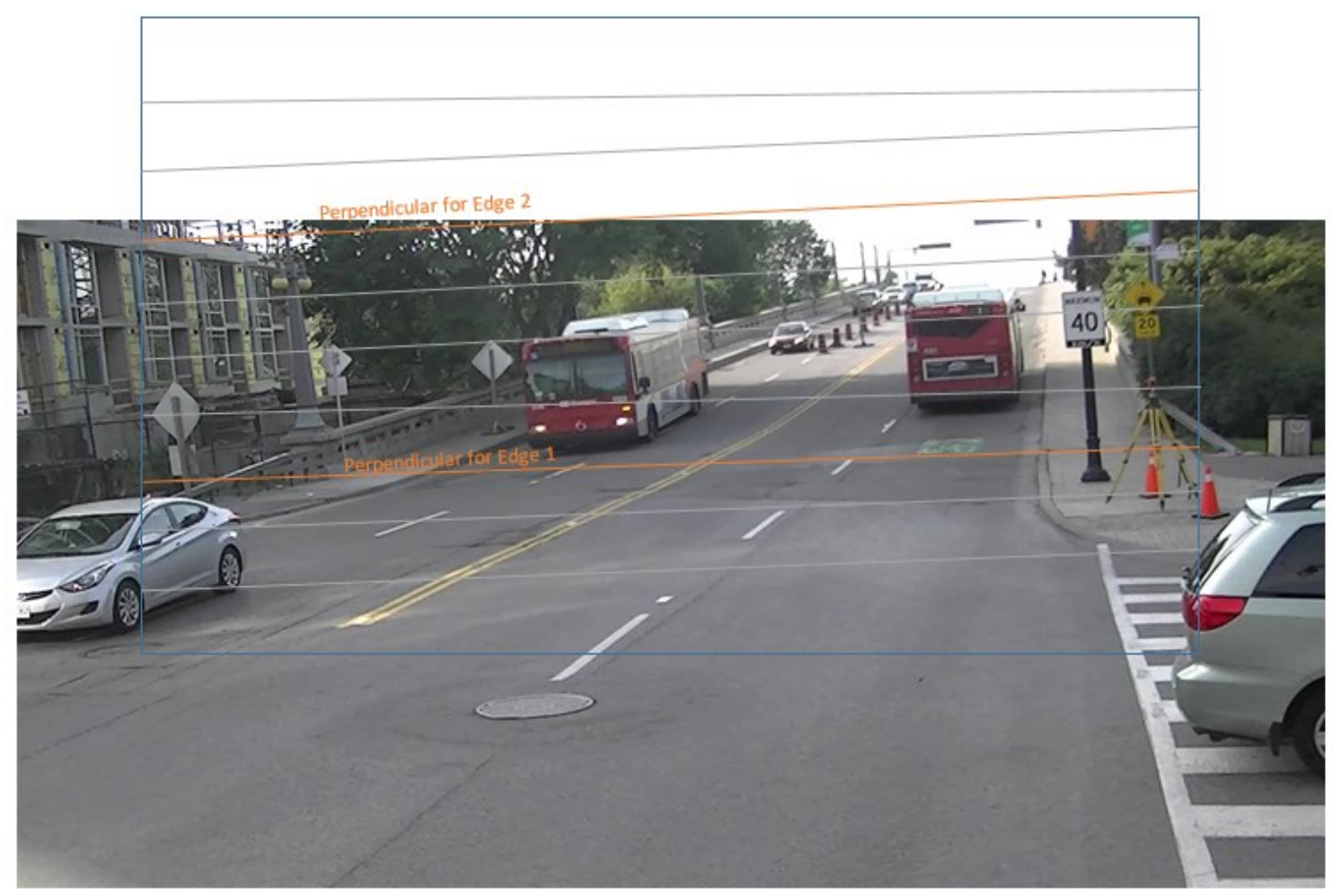

Figure 3-12: Using Perpendicular line plot to locate starting point frame for speed estimation on Bank Street 


\subsubsection{Lateral Passing Distance}

The lateral distance of the bicyclist and the motor vehicle to the edge of the road or any hazard (i.e., parking, edge line, curb) whichever is closest was measured. As mentioned in the procedure leading to the determination of the speed. All the extracted frames for each passing event were observed until a particular frame showing clearly: [i] the motor vehicle and the bicycle aligned along a perpendicular line across the lane from either the front or the back; [ii] a good length of space in front or behind the motor vehicle and bicycle allowing an observer to see the tires of the bicycle and vehicle, the edge and center lines (i.e., there should not be another vehicle behind or in front that obstructs the distance measurement). Due to limited length of road covered by the camera, not all passing maneuvers satisfy the two criteria mentioned (see Table 3-3). In some few cases, a frame indicating the positions of the motor vehicle and bicycle immediately before or after the passing were considered. This is well-founded considering that, of all the videos measured in this fashion, neither the bicycle nor the motor vehicle made an observable change in direction (i.e., by observing from direction of tires) within a second before and after the maneuver.

To obtain the distances, a script was written in Matlab which allows each frame to be opened in Matlab and the relevant points specified on the slide. The script allows points to be indicated on the picture, with the flexibility of zooming if necessary and then a click of the mouse. Points specified include: curb edge line for the lane of interest, center line, bicycle tire and motor vehicle tire closest to the bicyclist. The points are specified such that they are aligned across the lane along a perpendicular to the lane. The co- 
ordinates for each point are obtained in pixel units. These points were saved in excel and subsequently used to generate distances. The distances were then converted to real world distances of meters, by using factors obtained from comparison of the actual lane widths and pixel lane widths. Figures $3-13$ to 3-16 shows some lateral width measurements.

In order to validate the distance measurement procedure, the width of an OC buses was measured at random points along the road sections of study on each site. The results obtained on all the sites were $2.58,2.56,2.60,2.60,2.58$, and 2.59m, giving an average of $2.585 \mathrm{~m}$. The actual width of an OC Transpo bus is $2.591 \mathrm{~m}$ (102 in). The worst measurement of them all is within $3 \mathrm{~cm}$ accuracy and since the points are picked by zooming in and clicking, a precision of $2 \mathrm{~cm}$ was established after several measurements. The method was further validated by measuring lateral distances for 50 randomly selected snapshot slides taken from all the sites using a different method by a PhD graduate and engineer at the City of Ottawa. The maximum difference in measured distances at any point was $8 \mathrm{~cm}$ and the minimum was zero. A sum of the absolute values of all the measurement differences was used to determine an average difference, which was $3 \mathrm{~cm}$. The average difference between the two measurements is acceptable and barely different from the precision of the method. 


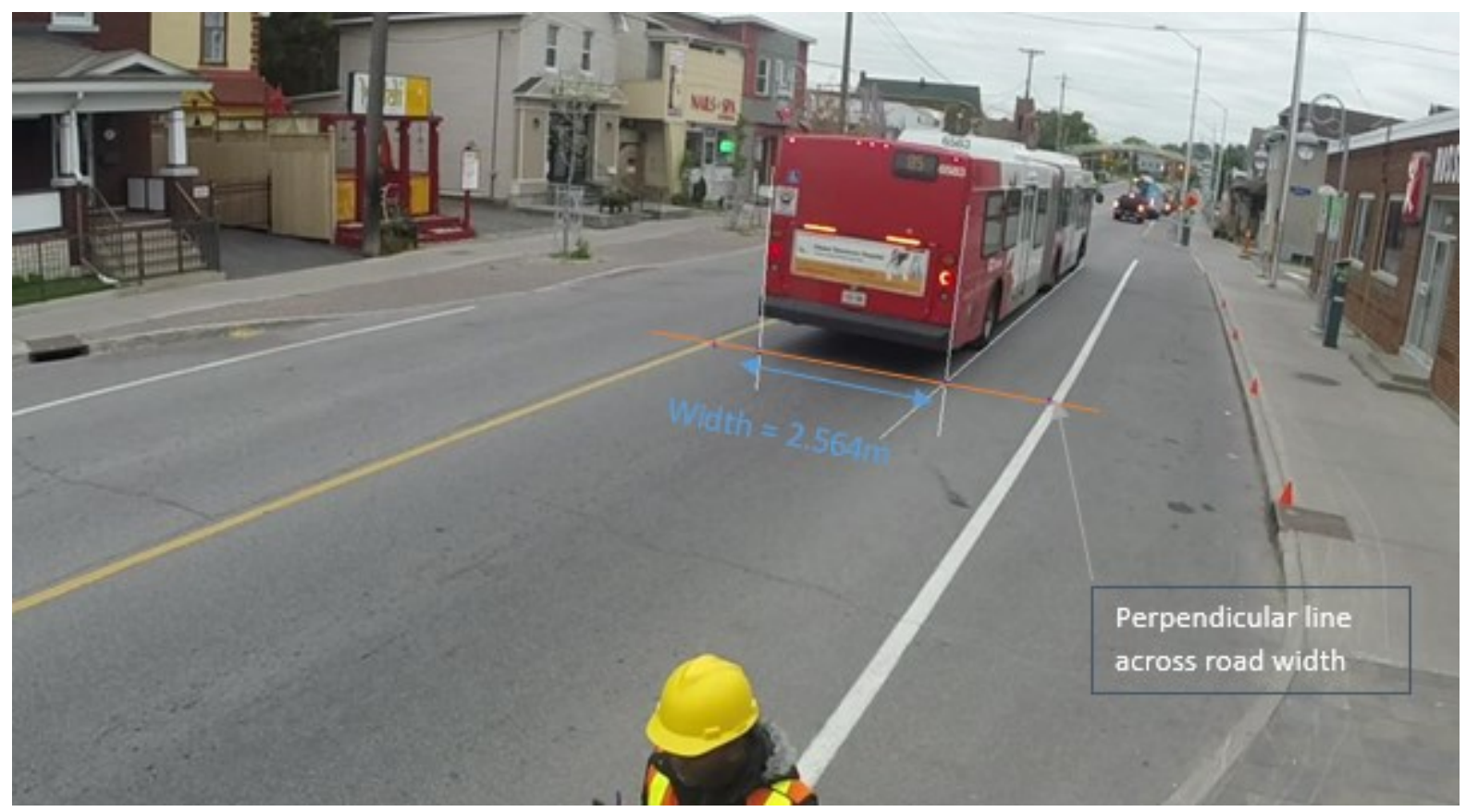

Figure 3-13: Measuring Width of an OC Transpo bus using the Matlab script and Perpendicular line plot (Preston Street)

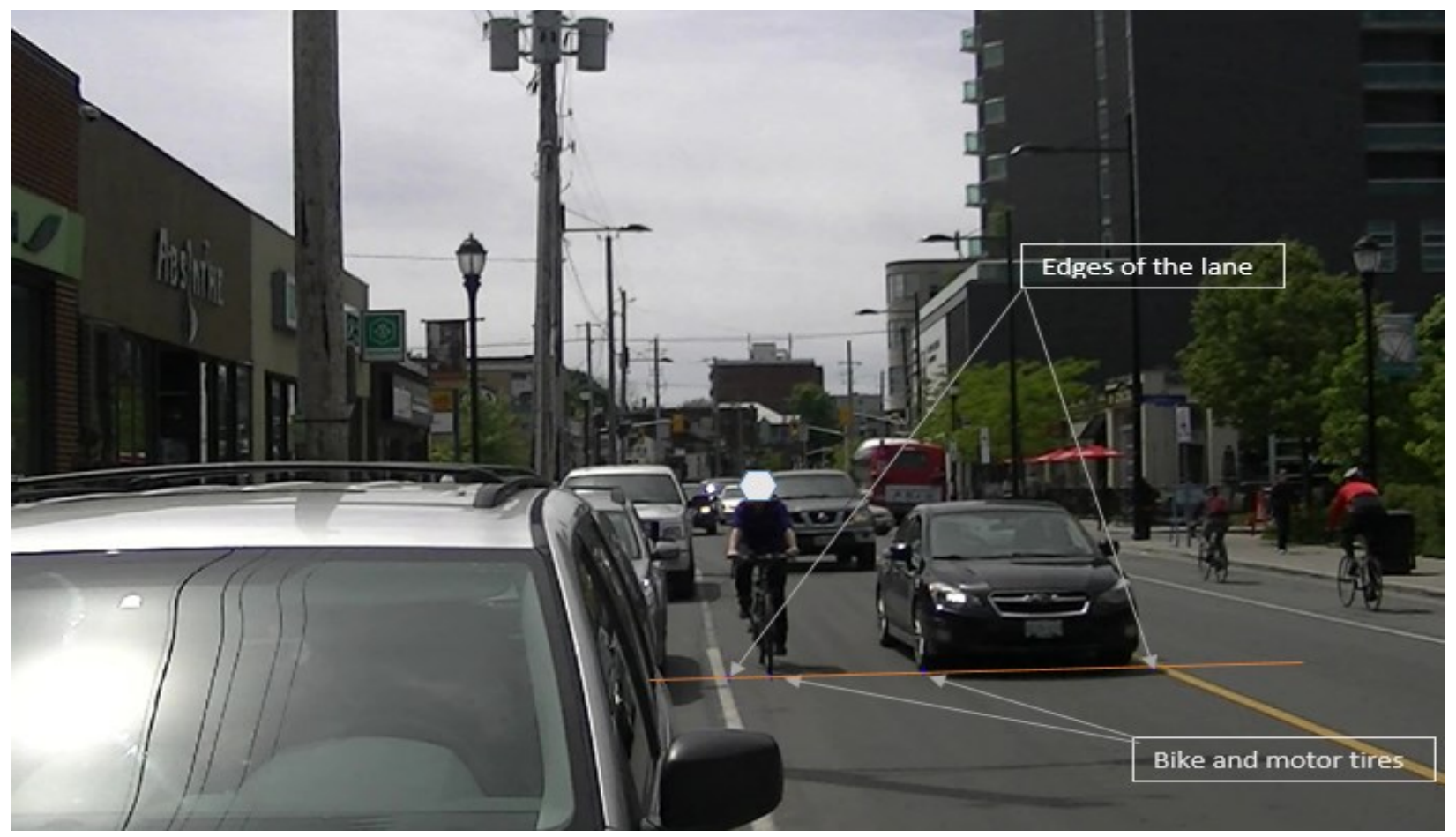

Figure 3-14: Measuring lateral distance on Wellington Street 


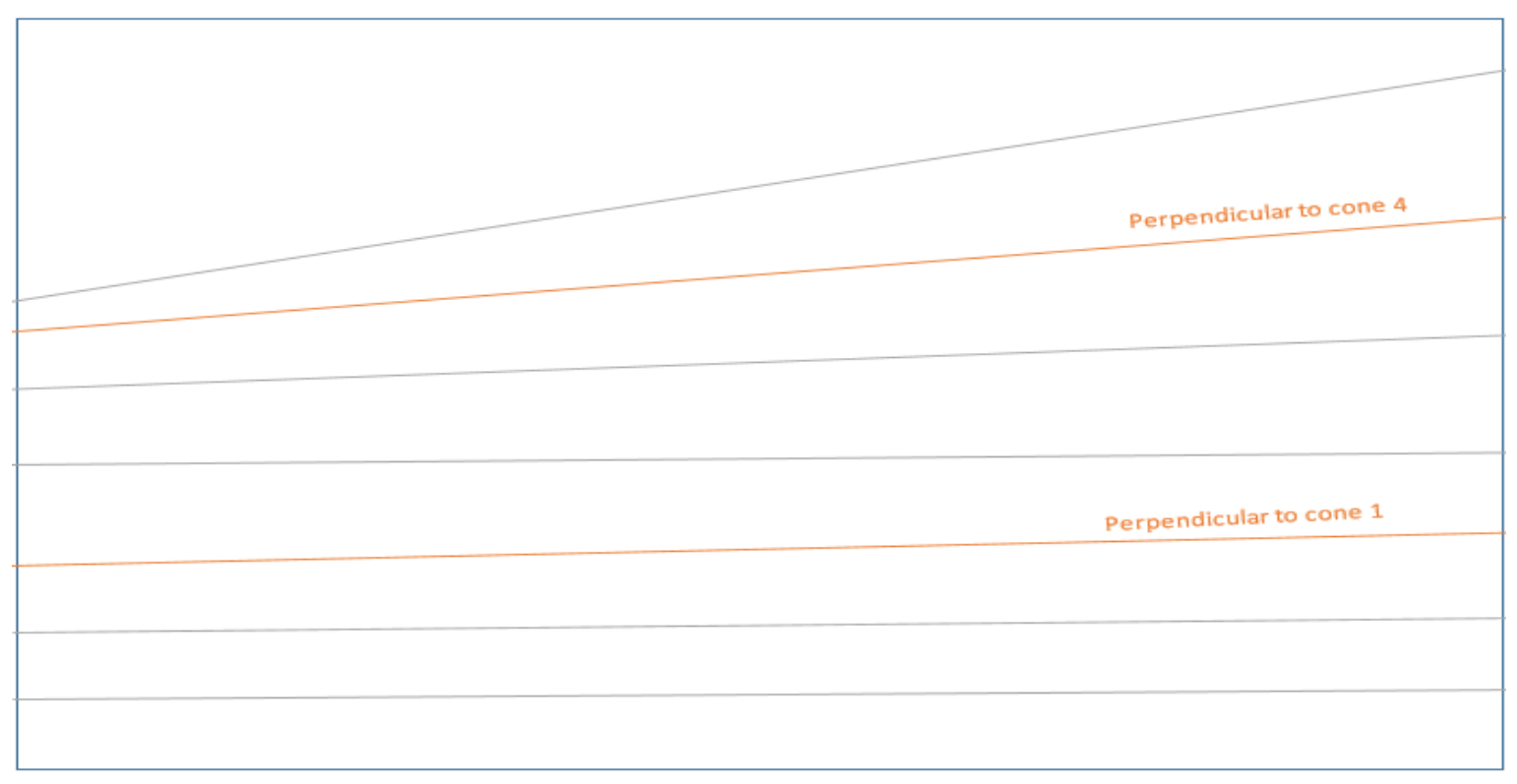

Figure 3-15: Transparent plot for day 1 of Gladstone Avenue

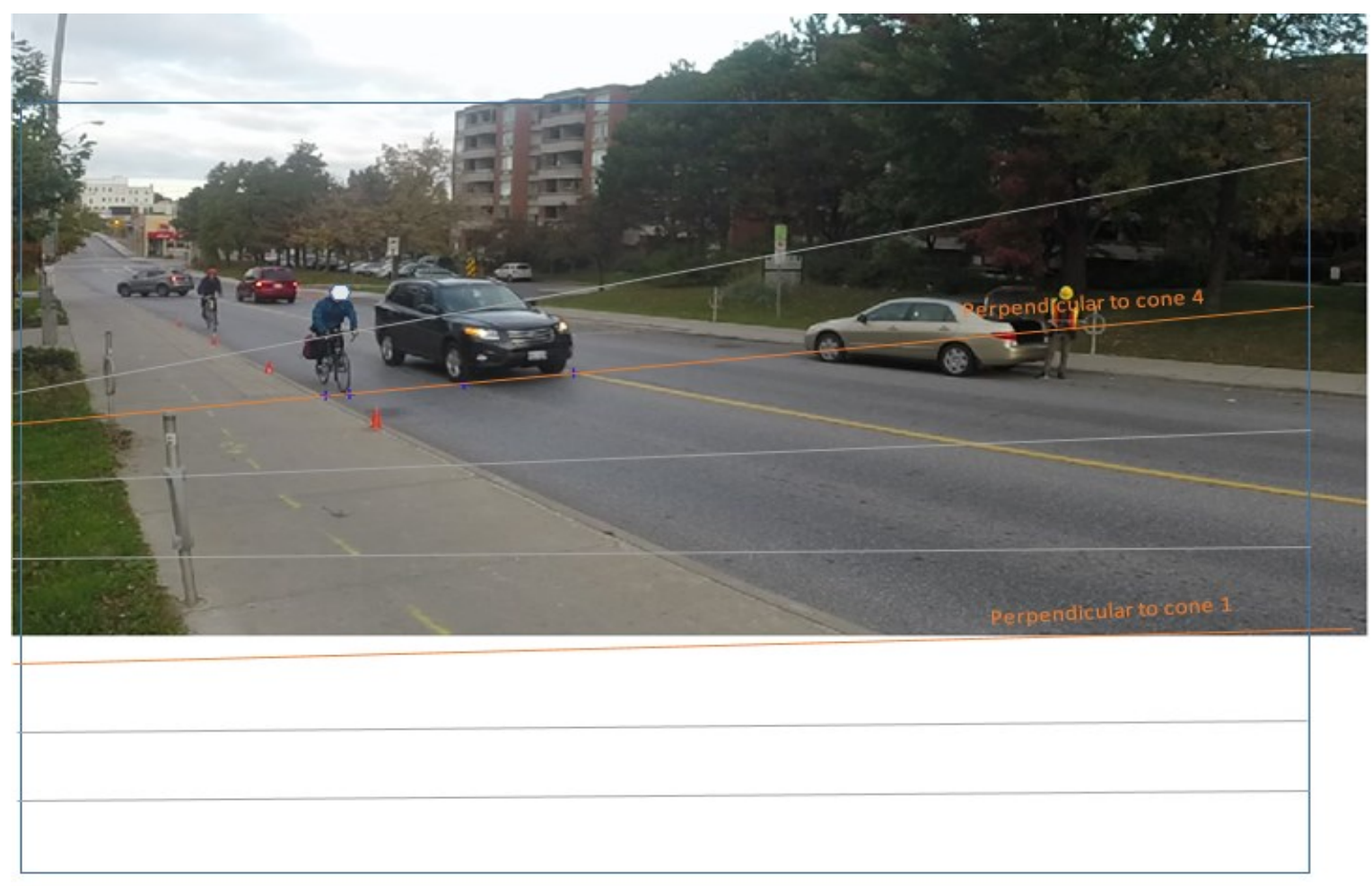

Figure 3-16: Using Perpendicular line plot to locate frame with properly aligned bicyclist and motor vehicle on Gladstone Avenue 


\subsubsection{Ambient Traffic Density (ATD)}

This parameter is a measure of traffic density specific to a passing event. The rationale is to determine the weight of vehicular volume effect on the bicyclist movement. In order to obtain a length over which the ATD will be counted, there is a need to determine the length within which the presence of a vehicle is considered to influence the bicyclist. Therefore, an auditory perception experiment was carried out to obtain an effective length for which bicyclists will perceive the presence of a vehicle behind them. Barnecutt and Pfeffer (1998) states the difficulty and inaccuracy in estimating distance from loudness of sound. Nevertheless, the experiment herein is to determine when a vehicle sound is heard and not the intensity of it. Three different bicyclists with normal hearing ability traversed the Pleasant Park site twenty times each at an off peak period. They acknowledged hearing a vehicle from behind by raising a flag. The distances of the vehicles from the bicyclist upon flag indication were determined and the averages obtained for the three bicyclists were $45.8 \mathrm{~m}, 34.2 \mathrm{~m}$, and $45.1 \mathrm{~m}$. The overall average is 41.7m. It was difficult to determine an effective visual length ahead for the ATD, hence vehicles within $45 \mathrm{~m}$ behind or ahead of the bicyclist during a passing event were counted and assumed to impact bicyclist riding behavior. ATD is then calculated as the number of vehicles divided by an effective distance of $90 \mathrm{~m}$. For some passing events, the distance behind or ahead during the passing event captured in the video scene is less than $45 \mathrm{~m}$. In such cases, for example when the distance behind during the passing event is less than $45 \mathrm{~m}$, then the speed of vehicles arriving in the scene immediately after the passing event are used to estimate whether the arriving vehicles fall within the $45 \mathrm{~m}$ effective distance. 


\subsubsection{Road Features}

The lane width for each edge adopted in the distance measurement was measured on site (see Table 3-1). Measurements on each site was taken trice at different points along the road section with a $30 \mathrm{~m}$ plastic tape measure. There was no need for taking means due to a good precision within $2 \mathrm{~cm}$. The number of lanes may influence the passing interaction in that, many motor vehicles tend to occupy part of the inner lane if it is unoccupied. In addition, adjacent curb side parking and a grade slope in the direction of travel are recorded as binary terms (i.e., whether they are present or absent). If a parked vehicle exist adjacent to a bicycle during an event of vehicle passing, it is marked 1 and if otherwise, 0. Two sites i.e. Bank Street and Gladstone Avenue were slightly steep (between 4-6\%) in grade and hence events taken from them were marked 1, whiles all other events were recorded as 0 due to almost flat grades.

\subsection{Data reduction}

For some passing events, one or more variables could not be measured or estimated with reasonable accuracy. Such events were excluded from the study. A total of 17 events were excluded, mostly due to inability to determine the lateral passing distance. The distribution of data reduction is shown in Table 3-3. For some passing events the passing vehicle or the bicycle was blocked from scene by other vehicles or objects. Also some passes occurred at points that were too far from the camera such that it was visually difficult to identify the vehicle or bicycle tires and the adjacent curb side edge lines even upon zooming. 
Table 3-3: Distribution of Data reduction

\begin{tabular}{|c|c|c|c|c|}
\hline Street Name & Edge \#No. & Total Events & Discarded & Used Events \\
\hline Bank & 1 & 238 & 4 & 234 \\
\hline \multirow{2}{*}{ Gladstone } & 2 & 77 & 1 & 76 \\
\hline & 3 & 11 & 1 & 10 \\
\hline \multirow{2}{*}{ Pleasant Park } & 4 & 33 & 0 & 33 \\
\hline & 5 & 16 & 1 & 15 \\
\hline \multirow{2}{*}{ Preston } & 6 & 45 & 2 & 43 \\
\hline & 7 & 26 & 0 & 26 \\
\hline Wellington & 8 & 52 & 6 & 46 \\
\hline \multirow{2}{*}{ St. Patrick } & 9 & 80 & 2 & 78 \\
\hline & 10 & 2 & 0 & 2 \\
\hline Total & & 580 & 17 & 563 \\
\hline
\end{tabular}

\subsection{Statistical Analysis and Model Development}

The data obtained for all the variables and for each event was stored in excel for further analysis. The Stata program (Stata/SE 14.0 - 2015) and R software (version 3.1.3 2015/03/09) were employed to carry out hypothesis testing, comparison and analysis of variables, and finally development of models for both passing distance and bicycling comfort perception. Variables were analysed using t-tests, ANOVA, box and scatter plots. Ordinary Least Square (OLS) Linear regression models were developed for each of passing distance and bicycling comfort perception. 


\subsection{Summary}

In sum, ninety hours of video data was collected on six shared roads. The data was cut into 580 (becoming 563, after data reduction) passing events for which ten variables was measured from each event. The variables include: Passing distance (m), Bicycle Speed $(\mathrm{Km} / \mathrm{h})$, Motor Speed $(\mathrm{Km} / \mathrm{h})$, Bicycle-to-edge distance/Bicyclist position $(\mathrm{m})$, Ambient Traffic Density (Veh/km), Lane width (m), Comfort Score, No. of Lanes, Parking and Grade. Comfort scores were obtained by bicyclists' evaluation of the events, while all other variables were measured by well-planned and validated methods. 


\section{CHAPTER 4: ANALYSIS AND RESULTS}

The results of the obtained data from the previous chapter are presented and analysed in this chapter. The focus of discussion is on the influence of the various variables on passing distance and comfort. In addition the models fitted to passing distance and comfort are discussed.

A total of 563 events were obtained, for which 483 of them were evaluated by bicyclists regarding comfort perception. A statistical summary of each variable is presented in Table 4-1.

Table 4-1: Descriptive Summary of variables

\begin{tabular}{|c|c|c|c|c|c|}
\hline Variable & $\begin{array}{c}\text { Sample } \\
\text { Size }\end{array}$ & Mean & Std. Dev. & Min & Max \\
\hline Passing distance (m) & 563 & 1.878 & 0.520 & 0.45 & 3.82 \\
\hline Bicycle Speed (Km/h) & 563 & 14.317 & 6.272 & 3.03 & 38.03 \\
\hline Motor Speed (Km/h) & 563 & 29.331 & 11.113 & 0 & 66.12 \\
\hline Bicycle-to-edge distance (m) & 563 & 0.571 & 0.359 & 0 & 4.26 \\
\hline Ambient Traffic Density (Veh/km) & 563 & 24.904 & 11.437 & 11.1 & 55.6 \\
\hline Lane width (m) & 563 & \multirow{3}{*}{\multicolumn{2}{|c|}{ categorical }} & 3.3 & 5.1 \\
\hline Comfort Score & 483 & & & 1 & 5 \\
\hline No. of Lanes & 563 & & & 1 & 2 \\
\hline Parking (presence of curbside parking) & 563 & \multirow{2}{*}{\multicolumn{2}{|c|}{ binary }} & 0 & 1 \\
\hline Grade (presence of slope) & 563 & & & 0 & 1 \\
\hline
\end{tabular}




\subsection{Variable comparisons and tests of Hypothesis}

\subsubsection{Effects of Parking, Grade and number of Lanes on Road Sharing}

A Welch Two sample T-test indicates that a significant difference exists between means for the presence and absence of parking ( $p$-value of 0.000202 at $95 \%$ confidence level). The average passing distances are $1.92 \mathrm{~m}$ and $1.66 \mathrm{~m}$ for parking absent and present respectively. Meanwhile the average distance of bicyclists to the road edge or hazard shows that bicyclists ride much closer to the edge in the presence of parked vehicles. The average length for presence and absence of parking are $0.35 \mathrm{~m}$ and $0.61 \mathrm{~m}$ respectively and was also very significant at $95^{\text {th }}$ percentile confidence ( $p$-value of $\left.2.41 \mathrm{e}-14\right)$. A linear regression shows that parking accounts for $3 \%$ of the variability in PD, with a $p<0.0001$. The average passing distances for one and two lane roads are $1.876 \mathrm{~m}$ and $1.880 \mathrm{~m}$ respectively and was found insignificant at $95 \%$ confidence level in a t-test with a $p$-value of 0.926 . Most passing vehicles use a section of the adjacent lane (regardless of traffic direction) when the bicyclist is further from the adjacent curb and in the absence of adjacent lane traffic. Hence, the latter result may be due to a balance in the occurrence of such instances on roads with one and two lanes in the travel direction. However, the number of lanes was significant to cycling position as bicyclists recorded a higher average distance from the edge on two lane roads with an average of $0.61 \mathrm{~m}$ compared to $0.52 \mathrm{~m}$ on one lane roads. A box plot showing the effect of the combinations of parking and number of lanes on Passing and bicyclist position is presented in Figure 4-1. 


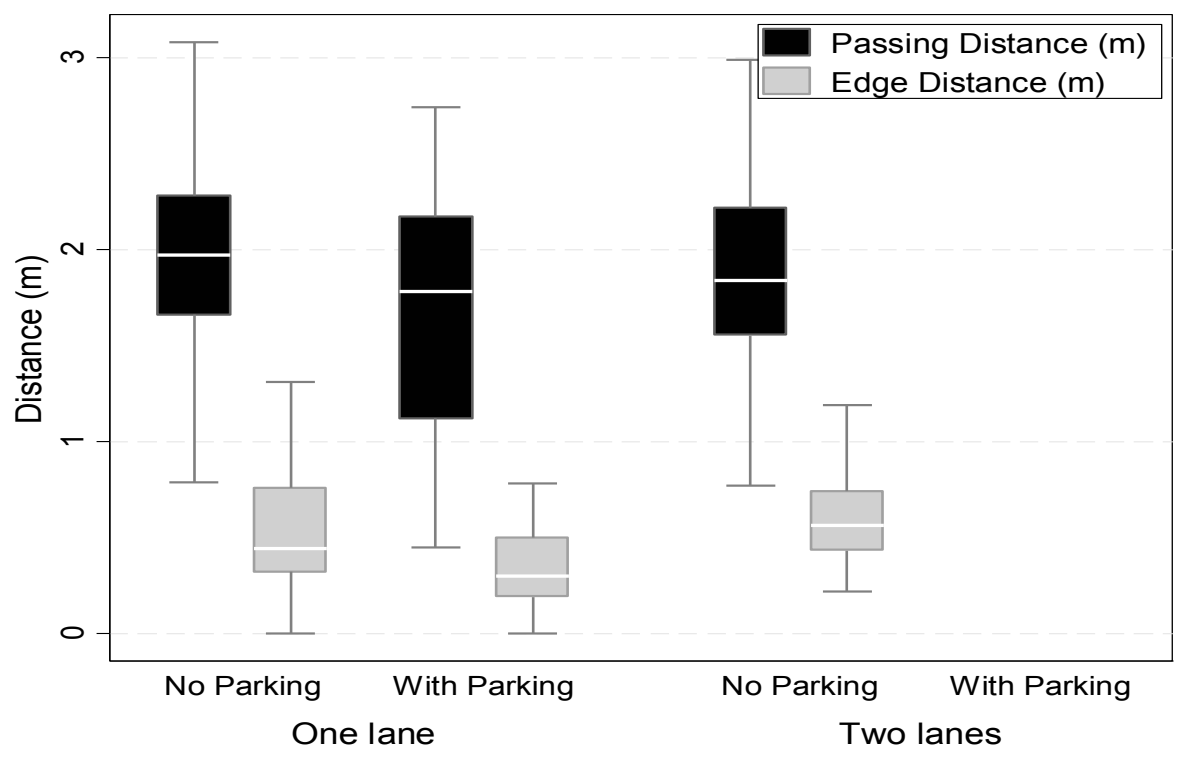

Figure 4-1: Comparing Distances by number of lanes and Parking

NB: The "Edge distance" denotes the bicyclist distance from the adjacent curb edge line. All passing events taken from the two lane roads were without parking, hence the empty column.

It is problematic that the average bicyclist position away from the edge line in events with parked vehicles is $0.35 \mathrm{~m}$, a length that is within "dooring 7 " zone. The above result may be attributed to the fact that most of the events with parking occurred on Wellington Street, which has a combination of high traffic volumes, and the narrowest lane width of $3.3 \mathrm{~m}$. The situation on this road is such that bicyclists will either have to be too close to the moving vehicle or the passing vehicle. The effect of grade on both passing and bicyclist position is insignificant, yielding $p$-values of 0.58 and 0.72 respectively.

\footnotetext{
${ }^{7}$ When a bicyclist runs or crashes into an open vehicle side door
} 


\subsubsection{Effect of Lane width and ATD on Road Sharing}

An ANOVA test was also carried out to establish the variance between lane width categories in reference to each of Passing distance and Bicyclist position from the edge line. The null hypothesis is that, there is no difference in means i.e.:

$\mathrm{H}_{0}: \quad \mu 1=\mu 2=\mu 3=\mu 4 \quad$ (i.e. the means are equal)

$\mathrm{H}_{1}$ : The means are not all equal

The ANOVA tests resulted in an $F$-value of 18.71 with a $p$-value $=0$ and an $F-$ value of 36.15 with a $p$-value $=0$ for Passing distance and Bicyclist position from the curb edge line respectively. This is further highlighted in the box plot in Figure 4-2.

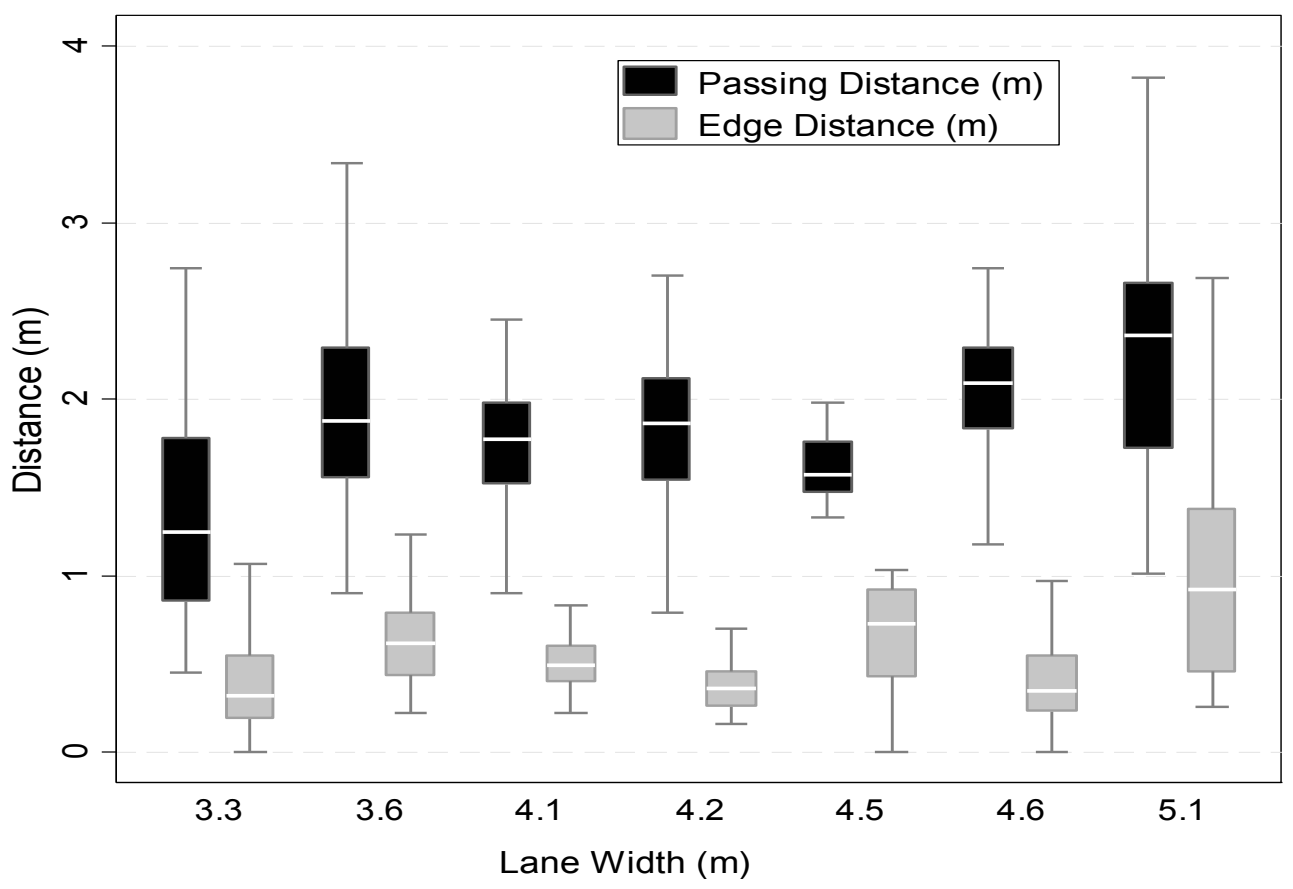

Figure 4-2: Comparing Distances by Lane Width 
The box plot gives the indication that bicyclists will rather go as close as possible to the curb in other to increase the passing distance between them and vehicles. The average passing distance for each lane is significantly greater than the distance of the bicyclist to the curb adjacent edge line (approximately twice or greater for each lane width). Moreover, none of the average bicyclist's position exceeds $1 \mathrm{~m}$. That being said, it is worth noting that the average passing distance for all the different lane widths exceeds $1 \mathrm{~m}$. In fact, aside the $3.3 \mathrm{~m}$ lane width, they all exceed $1.5 \mathrm{~m}$. Regardless of the fall and rise in means due the stochastic nature of the data, a fair deduction is that the wider lane widths are associated with greater passing distances. A linear regression between lane width and passing shows that lane width explains $7 \%$ of the variability in PD, with a $p<0.0001$.

Increasing ATD seem to have the effect of reducing the passing distance. In the presence of only the passing vehicle or two vehicles during passing the average passing distances are almost $2 \mathrm{~m}$ (Figure 4.3). A visible reduction in average passing can be seen as the number of vehicles within the effective 90m length (see section 3.4.3) increases to three, four and five. A linear regression revealed that ATD is able to predict $6 \%$ of the variability in $\mathrm{PD}$, with $p<0.0001$. A similar observation exist for the bicyclist position from the adjacent curb edge line, but just not as significant. 


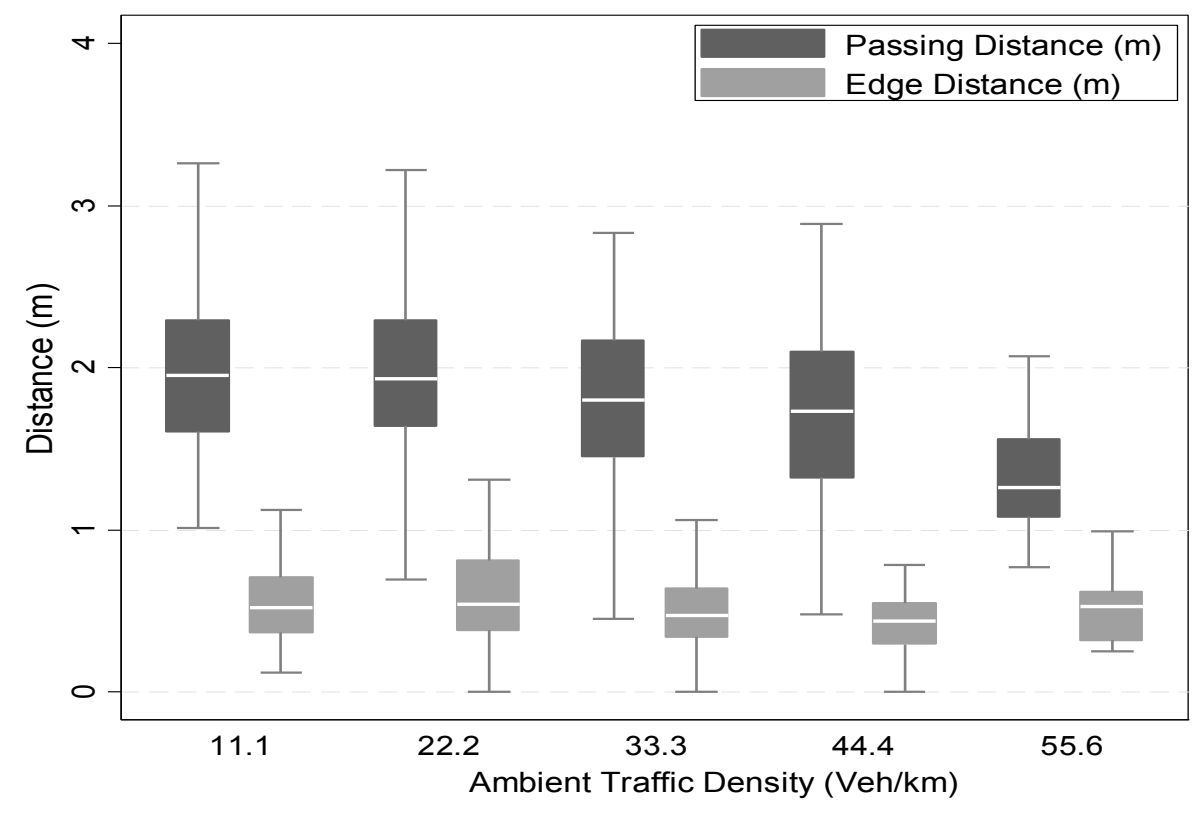

Figure 4-3: Comparing Distances by ATD

\subsubsection{Effect of Bicyclist position, Vehicle and Bicycle Speeds on Road Sharing}

With reference to Figure 4-4, the relationship between bicycle speed and passing distance is an inverse one. This could be due to less wavering in bicycle movement at higher speeds making motorists more comfortable to pass closer. It could also be that, motorists build the perception that a bicyclist is less vulnerable or more experienced when riding faster. The concept of motorist action based on perception of bicyclist vulnerability is supported by Walker (2007). The average vehicle speed on the $5.1 \mathrm{~m}$ lane is $45 \mathrm{Km} / \mathrm{h}$, whiles that of all the other lanes are between 25 to $38 \mathrm{Km} / \mathrm{h}$. Hence wider lanes are associated with higher speeds. The vehicle speed and passing distance are positively correlated. This is reasonable as both bicyclist and vehicles will try as much as possible to avoid close passing when traffic speed is high. Upon regressing each of the three variables with passing distance to determine their individual effects, the relationship between 
passing distance and bicyclist position from the adjacent curb is the least in strength among the three. The motor speed explained $10 \%$ of the variability in PD, $p<0.0001$ ); bicycle speed explained $2 \%$ of the variability in PD, $p<0.001$; and the bicycle position from adjacent curb edge line explained $1 \%$ of the variability in PD, $p<0.011$. The positive correlation between passing distance and bicycle distance from the curb buttresses the belief of many experienced bicyclists who are of the view that vehicles give them more space when they are further from the curb and more visible to motorists. This view is also supported and encourage by some state departments of transportation and literature like Franklin (2014), and Parkin and Meyers (2010). That notwithstanding, the relationship is not strong and should not be the focus when evaluating or analyzing passing distance. That view is however contradicted by the findings of (Walker 2007). 
Passing Distance vs. Bicycle Speed

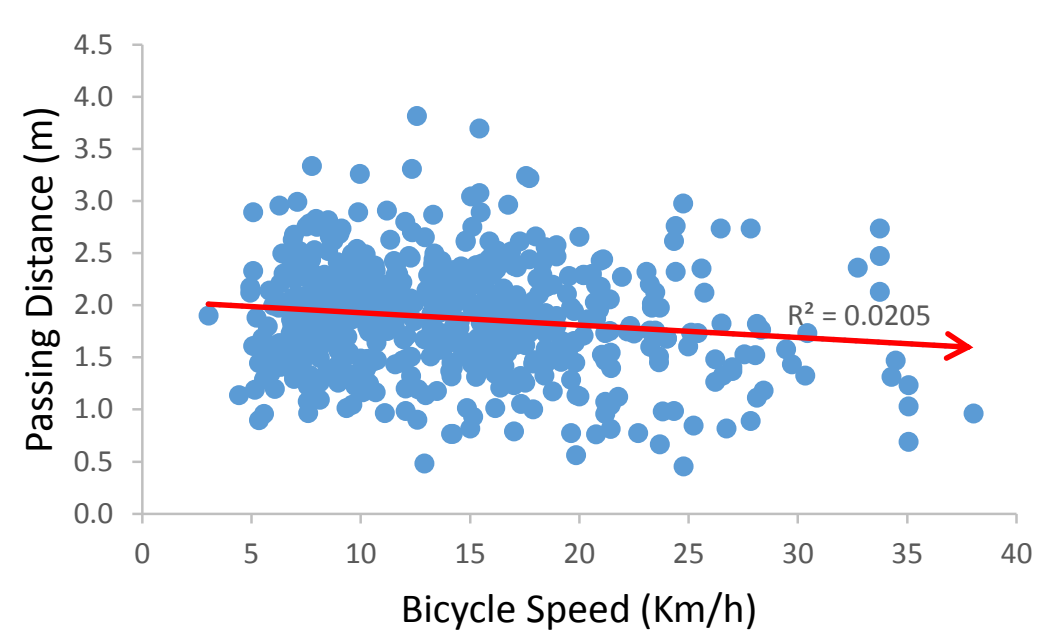

Passing Distance vs. Vehicle Speed

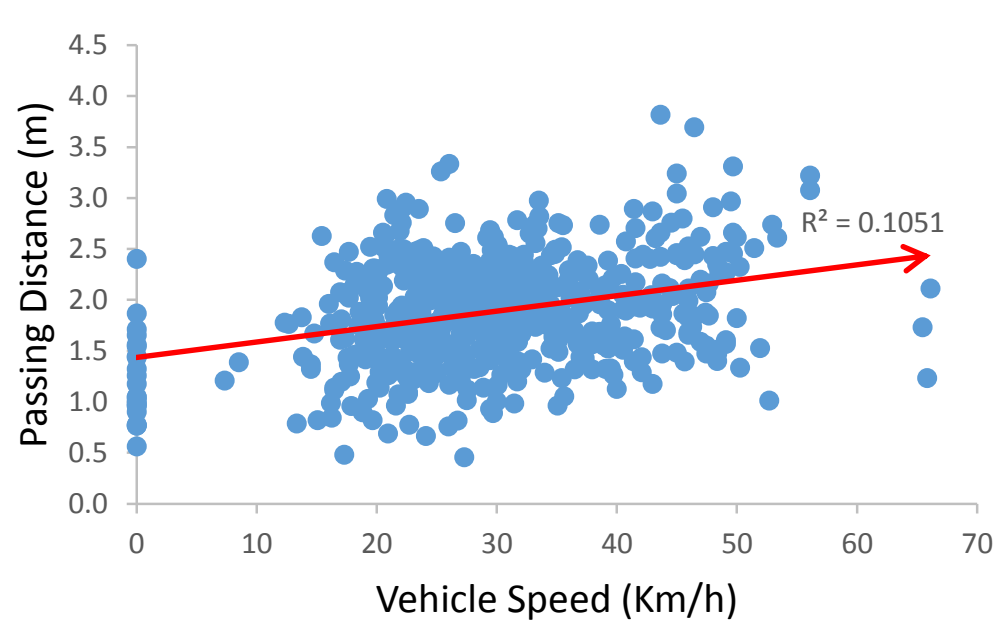

Passing Distance vs. Bicyclist to Edge-line

Distance

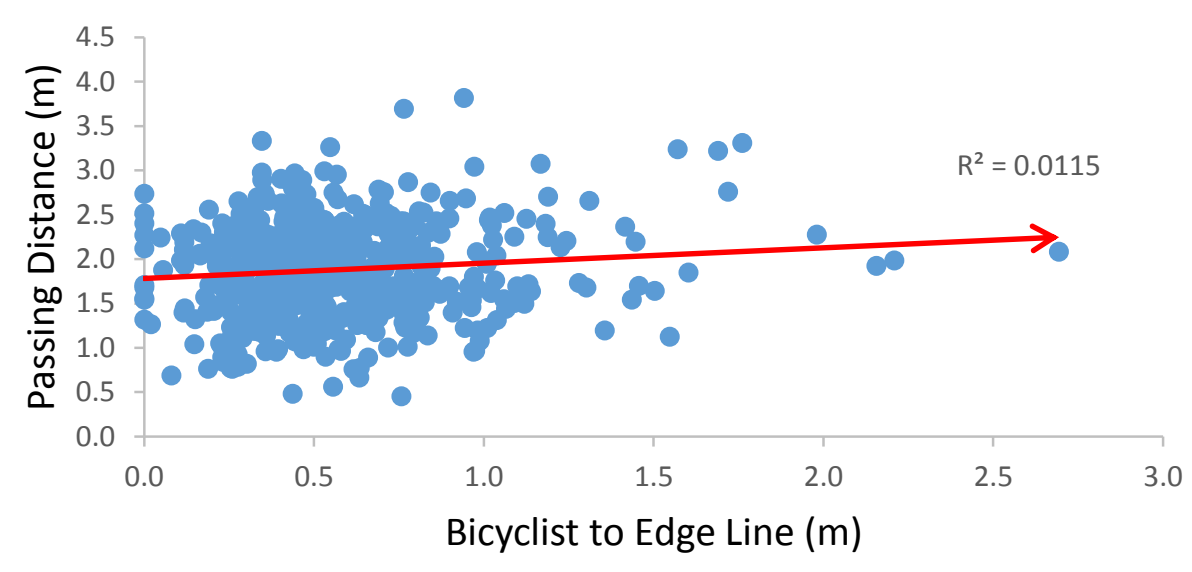

Figure 4-4: Scatter Plots of Passing Distance with Speeds and Bicycle Position 


\subsubsection{Effect of variables on Comfort Perception of Road Sharing}

A positive correlation with $\mathrm{BCP}$ exist for $\mathrm{PD}$, bicycle distance from curb edge line, lane width, motor vehicle speed, bicycle speed, and grade. All other variables are inversely correlated to BCP. PD, ATD, lane width, parking and motor vehicle speed have the highest predictions of BCP variability, i.e. $16.6 \%, 13 \%, 9.6 \%, 8 \%$ and $4 \%$ respectively, all with $p<0.0001$ and at $95 \%$ confidence level. The remaining variables all exhibit low correlations to $\mathrm{BCP}$, i.e. $<2 \%$ prediction of its variability.

\subsubsection{Summary and Other investigation}

All the variables considered herein have some effect on the variability of PD which is the primary variable in vehicle-bicycle interactions. The same can be said for their effect on BCP. The observation is that vehicles generally give appreciable PD to bicycles in Ottawa, with over $90 \%$ of the passes providing up to $1.23 \mathrm{~m}$ gaps (see Figure $4-5$ ). This is an overwhelming compliance of drivers in Ottawa to the $1 \mathrm{~m}$ spacing requirement made effective on September 1st, 2015 (City of Ottawa, Road Safety 2015).

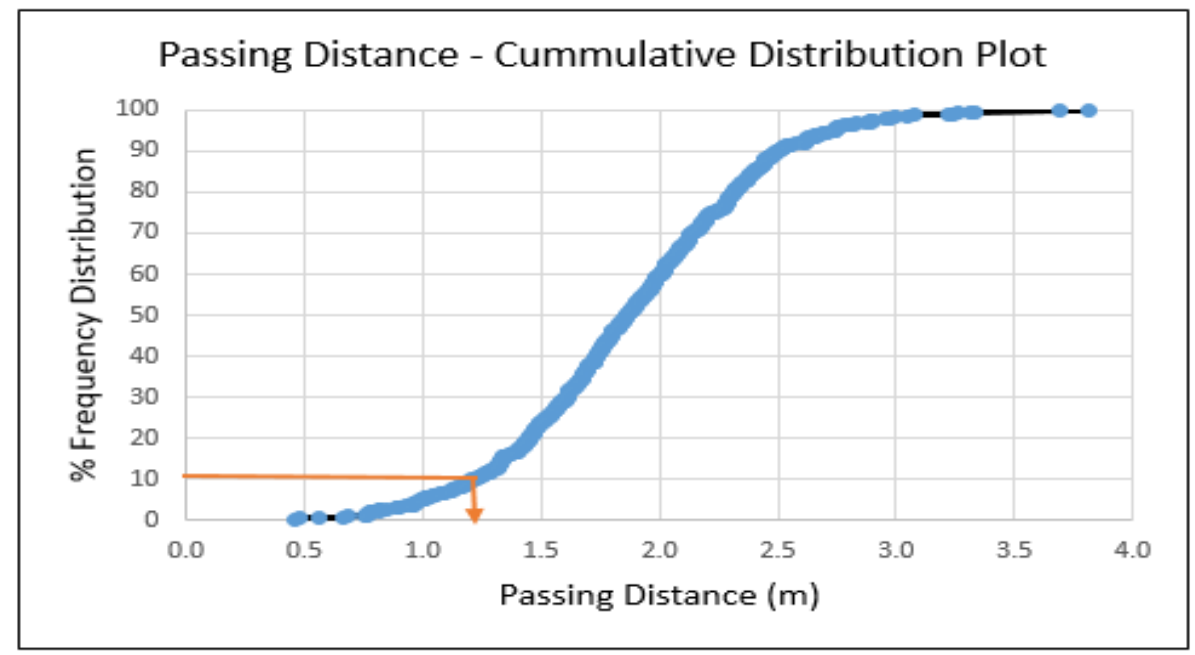

Figure 4-5: Cumulative distribution plot for Passing distance 


\subsection{Model Development}

In a mixed traffic setting outside of intersections, the point of interaction between the bicycle and motor vehicle is during the passing event. Hence a model that predicts the lateral passing distance provided by the vehicle in a passing event is absolutely relevant. Close passing to bicycles especially involving heavy vehicles can destabilize the bicyclist and is a disincentive to cycling. Moreover, collisions resulting from close passing are likely to be severer due to higher vehicle speeds at road mid-sections compared to the more frequent and mostly researched intersection collisions.

The initial hypothesis is that, both the passing distance and comfort models will take linear forms represented as Passing distance $=f\left(\operatorname{var}_{1}, \operatorname{var}_{2}, v a_{3} \ldots v a r_{n} ; a_{1}, a_{2}, a_{3} \ldots a_{m}\right)$ and Comfort $=f\left(\operatorname{var}_{1}, \operatorname{var}_{2}, \operatorname{var}_{3} \ldots v a r_{n} ; a_{1}, a_{2}, a_{3} \ldots a_{m}\right)$.

Where: $v a r_{1}$ through to $v a r_{n}$ are the $n$ independent variables, and $a_{1}$ through to $a_{m}$, are the $m$ model parameters to be estimated.

An OLS linear prediction was assumed for the models. The procedure for the model development involve: [i] checking the initial hypothesis of variable selection to establish variable significance in predicting the dependent variable, [ii] carrying out transformations on predictor variables to create the best predictive form, [iii] testing combinations of variable interactions and forms in trial regression models to obtain the best possible model. Several Pearson Correlation analyses were run using the Stata program to test the co-linearity relationships existing between the predictor variables and each dependent variable (i.e. passing distance and comfort) for the two models 
respectively. In addition a co-linearity test between predictor variables was done by the variance inflation factor (VIF) (Table 4-2). None of the VIF's exceeds 5, hence no strong co-linearity exist between any two predictor variables.

Table 4-2: Co-linearity test by variance inflation factor (VIF)

\begin{tabular}{|c|c|c|c|c|c|c|c|c|}
\hline & PD & $\mathrm{BD}$ & ATD & $\# N L$ & BS & MS & Grade & Parking \\
\hline Passing distance (PD) & 0 & & & & & & & \\
\hline Bicycle distance (CD) & 1 & 0 & & & & & & \\
\hline Ambient Traffic Density (ATD) & 1 & 1 & 0 & & & & & \\
\hline \#No. of Lanes (\#NL) & 1 & 1 & 1 & 0 & & & & \\
\hline Bicycle speed (BS) & 1 & 1 & 1 & 3 & 0 & & & \\
\hline Motor speed (MS) & 1 & 1 & 1 & 1 & 1 & 0 & & \\
\hline Grade & 1 & 1 & 1 & 2 & 2 & 1 & 0 & \\
\hline Parking & 1 & 1 & 1 & 2 & 2 & 1 & 2 & 0 \\
\hline
\end{tabular}

\subsubsection{Passing Distance Model}

For the passing distance model, all variables totaling eight (excluding comfort score) were used at the beginning as none was removed on the basis of high correlation to other predictors. A total of 563 real time events were employed in a stepwise regression analysis to establish the passing distance model. Upon numerous transformation and combinations of predictor variables, the best regression model fit and its relevant terms for passing distance are shown in Table 4-3. The correlation coefficient $\left(R^{2}\right)$ is 0.28 , at $95 \%$ significance level. The base model for passing distance prediction without variable transformations nor combinations is shown in appendix $\mathrm{C}$. 
Table 4-3: Summary Statistics of the Linear Regression Model for Passing Distance

\begin{tabular}{|c|c|c|c|c|c|c|}
\hline Variable & Coefficient & SE & t - stat. & $P>|t|$ & \multicolumn{2}{|c|}{ 95\% Conf. Interval } \\
\hline $\mathrm{K} 1$ & -0.00149 & 0.00039 & -3.81 & $<0.0001$ & -0.00226 & -0.00072 \\
\hline $\mathrm{K} 2$ & -0.00269 & 0.00072 & -3.75 & $<0.0001$ & -0.0041 & -0.00128 \\
\hline $\mathrm{K} 3$ & 0.03530 & 0.00560 & 6.31 & $<0.0001$ & 0.024308 & 0.046299 \\
\hline No. of Lanes & 0.29616 & 0.07551 & 3.92 & $<0.0001$ & 0.147835 & 0.444484 \\
\hline Bicycle Speed & -0.01834 & 0.00463 & -3.96 & $<0.0001$ & -0.02743 & -0.00925 \\
\hline Motor Speed & 0.01444 & 0.00194 & 7.46 & $<0.0001$ & 0.010638 & 0.018245 \\
\hline Grade & 0.20456 & 0.06739 & 3.04 & 0.003 & 0.072187 & 0.336929 \\
\hline Parking & 0.33456 & 0.08817 & 3.79 & $<0.0001$ & 0.161374 & 0.507737 \\
\hline Intercept & 0.58827 & 0.28192 & 2.09 & 0.037 & 0.034504 & 1.142039 \\
\hline \multicolumn{2}{|c|}{ R-squared: 0.2817} & \multicolumn{2}{|c|}{ RMSE: 0.4435} & & & \\
\hline \multicolumn{2}{|c|}{ Adjusted R-squared: 0.2713} & \multicolumn{2}{|c|}{$p$-value: $<2.2 e-16$} & & & \\
\hline
\end{tabular}

$$
\text { Where: } \begin{aligned}
K 1 & =\frac{A T D^{2}}{2^{\text {lanewidth }}} \\
K 2 & =\sqrt{20^{\text {biketoedge } \times \text { No. of lanes }}} \\
K 3 & =2^{\text {lanewidth }}
\end{aligned}
$$

The three variable transformation and interactions are all significant and so are all the included variables. Also the coefficients of all variables are reasonable except for grade and parking which may be partly due to combined effect of the other variables and the stochastic nature of events. This gives the indication that most of the significant variables have been captured in the model. Furthermore, plots of the residuals as shown in Figures 4-6 to 4-8 exhibit random scatter. The inference is that, the residuals do not contradict the linear assumption and hence the OLS linear regression model is appropriate. 


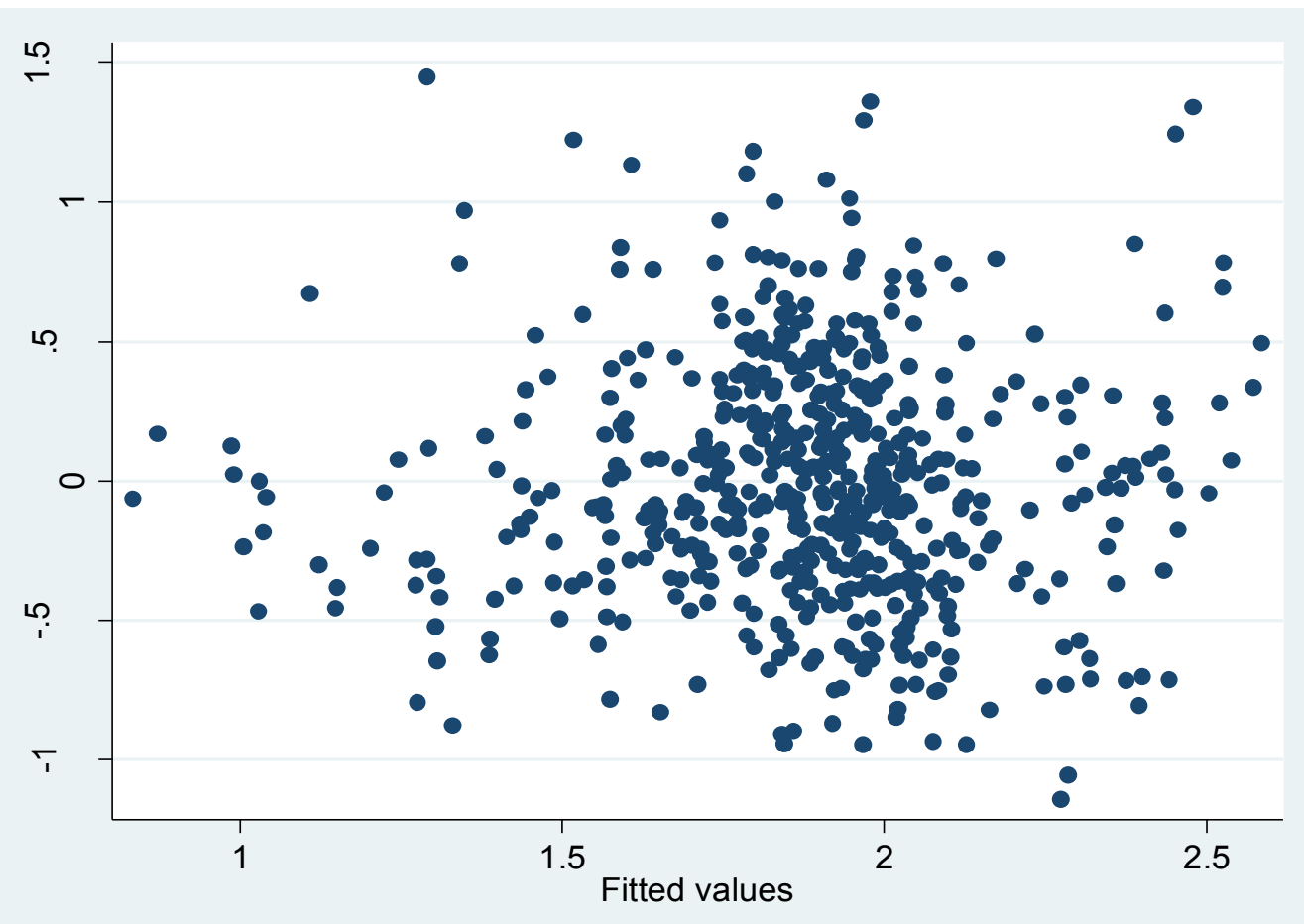

Figure 4-6: Residual Plot of Fitted values vs. Predicted

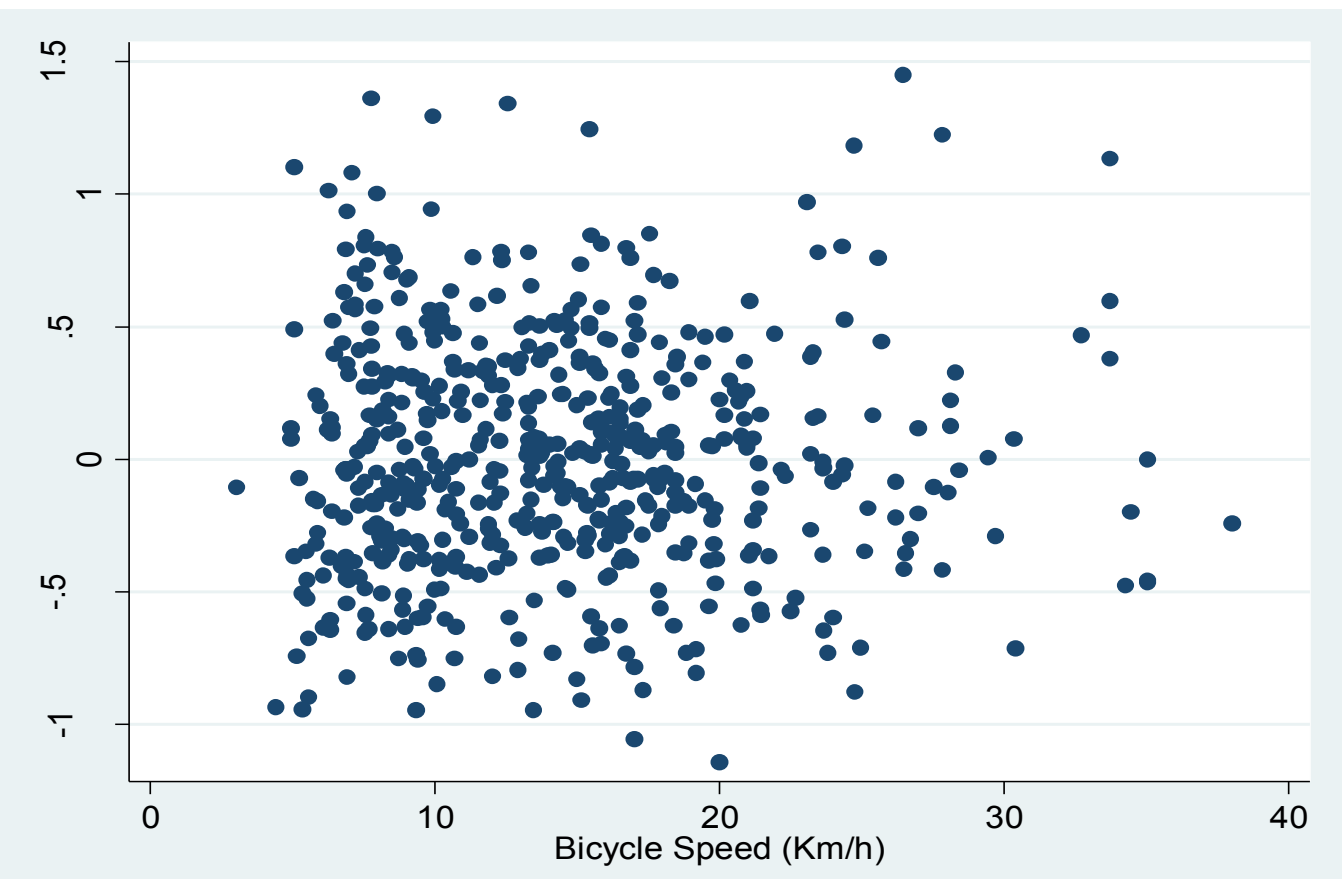

Figure 4-7: Plot of Predicted values vs. Bicycle Speed 


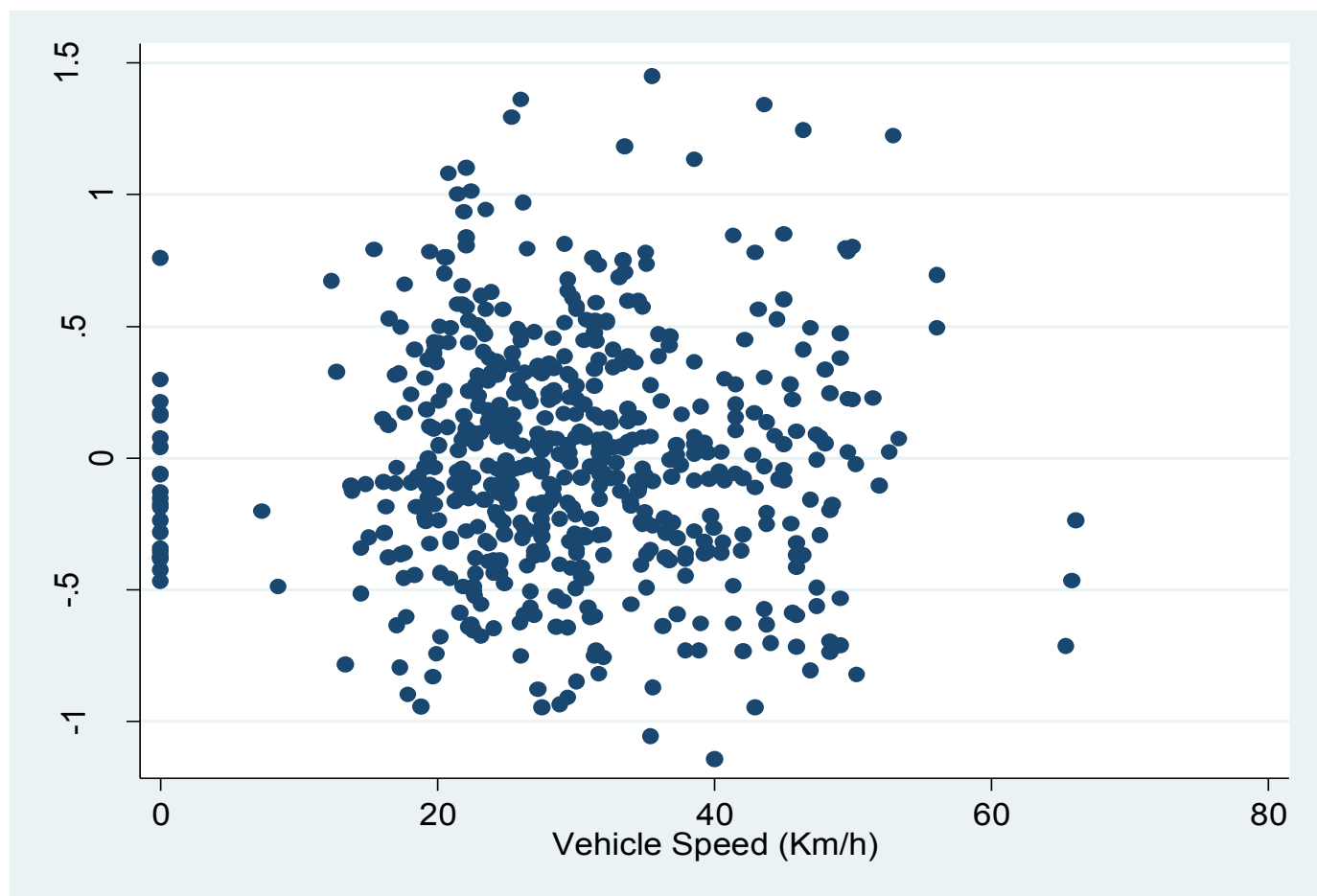

Figure 4-8: Plot of Predicted values vs. Vehicle Speed

NB: stationary motor vehicles passed by bicycles in jam situations were considered events.

Notwithstanding the limited correlation of the overall model (i.e. at $28 \%$ ), this is a big step towards creating a model that will serve as the basis for simulating the interactions between bicycles and vehicles. The low fit may be attributed to the absence of one or more variables and the sample size. Aside the visible and measureable variables considered herein for the model, it is worth noting the effect of the fairly unpredictable nature of drivers and bicyclists. The individual driver traits like driving experience, pragmatism, mood, perception of bicyclist vulnerability and familiarity with a road all affects the passing distance a driver provides an adjacent bicycle. 


\subsubsection{Comfort Perception Model}

The Pearson tests of correlations showed high and low correlations between the nine predictor variables and comfort scores. There was no high co-linearity between any of the predictors and therefore all the variables were used for the model. A total of 483 passing events, each with an average comfort score from at least three respondents was used to create the comfort perception model. The nine variables were each put through several transformations and subsequent individual regression with the comfort scores to determine the best transformation. Also several variable combinations were executed in other to generate the best possible model fit. Table 4-4 shows a summary of the bicycle comfort perception model. Four variables are not significant, however their presence in the model improves its prediction. Moreover, variables such as the lane width and the bicyclist position are reasonably important to a bicyclist's comfort on a mixed street, notwithstanding lane width's high individual prediction of BCP at $9.6 \%$. The effect of all the coefficients are logical except for the number of lanes and lane width which are both negative, implying narrower shared lane widths are better for bicyclists. This may however be due to an induced effect of motor vehicle speed, since there is a potential for higher vehicle speeds when lanes are wider. The fit of the model is limited to $34 \%$. The low fit obtained may be attributed to factors such as sample size limitation, and absence of some variables. The base model for bicycle comfort perception without variable transformation nor combinations is shown in appendix C. 
Table 4-4: Summary Statistics of the Linear Regression Model for Comfort Perception

\begin{tabular}{|c|c|c|c|c|c|c|}
\hline Variable & Coefficient & SE & t - stat. & $P>|t|$ & \multicolumn{2}{|c|}{ 95\% Conf. Interval } \\
\hline $\mathrm{C} 1$ & 0.05649 & 0.06113 & 0.92 & 0.356 & -0.063631 & 0.176609 \\
\hline $\mathrm{C} 2$ & -0.64324 & 0.21498 & -2.99 & 0.003 & -1.065705 & -0.220772 \\
\hline $\mathrm{C} 3$ & -0.15950 & 0.11568 & -1.38 & 0.169 & -0.386834 & 0.067826 \\
\hline ATD & -0.01925 & 0.00304 & -6.34 & 0 & -0.025220 & -0.013283 \\
\hline Passing Distance & 0.50933 & 0.06650 & 7.66 & 0 & 0.378641 & 0.640016 \\
\hline Lane Width & -0.14239 & 0.11916 & -1.19 & 0.233 & -0.376547 & 0.091771 \\
\hline No. of Lanes & -0.60521 & 0.14843 & -4.08 & 0 & -0.896894 & -0.313528 \\
\hline Grade & -0.16160 & 0.13371 & -1.21 & 0.227 & -0.424353 & 0.101148 \\
\hline Parking & -0.78313 & 0.15865 & -4.94 & 0 & -1.094888 & -0.471371 \\
\hline Intercept & 5.72691 & 0.86215 & 6.64 & 0 & 4.032690 & 7.421130 \\
\hline \multicolumn{2}{|c|}{ R-squared: 0.3434} & \multicolumn{3}{|c|}{ RMSE: 0.67237} & & \\
\hline \multicolumn{2}{|c|}{ Adjusted R-squared: 0.3307} & \multicolumn{3}{|c|}{ p-value: $<0.00001$} & & \\
\hline
\end{tabular}

Where: $\quad C 1=\log ($ bike_to_edgeline $)$

$$
\begin{aligned}
& C 2=\text { motor_speed }{ }^{0.2} \\
& C 3=\log (\text { bike_speed })
\end{aligned}
$$

The number of lanes, passing distance, motor vehicle speed, parking and ATD are all significant to the comfort perception model at $95 \%$ confidence level. The significance of the aforementioned variables to comfort reinforces the comfort survey findings of Winters et al. (2011), and Kirner and Penha (2011). The grade slope's insignificance to comfort perception herein contradicts Li et al. (2012), but this may be due to significant differences in level of slope steepness. Moreover, respondents were required to score passing events based on the safety of the interactions and not necessarily to consider road grade in their evaluation. The residuals plots for the fitted comfort scores as well as the predictor variables all appear randomly scattered and hence the OLS linear assumption may be maintained for the model (see Figure 4-9). 

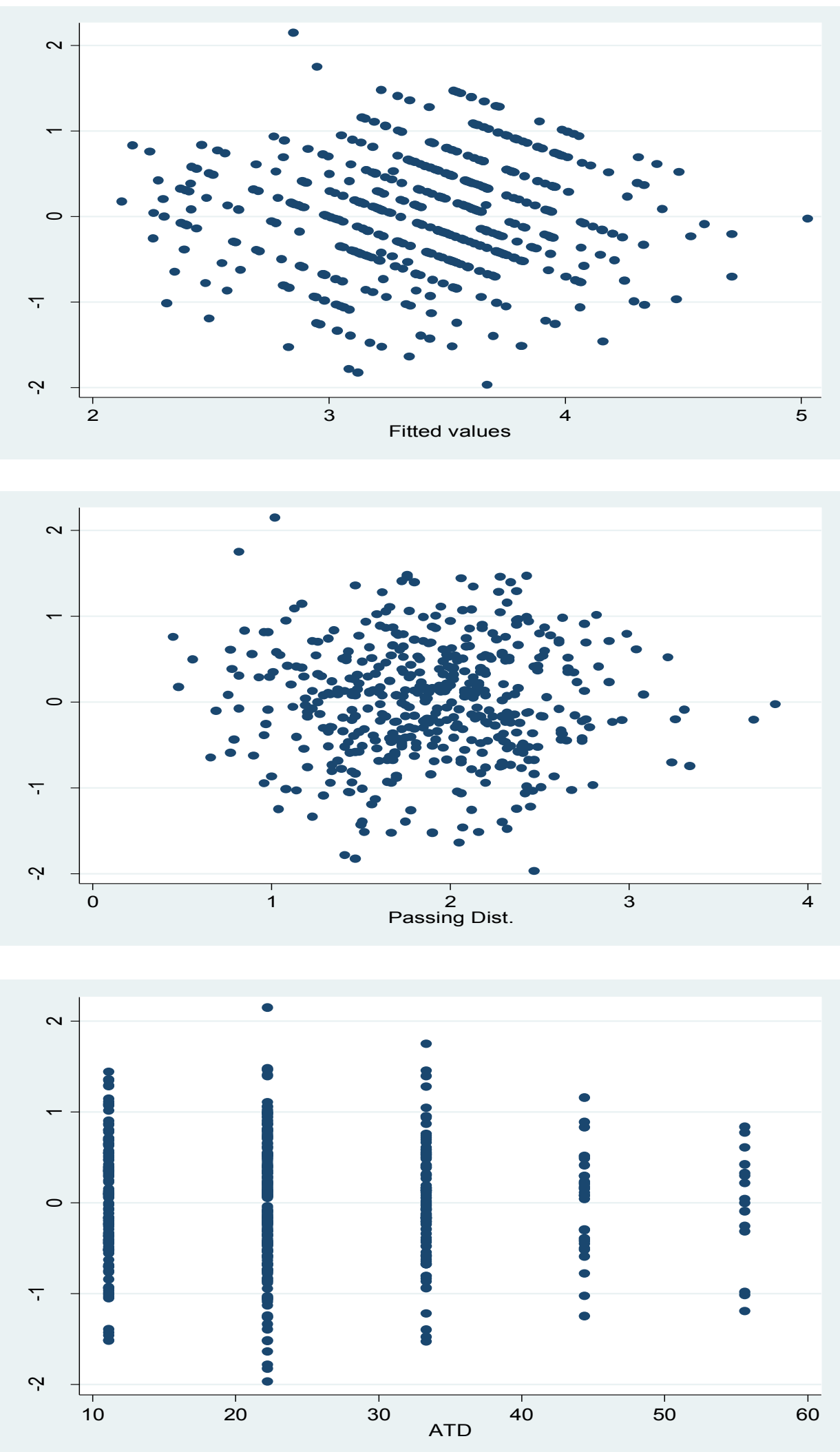

Figure 4-9: Plots of Residuals for the comfort Perception Model 


\section{CHAPTER 5: CONCLUSION AND FUTURE WORK}

\subsection{Research Summary and Recommendations}

This thesis has elaborated on the benefits of cycling in the modern day where transportation between even short destinations is so rife with motorized modes. The necessity of studying mixed traffic, particularly road sharing interactions between bicycles and vehicles has also been highlighted. The study has discussed bicycle-motor vehicle interactions, with the point of focus being the passing event which is the expected primary form of interaction at the mid-section of a road. A total of 563 passes were identified from video data obtained from six mixed traffic sites and ten unique edges. Nine variables comprising: Passing distance $(\mathrm{m})$, Bicycle Speed $(\mathrm{Km} / \mathrm{h})$, Motor Speed $(\mathrm{Km} / \mathrm{h})$, Bicycle-to-edge distance / bicycle position (m), Ambient Traffic Density (Veh/km), Lane width (m), No. of Lanes, adjacent curb Parking status and Grade status were measured from the passing events. Comfort scores were obtained through selfadministered evaluation of passing events.

It is observed that bicyclists ride slightly further away from the curb on two lane roads compared to single lanes in the direction of travel. The average bicycle position from the adjacent curb edge line in the presence of parked vehicles is $0.35 \mathrm{~m}$, which is smaller compared to passes without parked vehicles. The latter result may be attributed to the fact that the events with parking are not many and most of them occurred on a road with high traffic volumes, and a narrow lane width of $3.3 \mathrm{~m}$. Regardless of the lane width, bicyclists generally ride at distances below $1 \mathrm{~m}$ from the adjacent curb or hazard, 
an attempt to increase the passing distance between them and vehicles. Passing distance in all cases irrespective of the variable in question is greater than $1 \mathrm{~m}$ on the average. In fact, over $90 \%$ of the passes give up to $1.23 \mathrm{~m}$ passing distance gaps, indicating an excellent compliance of drivers in Ottawa to the $1 \mathrm{~m}$ gap requirement. Each variable was regressed individually with PD to determine their individual effects. The most significant variables are: motor speed (explaining $10 \%$ of the variability in $P D, p<0.0001$ ), lane width (explaining $7 \%$ of the variability in PD, $p<0.0001$ ), ATD (explaining $6 \%$ of the variability in $\mathrm{PD}, p<0.0001$ ), parking (explaining $3 \%$ of the variability in PD, $p<0.0001$ ), bicycle speed (explaining $2 \%$ of the variability in PD, $p<0.001$ ), and the bicyclist position from adjacent curb edge line (explaining $1 \%$ of the variability in PD, $p<0.011$ ). The remaining variables were insignificant and had predictions of PD variability less than $1 \%$.

$\mathrm{BCP}$ is positively correlated to PD, bicycle distance from curb edge line, lane width, motor vehicle speed, bicycle speed, and grade, while inversely correlated to ATD, bicycle speed, number of lanes, grade and parking. The most significant variables to BCP's variability are PD, ATD, lane width, parking and motor vehicle speed.

For wider lanes greater than $4.5 \mathrm{~m}$, the motor vehicle speeds begin to increase and therefore, speed calming treatments and lane width limitations may be helpful to reduce the hazard posed by vehicle speeding to bicyclists. Many bicyclists ride within the "dooring" zone regardless of the road width and it is worse on the $3.3 \mathrm{~m}$ lane. Hence, for roads with lanes narrower than $3.6 \mathrm{~m}$, transportation departments may consider treatments like sharrows, road signs instructing road sharing, and educating road users against dooring crashes. In addition it is important to avoid installing parking on narrow 
shared roads, as bicyclists tend to find themselves in a dangerous situation of being very close to parked and moving vehicles simultaneously. All these treatments will help to reduce the hazard faced by bicyclists and improve their safety.

The two models developed in this thesis are both limited in fit. The Passing distance model has a fit of $28 \%$ while the bicycle comfort perception is $34 \%$ similar to the correlations achieved by Love et al. (2012) and Stewart and McHale (2014). The plots of residuals and significance of included variables are nevertheless indicative of correct assumptions for the models. The low fit may be attributed to the absence of one or more variables and a small sample size. Moreover, the unpredictable nature of the traits and behaviors of drivers and bicyclists is bound to impact the models.

\subsection{Future work}

Due to time and resource constraints, this study is limited to only six mixed traffic sites and ten unique edges in Ottawa, Canada. It is known that driver and bicyclist behavior varies from place to place, hence an expanded study based on this methodology and capturing more sites, more respondents, and with a resulting larger sample size will definitely improve the proposed models. In such a study, additional variables like the type of vehicle, the use of safety gear, and the gender of bicyclist may be investigated.

It would also be useful to consider the opposing ambient traffic density, and the position of adjacent lane traffic that is moving either in the same or opposite direction of travel. It is expected that, the vehicle traffic density and the position of traffic in the 
adjacent lane during a passing event will affect the amount passing distance afforded to the bicyclist. It will be plausible to carry out the comfort evaluation in another way either than self-administered, as the latter provides no guarantee as to how much attention is given to the evaluation process. All roads in this study had speed limits of $40 \mathrm{Km} / \mathrm{h}$ for which only the $5.1 \mathrm{~m}$ lane had an average speed exceeding the $40 \mathrm{Km} / \mathrm{h}$ limit. Further investigation with shared roads of different speed limits will be valuable.

In the long term, once statistical models with acceptable level of prediction are developed, they may be incorporated into microsimulation models to enhance a good representation of the bicyclists' features and promote further studies on how the two road users interact. Similar to existing microsimulations for vehicles, designers will be able to model, and compare several alternatives of new shared roads resulting in better decisions that will ensure safety for the bicyclist and hopefully improve bicycling. 


\section{REFERENCES}

Abdul Rahimi, Abdul Rahman, Aya Kojima, and Hisashi Kubota. 2013. "Experimental Research on Bicycle Safety Measures at Signalized Intersections."

Barnecutt, Peter, and Karen Pfeffer. 1998. “Auditory Perception of Relative Distance of Traffic Sounds." Current Psychology 17 (1): 93-101. doi:10.1007/s12144-998$1023-6$

Calvey, J. C., J. P. Shackleton, M. D. Taylor, and R. Llewellyn. 2015. “Engineering Condition Assessment of Cycling Infrastructure: Bicyclists' Perceptions of Satisfaction and Comfort." Transportation Research Part A: Policy and Practice 78 (August): 134-43. doi:10.1016/j.tra.2015.04.031.

Chataway, Elijah Steven, Sigal Kaplan, Thomas Alexander Sick Nielsen, and Carlo Giacomo Prato. 2014. "Safety Perceptions and Reported Behavior Related to Cycling in Mixed Traffic: A Comparison between Brisbane and Copenhagen." Transportation Research Part F: Traffic Psychology and Behaviour 23 (March): 32-43. doi:10.1016/j.trf.2013.12.021.

City of Ottawa, Road Safety. 2015. "Bill 31 - Changes to the Highway Traffic Act."

December 22. [Online] Available at: http://ottawa.ca/en/residents/transportation-and-parking/road-safety/bill-31changes-highway-traffic-act. [Accessed 3 July, 2016]

Dill, Jennifer, and John Gliebe. 2008. “Understanding and Measuring Bicycling Behavior: A Focus on Travel Time and Route Choice." Urban Studies and Planning Faculty Publications and Presentations, December. [Online] Available at: http://pdxscholar.library.pdx.edu/usp_fac/28.

Epperson, Bruce. 1994. “Evaluating Suitability of Roadways for Bicycle Use: Toward a Cycling Level-Of-Service Standard." Transportation Research Record, no. 1438. [Online] Available at: http://trid.trb.org/view.aspx?id=413762.

Franklin, John. 2014. Cyclecraft: The Complete Guide to Safe and Enjoyable Cycling for Adults and Children. Stationery Office. 
Handy, Susan, Yan Xing, and Theodore J. Buehler. 2010. “Factors Associated with Bicycle Ownership and Use: A Study of Six Small U.S. Cities." Transportation 37 (6): 96785.

Harkey, David, Richard Stewart, and Eric Rodgman. 1997. "Evaluation of Shared-Use Facility for Bicycles and Motor Vehicles," March.

Heinen, Eva, Bert Van Wee, and Kees Maat. 2010. “Commuting by Bicycle: An Overview of the Literature" 30 (1): 59-96. [Online] Available at: http://resolver.scholarsportal.info/resolve/01441647/v30i0001/59_cbbaootl.xml Hull, Angela, and Craig O’Holleran. 2014. “Bicycle Infrastructure: Can Good Design Encourage Cycling?" Vol. 2, No. 1 (Urban, Planning and Transport Research): 369-406.

Hunter, William W., Raghavan Srinivasan, and Carol A. Martell. 2009. “An Examination of Bicycle Counts and Speeds Associated with the Installation of Bicycle Lanes in St. Petersburg, Florida," September. [Online] Available at: https://trid.trb.org/view.aspx?id=907624.

Kirner, Janice Providelo, and Suely Sanches Penha. 2011. "Roadway and Traffic Characteristics for Bicycling." Transportation 38 (5): 765-77. [Online] Available, http://resolver.scholarsportal.info/resolve/00494488/v38i0005/765_ratcfb.xml

Landis, Bruce W. 1994. "Bicycle Interaction Hazard Score: A Theoretical Model." Transportation Research Record, no. 1438. [Online] Available at: http://trid.trb.org/view.aspx?id=413761.

Li, Mingxin, and Ardeshir Faghri. 2014. "Cost-Benefit Analysis of Added Cycling Facilities." Transportation Research Record: Journal of the Transportation Research Board 2468 (December): 55-63. doi:10.3141/2468-07.

Li, Zhibin, Wei Wang, Pan Liu, and David Ragland. 2012. "Physical Environments Influencing Bicyclists' Perception of Comfort on Separated and on-Street Bicycle Facilities." Transportation Research Part D 17 (3): 256-61.

Love, David C., Autumn Breaud, Sean Burns, Jared Margulies, Max Romano, and Robert Lawrence. 2012. "Is the Three-Foot Bicycle Passing Law Working in Baltimore, 
Maryland?" Accident Analysis and Prevention 48: 451-56.

doi:10.1016/j.aap.2012.03.002.

McKibbin, Des. 2011. "The Wider Contribution of Cycling and Its Potential to Replace Car Journeys." Research and Information Service Research Paper, October.

Mekuria, Maaza C., Peter G. Furth, and Hilary Nixon. 2012. “Low-Stress Bicycling and Network Connectivity | Mineta Transportation Institute Research Report." Mineta Transportation Institute. May. [Online] Available at: http://transweb.sjsu.edu/project/1005.html.

“Ottawa Cycling Master Plan.” 2013. November. [Online] Available at: http://documents.ottawa.ca/en/node/5842. [Accessed on 26 April, 2016]

Parkin, J., Mark Wardman, and Matthew Page. 2007. “Models of Perceived Cycling Risk and Route Acceptability." Accident Analysis and Prevention 39 (2): 364-71.

Parkin, John, and Ciaran Meyers. 2010. "The Effect of Cycle Lanes on the Proximity between Motor Traffic and Cycle Traffic." Accident Analysis and Prevention 42 (1): 159-65.

Pucher, John, and Ralph Buehler. 2008. “Making Cycling Irresistible: Lessons from The Netherlands, Denmark and Germany" 28 (4): 495-528.

Pucher, John, and Lewis Dijkstra. 2003. “Promoting Safe Walking and Cycling to Improve Public Health: Lessons From The Netherlands and Germany." American Journal of Public Health 93 (9): 1509-16.

Pucher, John, Jennifer Dill, and Susan Handy. 2010. “Infrastructure, Programs, and Policies to Increase Bicycling: An International Review." Preventive Medicine 50, Supplement (January): S106-25. doi:10.1016/j.ypmed.2009.07.028.

Pucher, John, Charles Komanoff, and Paul Schimek. 1999. "Bicycling Renaissance in North America?" Transportation Research Part A: Policy and Practice 33 (7-8): $625-54$

Shackel, Stella C., and John Parkin. 2014. "Influence of Road Markings, Lane Widths and Driver Behaviour on Proximity and Speed of Vehicles Overtaking Bicyclists." 
Accident Analysis \& Prevention 73 (December): 100-108.

doi:10.1016/j.aap.2014.08.015.

Shi, Jianbo, and C. Tomasi. 1994. "Good Features to Track." In, 1994 IEEE Computer Society Conference on Computer Vision and Pattern Recognition, 1994. Proceedings CVPR '94, 593-600. doi:10.1109/CVPR.1994.323794. [Online] Available at: http://documents.ottawa.ca/en/node/5842

Sorton, Alex, and Thomas Walsh. 1994. "Bicycle Stress Level as a Tool to Evaluate Urban and Suburban Bicycle Compatibility." Transportation Research Record, no. 1438. [Online] Available at: http://trid.trb.org/view.aspx?id=413763.

Stewart, Kathryn, and Adrian McHale. 2014. "Cycle Lanes: Their Effect on Driver Passing Distances in Urban Areas" 29 (3): 307-16. [Online] Available at: http://resolver.scholarsportal.info/resolve/16484142/v29i0003/307_clteodpdiu a.xml

“Strava Global Heatmap." 2016. Strava Labs. [Online] Available at: http://labs.strava.com/heatmap/. [Accessed on 11th July, 2015]

Thompson, D. C., V. Rebolledo, R. S. Thompson, A. Kaufman, and F. P. Rivara. 1997. "Bicycle Speed Measurements in a Recreational Population: Validity of SelfReported Speed." Injury Prevention 3 (1): 43-45.

Walker, Ian. 2007. "Drivers Overtaking Bicyclists: Objective Data on the Effects of Riding Position, Helmet Use, Vehicle Type and Apparent Gender." Accident Analysis \& Prevention 39 (2): 417-25. doi:10.1016/j.aap.2006.08.010.

Winters, Meghan, Gavin Davidson, Diana Kao, and Kay Teschke. 2011. "Motivators and Deterrents of Bicycling: Comparing Influences on Decisions to Ride." Transportation 38 (1): 153-68.

Winters, Meghan, Kay Teschke, Michael Grant, Eleanor Setton, and Michael Brauer. 2010. “How Far Out of the Way Will We Travel?" Transportation Research Record: Journal of the Transportation Research Board 2190 (December): 1-10. doi:10.3141/2190-01. 
Zaki, Mohamed, Tarek Sayed, and Andrew Cheung. 2013. “Computer Vision Techniques for the Automated Collection of Bicyclist Data." Transportation Research Record: Journal of the Transportation Research Board 2387 (December): 10-19. doi:10.3141/2387-02.

Zhiwei, H., L. Yuanyuan, and Y. Xueyi. 2007. “Models of Vehicle Speeds Measurement with a Single Camera." In International Conference on Computational Intelligence and Security Workshops, 2007. CISW 2007, 283-86.

doi:10.1109/CISW.2007.4425492. 


\section{APPENDICES}

Appendix A: Summary of Comfort Evaluation Responses

\begin{tabular}{|c|c|c|c|c|c|c|c|c|c|c|c|c|c|c|c|c|}
\hline \multirow{2}{*}{ \#No } & \multicolumn{4}{|c|}{ Set 01} & \multicolumn{4}{|c|}{ Set 02} & \multicolumn{4}{|c|}{ Set 03} & \multicolumn{4}{|c|}{ Set 04} \\
\hline & 1 & 2 & 3 & Average & 1 & 2 & 3 & Average & 1 & 2 & 3 & Average & 1 & 2 & 3 & Average \\
\hline 1 & 4 & 5 & 4 & 4.3 & 3 & 3 & 5 & 3.7 & 2 & 4 & 3 & 3.0 & 3 & 3 & 5 & 3.7 \\
\hline 2 & 5 & 5 & 4 & 4.7 & 3 & 3 & 5 & 3.7 & 2 & 4 & 2 & 2.7 & 2 & 3 & 3 & 2.7 \\
\hline 3 & 5 & 5 & 5 & 5.0 & 1 & 3 & 3 & 2.3 & 4 & 4 & 1 & 3.0 & 3 & 3 & 4 & 3.3 \\
\hline 4 & 4 & 5 & 4 & 4.3 & 3 & 4 & 5 & 4.0 & 4 & 4 & 1 & 3.0 & 3 & 5 & 2 & 3.3 \\
\hline 5 & 3 & 2 & 4 & 3.0 & 2 & 3 & 3 & 2.7 & 3 & 4 & 2 & 3.0 & 4 & 2 & 4 & 3.3 \\
\hline 6 & 4 & 1 & 5 & 3.3 & 2 & 4 & 5 & 3.7 & 5 & 4 & 4 & 4.3 & 2 & 2 & 5 & 3.0 \\
\hline 7 & 4 & 5 & 4 & 4.3 & 3 & 3 & 5 & 3.7 & 2 & 4 & 3 & 3.0 & 4 & 5 & 5 & 4.7 \\
\hline 8 & 5 & 3 & 4 & 4.0 & 2 & 2 & 5 & 3.0 & 2 & 4 & 1 & 2.3 & 1 & 3 & 2 & 2.0 \\
\hline 9 & 4 & 2 & 4 & 3.3 & 2 & 3 & 2 & 2.3 & 3 & 4 & 4 & 3.7 & 4 & 4 & 5 & 4.3 \\
\hline 10 & 4 & 5 & 4 & 4.3 & 2 & 3 & 5 & 3.3 & 3 & 4 & 4 & 3.7 & 3 & 4 & 5 & 4.0 \\
\hline 11 & 3 & 5 & 5 & 4.3 & - & - & - & - & 4 & 4 & 2 & 3.3 & 2 & 5 & 5 & 4.0 \\
\hline 12 & 4 & 5 & 5 & 4.7 & 3 & 4 & 5 & 4.0 & 5 & 4 & 4 & 4.3 & 3 & 3 & 5 & 3.7 \\
\hline 13 & 3 & 5 & 5 & 4.3 & 2 & 2 & 5 & 3.0 & 3 & 4 & 5 & 4.0 & 3 & 2 & 3 & 2.7 \\
\hline 14 & 4 & 5 & 3 & 4.0 & 3 & 4 & 5 & 4.0 & 3 & 4 & 5 & 4.0 & 4 & 2 & 3 & 3.0 \\
\hline 15 & 3 & 4 & 3 & 3.3 & 1 & 3 & 4 & 2.7 & 4 & 4 & 5 & 4.3 & 4 & 2 & 4 & 3.3 \\
\hline 16 & 4 & 4 & 4 & 4.0 & 2 & 3 & 4 & 3.0 & 2 & 4 & 4 & 3.3 & 4 & 2 & 5 & 3.7 \\
\hline 17 & 5 & 5 & 5 & 5.0 & 3 & 3 & 5 & 3.7 & 3 & 4 & 4 & 3.7 & 4 & 4 & 5 & 4.3 \\
\hline 18 & 4 & 5 & 5 & 4.7 & 3 & 2 & 5 & 3.3 & 2 & 3 & 4 & 3.0 & 3 & 4 & 5 & 4.0 \\
\hline 19 & 4 & 5 & 5 & 4.7 & 3 & 3 & 3 & 3.0 & 3 & 3 & 4 & 3.3 & 4 & 4 & 5 & 4.3 \\
\hline 20 & 4 & 5 & 5 & 4.7 & 3 & 4 & 5 & 4.0 & 4 & 4 & 1 & 3.0 & 2 & 1 & 3 & 2.0 \\
\hline 21 & 3 & 5 & 5 & 4.3 & 2 & 3 & 5 & 3.3 & 3 & 4 & 4 & 3.7 & 1 & 2 & 2 & 1.7 \\
\hline 22 & 3 & 5 & 4 & 4.0 & 3 & 4 & 5 & 4.0 & 4 & 3 & 2 & 3.0 & 2 & 2 & 4 & 2.7 \\
\hline 23 & 1 & 5 & 3 & 3.0 & 1 & 2 & 2 & 1.7 & 3 & 2 & 3 & 2.7 & 2 & 2 & 3 & 2.3 \\
\hline 24 & 1 & 5 & 2 & 2.7 & 1 & 2 & 3 & 2.0 & 4 & 2 & 1 & 2.3 & 2 & 2 & 3 & 2.3 \\
\hline 25 & 1 & 5 & 3 & 3.0 & 2 & 3 & 5 & 3.3 & 3 & 2 & 3 & 2.7 & 3 & 1 & 1 & 1.7 \\
\hline
\end{tabular}




\begin{tabular}{|c|c|c|c|c|c|c|c|c|c|c|c|c|c|c|c|c|c|}
\hline \multirow{2}{*}{ \#No } & \multicolumn{4}{|c|}{ Set 05} & \multicolumn{4}{|c|}{ Set 06} & \multicolumn{5}{|c|}{ Set 07} & \multicolumn{4}{|c|}{ Set 08} \\
\hline & 1 & 2 & 3 & Average & 1 & 2 & 3 & Average & 1 & 2 & 3 & 4 & Average & 1 & 2 & 3 & Average \\
\hline 1 & 2 & 2 & 4 & 2.7 & 3 & 3 & 4 & 3.3 & 4 & 2 & 3 & 1 & 2.5 & 4 & 3 & 5 & 3.0 \\
\hline 2 & 2 & 3 & 5 & 3.3 & 3 & 3 & 4 & 3.3 & 5 & 4 & 3 & 2 & 3.5 & 4 & 4 & 5 & 4.3 \\
\hline 3 & 3 & 2 & 5 & 3.3 & 5 & 4 & 5 & 4.7 & 4 & 3 & 3 & 2 & 3.0 & 2 & 2 & 3 & 2.0 \\
\hline 4 & 3 & 3 & 5 & 3.7 & 4 & 3 & 4 & 3.7 & 4 & 3 & 3 & 2 & 3.0 & 3 & 1 & 5 & 3.0 \\
\hline 5 & 2 & 3 & 5 & 3.3 & 2 & 2 & 4 & 2.7 & 5 & 3 & 3 & 1 & 3.0 & 3 & 3 & 4 & 3.7 \\
\hline 6 & 1 & 4 & 3 & 2.7 & 4 & 4 & 3 & 3.7 & 3 & 1 & 3 & 1 & 2.0 & 3 & 2 & 3 & 2.7 \\
\hline 7 & 2 & 4 & 3 & 3.0 & 3 & 3 & 4 & 3.3 & 5 & 5 & 2 & 2 & 3.5 & 1 & 3 & 5 & 2.7 \\
\hline 8 & 2 & 2 & 4 & 2.7 & 4 & 4 & 4 & 4.0 & 5 & 4 & 4 & 3 & 4.0 & 3 & 3 & 5 & 3.7 \\
\hline 9 & 3 & 3 & 5 & 3.7 & 3 & 3 & 4 & 3.3 & 5 & 5 & 3 & 3 & 4.0 & 1 & 2 & 2 & 2.0 \\
\hline 10 & 3 & 4 & 5 & 4.0 & 5 & 4 & 5 & 4.7 & 5 & 4 & 4 & 3 & 4.0 & 4 & 5 & 5 & 4.7 \\
\hline 11 & 1 & 2 & 3 & 2.0 & 4 & 4 & 4 & 4.0 & 5 & 4 & 3 & 2 & 3.5 & 5 & 5 & 5 & 4.3 \\
\hline 12 & 1 & 3 & 3 & 2.3 & 4 & 4 & 5 & 4.3 & 5 & 4 & 4 & 3 & 4.0 & 4 & 4 & 4 & 3.7 \\
\hline 13 & 4 & 5 & 5 & 4.7 & 3 & 3 & 3 & 3.0 & 5 & 4 & 4 & 3 & 4.0 & 3 & 4 & 4 & 3.3 \\
\hline 14 & 4 & 3 & 5 & 4.0 & 4 & 3 & 4 & 3.7 & 5 & 3 & 5 & 3 & 4.0 & 4 & 2 & 4 & 3.0 \\
\hline 15 & 3 & 4 & 5 & 4.0 & 5 & 5 & 4 & 4.7 & 5 & 4 & 3 & 2 & 3.5 & 3 & 4 & 5 & 3.0 \\
\hline 16 & 3 & 5 & 5 & 4.3 & 5 & 4 & 5 & 4.7 & 5 & 4 & 4 & 3 & 4.0 & 4 & 4 & 5 & 4.0 \\
\hline 17 & 4 & 3 & 3 & 3.3 & 5 & 5 & 5 & 5.0 & 5 & 4 & 5 & 4 & 4.5 & 4 & 5 & 5 & 4.3 \\
\hline 18 & 4 & 2 & 4 & 3.3 & 5 & 3 & 3 & 3.7 & 5 & 5 & 4 & 4 & 4.5 & 5 & 5 & 5 & 5.0 \\
\hline 19 & 3 & 4 & 4 & 3.7 & 4 & 3 & 4 & 3.7 & 5 & 3 & 4 & 2 & 3.5 & 4 & 5 & 5 & 4.0 \\
\hline 20 & 3 & 5 & 4 & 4.0 & 4 & 3 & 3 & 3.3 & 5 & 5 & 2 & 2 & 3.5 & 2 & 3 & 4 & 2.3 \\
\hline 21 & 3 & 5 & 4 & 4.0 & 3 & 3 & 5 & 3.7 & 5 & 3 & 3 & 1 & 3.0 & 3 & 3 & 5 & 3.3 \\
\hline 22 & 3 & 5 & 5 & 4.3 & 3 & 4 & 5 & 4.0 & 5 & 3 & 4 & 2 & 3.5 & 4 & 2 & 5 & 3.3 \\
\hline 23 & 3 & 3 & 4 & 3.3 & 4 & 4 & 5 & 4.3 & 5 & 3 & 5 & 3 & 4.0 & 3 & 4 & 5 & 3.7 \\
\hline 24 & 3 & 2 & 4 & 3.0 & 2 & 3 & 4 & 3.0 & 3 & 1 & 4 & 2 & 2.5 & 2 & 3 & 5 & 3.3 \\
\hline 25 & 3 & 2 & 4 & 3.0 & 3 & 2 & 2 & 2.3 & 4 & 4 & 3 & 3 & 3.5 & 4 & 5 & 5 & 3.3 \\
\hline
\end{tabular}




\begin{tabular}{|c|c|c|c|c|c|c|c|c|c|c|c|c|c|c|c|c|c|}
\hline \multirow{2}{*}{ \#No } & \multicolumn{4}{|c|}{ Set 09} & \multicolumn{4}{|c|}{ Set 10} & \multicolumn{5}{|c|}{ Set 11} & \multicolumn{4}{|c|}{ Set 12} \\
\hline & 1 & 2 & 3 & Average & 1 & 2 & 3 & Average & 1 & 2 & 3 & 4 & Average & 1 & 2 & 3 & Average \\
\hline 1 & 3 & 2 & 2 & 2.3 & 3 & 4 & 4 & 3.7 & 4 & 3 & 4 & 5 & 4.0 & 5 & 5 & 5 & 5.0 \\
\hline 2 & 4 & 5 & 2 & 3.7 & 3 & 5 & 3 & 3.7 & 1 & 3 & 3 & 5 & 3.0 & 5 & 5 & 3 & 4.3 \\
\hline 3 & 3 & 2 & 2 & 2.3 & 3 & 4 & 3 & 3.3 & 3 & 3 & 4 & 5 & 3.8 & 5 & 5 & 4 & 4.7 \\
\hline 4 & 2 & 5 & 3 & 3.3 & 3 & 1 & 2 & 2.0 & 3 & 3 & 5 & 5 & 4.0 & 5 & 5 & 5 & 5.0 \\
\hline 5 & 4 & 5 & 1 & 3.3 & 3 & 1 & 2 & 2.0 & 2 & 3 & 2 & 2 & 2.3 & 5 & 5 & 5 & 5.0 \\
\hline 6 & 5 & 3 & 2 & 3.3 & 3 & 3 & 4 & 3.3 & 2 & 3 & 3 & 3 & 2.8 & 5 & 5 & 4 & 4.7 \\
\hline 7 & 3 & 4 & 1 & 2.7 & 3 & 2 & 3 & 2.7 & 3 & 3 & 2 & 5 & 3.3 & 5 & 5 & 5 & 5.0 \\
\hline 8 & 5 & 5 & 3 & 4.3 & 3 & 1 & 2 & 2.0 & 2 & 3 & 2 & 2 & 2.3 & 5 & 5 & 4 & 4.7 \\
\hline 9 & 3 & 3 & 2 & 2.7 & 3 & 3 & 3 & 3.0 & 2 & 3 & 2 & 4 & 2.8 & 5 & 5 & 5 & 5.0 \\
\hline 10 & 5 & 5 & 3 & 4.3 & 3 & 3 & 3 & 3.0 & 2 & 3 & 1 & 3 & 2.3 & 5 & 5 & 4 & 4.7 \\
\hline 11 & 5 & 3 & 2 & 3.3 & 1 & 1 & 2 & 1.3 & 3 & 3 & 2 & 5 & 3.3 & 5 & 5 & 5 & 5.0 \\
\hline 12 & 5 & 3 & 4 & 4.0 & 1 & 1 & 2 & 1.3 & 3 & 3 & 5 & 2 & 3.3 & 5 & 5 & 5 & 5.0 \\
\hline 13 & 5 & 3 & 4 & 4.0 & 3 & 3 & 4 & 3.3 & 2 & 3 & 4 & 5 & 3.5 & 5 & 5 & 4 & 4.7 \\
\hline 14 & 5 & 3 & 3 & 3.7 & 2 & 3 & 2 & 2.3 & 3 & 3 & 4 & 5 & 3.8 & 5 & 5 & 4 & 4.7 \\
\hline 15 & 5 & 2 & 3 & 3.3 & 3 & 4 & 3 & 3.3 & 3 & 3 & 3 & 5 & 3.5 & 5 & 5 & 5 & 5.0 \\
\hline 16 & 5 & 4 & 4 & 4.3 & 3 & 3 & 3 & 3.0 & 2 & 3 & 3 & 5 & 3.3 & 5 & 5 & 3 & 4.3 \\
\hline 17 & 5 & 4 & 5 & 4.7 & 5 & 5 & 4 & 4.7 & 2 & 4 & 4 & 4 & 3.5 & 5 & 5 & 5 & 5.0 \\
\hline 18 & 5 & 5 & 5 & 5.0 & 4 & 3 & 4 & 3.7 & 3 & 4 & 4 & 3 & 3.5 & 5 & 5 & 5 & 5.0 \\
\hline 19 & 3 & 3 & 4 & 3.3 & 3 & 3 & 2 & 2.7 & 2 & 3 & 4 & 5 & 3.5 & 5 & 5 & 5 & 5.0 \\
\hline 20 & 4 & 2 & 4 & 3.3 & 3 & 3 & 3 & 3.0 & 3 & 3 & 1 & 5 & 3.0 & 5 & 5 & 3 & 4.3 \\
\hline 21 & 4 & 4 & 3 & 3.7 & 3 & 4 & 3 & 3.3 & 3 & 3 & 3 & 5 & 3.5 & 5 & 5 & 4 & 4.7 \\
\hline 22 & 4 & 4 & 2 & 3.3 & 3 & 3 & 2 & 2.7 & 2 & 3 & 3 & 2 & 2.5 & 5 & 5 & 3 & 4.3 \\
\hline 23 & 4 & 4 & 2 & 3.3 & 3 & 2 & 3 & 2.7 & 2 & 3 & 1 & 4 & 2.5 & 1 & 5 & 3 & 3.0 \\
\hline 24 & 4 & 5 & 4 & 4.3 & 2 & 1 & 2 & 1.7 & 2 & 3 & 2 & 3 & 2.5 & 1 & 5 & 3 & 3.0 \\
\hline 25 & 1 & 1 & 3 & 1.7 & 3 & 2 & 3 & 2.7 & 2 & 3 & 5 & 1 & 2.8 & 1 & 5 & 4 & 3.3 \\
\hline
\end{tabular}




\begin{tabular}{|c|c|c|c|c|c|c|c|c|c|c|c|c|}
\hline \multirow{2}{*}{ \#No } & \multicolumn{9}{|c|}{ Set 13} & \multicolumn{9}{|c|}{ Set 14} & \multicolumn{3}{|c|}{ Set 15} \\
\cline { 2 - 13 } & 1 & 2 & 3 & Average & 1 & 2 & 3 & Average & 1 & 2 & 3 & Average \\
\hline 1 & 2 & 5 & 4 & 3.7 & 2 & 5 & 4 & 3.7 & 4 & 2 & 2 & 2.7 \\
\hline 2 & 2 & 5 & 4 & 3.7 & 2 & 4 & 4 & 3.3 & 4 & 1 & 1 & 2.0 \\
\hline 3 & 2 & 4 & 4 & 3.3 & 2 & 4 & 4 & 3.3 & 4 & 3 & 3 & 3.3 \\
\hline 4 & 1 & 5 & 3 & 3.0 & 1 & 5 & 3 & 3.0 & 3 & 1 & 1 & 1.7 \\
\hline 5 & 1 & 5 & 3 & 3.0 & 2 & 5 & 3 & 3.3 & 3 & 1 & 1 & 1.7 \\
\hline 6 & 1 & 4 & 3 & 2.7 & 2 & 5 & 4 & 3.7 & 3 & 1 & 1 & 1.7 \\
\hline 7 & 1 & 3 & 3 & 2.3 & 2 & 4 & 4 & 3.3 & 3 & 2 & 2 & 2.3 \\
\hline 8 & 4 & 5 & 4 & 4.3 & 1 & 5 & 3 & 3.0 & 3 & 3 & 3 & 3.0 \\
\hline 9 & 2 & 5 & 4 & 3.7 & 2 & 5 & 4 & 3.7 & 4 & 2 & 2 & 2.7 \\
\hline 10 & 2 & 4 & 4 & 3.3 & 2 & 4 & 5 & 3.7 & 4 & 1 & 1 & 2.0 \\
\hline 11 & 3 & 5 & 4 & 4.0 & 2 & 5 & 4 & 3.7 & 3 & 2 & 2 & 2.3 \\
\hline 12 & 3 & 5 & 4 & 4.0 & 2 & 5 & 4 & 3.7 & 2 & 3 & 3 & 2.7 \\
\hline 13 & 3 & 5 & 4 & 4.0 & 2 & 5 & 4 & 3.7 & 3 & 4 & 4 & 3.7 \\
\hline 14 & 3 & 5 & 4 & 4.0 & 2 & 5 & 4 & 3.7 & 3 & 2 & 2 & 2.3 \\
\hline 15 & 3 & 5 & 4 & 4.0 & 2 & 5 & 4 & 3.7 & 3 & 4 & 4 & 3.7 \\
\hline 16 & 3 & 4 & 4 & 3.7 & 1 & 5 & 3 & 3.0 & 3 & 4 & 4 & 3.7 \\
\hline 17 & 3 & 4 & 3 & 3.3 & 1 & 5 & 3 & 3.0 & 2 & 3 & 3 & 2.7 \\
\hline 18 & 1 & 4 & 4 & 3.0 & 1 & 5 & 3 & 3.0 & 3 & 3 & 3 & 3.0 \\
\hline 19 & 2 & 4 & 4 & 3.3 & 1 & 5 & 3 & 3.0 & 2 & 1 & 1 & 1.3 \\
\hline 20 & 2 & 3 & 4 & 3.0 & 1 & 5 & 3 & 3.0 & 2 & 2 & 1 & 1.7 \\
\hline 21 & 2 & 2 & 4 & 2.7 & 2 & 5 & 4 & 3.7 & 2 & 2 & 2 & 2.0 \\
\hline 22 & 2 & 5 & 4 & 3.7 & 1 & 5 & 3 & 3.0 & 1 & 2 & 2 & 1.7 \\
\hline & & & & & & & & & \\
\hline 19
\end{tabular}




\begin{tabular}{|c|c|c|c|c|c|c|c|c|c|c|c|c|}
\hline \multirow{2}{*}{ \#No } & \multicolumn{4}{|c|}{ Set 16} & \multicolumn{4}{|c|}{ Set 17} & \multicolumn{4}{|c|}{ Set 18} \\
\hline & 1 & 2 & 3 & Average & 1 & 2 & 3 & Average & 1 & 2 & 3 & Average \\
\hline 1 & 5 & 5 & 5 & 5.0 & 3 & 4 & 5 & 4.0 & 5 & 4 & 4 & 4.3 \\
\hline 2 & 4 & 5 & 3 & 4.0 & 2 & 3 & 4 & 3.0 & 5 & 2 & 4 & 3.7 \\
\hline 3 & 5 & 5 & 4 & 4.7 & 2 & 4 & 4 & 3.3 & 4 & 1 & 5 & 3.3 \\
\hline 4 & 4 & 4 & 4 & 4.0 & 2 & 2 & 4 & 2.7 & 5 & 2 & 3 & 3.3 \\
\hline 5 & 5 & 4 & 4 & 4.3 & 3 & 4 & 3 & 3.3 & 5 & 2 & 4 & 3.7 \\
\hline 6 & 4 & 5 & 4 & 4.3 & 4 & 3 & 3 & 3.3 & 4 & 1 & 2 & 2.3 \\
\hline 7 & 4 & 4 & 4 & 4.0 & 2 & 4 & 4 & 3.3 & 3 & 1 & 2 & 2.0 \\
\hline 8 & 2 & 3 & 4 & 3.0 & 3 & 4 & 4 & 3.7 & 4 & 3 & 4 & 3.7 \\
\hline 9 & 4 & 5 & 4 & 4.3 & 2 & 4 & 3 & 3.0 & 5 & 3 & 4 & 4.0 \\
\hline 10 & 4 & 4 & 4 & 4.0 & 4 & 4 & 4 & 4.0 & 4 & 1 & 3 & 2.7 \\
\hline 11 & 5 & 5 & 4 & 4.7 & 3 & 3 & 2 & 2.7 & 5 & 1 & 3 & 3.0 \\
\hline 12 & 3 & 3 & 3 & 3.0 & 2 & 4 & 4 & 3.3 & 5 & 2 & 1 & 2.7 \\
\hline 13 & 5 & 5 & 4 & 4.7 & 3 & 3 & 4 & 3.3 & 5 & 2 & 3 & 3.3 \\
\hline 14 & 5 & 5 & 4 & 4.7 & 3 & 3 & 4 & 3.3 & 5 & 2 & 3 & 3.3 \\
\hline 15 & 5 & 5 & 4 & 4.7 & 4 & 4 & 5 & 4.3 & 5 & 3 & 4 & 4.0 \\
\hline 16 & 5 & 5 & 4 & 4.7 & 3 & 3 & 4 & 3.3 & 4 & 3 & 4 & 3.7 \\
\hline 17 & 5 & 4 & 4 & 4.3 & 3 & 3 & 4 & 3.3 & 4 & 1 & 3 & 2.7 \\
\hline 18 & 5 & 5 & 4 & 4.7 & 3 & 3 & 4 & 3.3 & 4 & 1 & 3 & 2.7 \\
\hline 19 & 5 & 5 & 4 & 4.7 & 2 & 2 & 3 & 2.3 & 4 & 1 & 3 & 2.7 \\
\hline 20 & 4 & 5 & 4 & 4.3 & 3 & 3 & 3 & 3.0 & 3 & 1 & 4 & 2.7 \\
\hline 21 & 1 & 4 & 2 & 2.3 & & & & & & & & \\
\hline 22 & 1 & 4 & 2 & 2.3 & & & & & & & & \\
\hline
\end{tabular}




\title{
Appendix B: Sample Survey Responses ${ }^{8}$
}

\section{Exhibit [1]}

\section{Survey: Bicycling Comfort on Shared Roads}

\author{
Years Biking: 36 \\ Sex: male \\ Age: 42
}

Self-score on Experience Level: 3

\begin{tabular}{|l|l|l|l|l|}
\hline Novice -1 & A bit experienced -2 & Well Experienced -3 & Expert rider -4 & Racer -5 \\
\hline
\end{tabular}

Please score each video on a scale of 1 (dangerous) to 5 (very comfortable) assuming you are the cyclist in the given situation.

\begin{tabular}{|l|l|l|l|l|}
\hline Dangerous - 1 & Uncomfortable - 2 & tolerable- 3 & Comfortable - 4 & Very Comfortable - 5 \\
\hline
\end{tabular}

\begin{tabular}{|c|c|}
\hline Video Number & Score (1-5) \\
\hline$\# 1$ & 2 \\
\hline$\# 2$ & 2 \\
\hline$\# 3$ & 4 \\
\hline$\# 4$ & 4 \\
\hline$\# 5$ & 3 \\
\hline$\# 6$ & 5 \\
\hline$\# 7$ & 2 \\
\hline \#8 & 2 \\
\hline$\# 9$ & 3 \\
\hline$\# 10$ & 3 \\
\hline$\# 11$ & 4 \\
\hline$\# 12$ & 5 \\
\hline$\# 13$ & 3 \\
\hline$\# 14$ & 3 \\
\hline$\# 15$ & 4 \\
\hline$\# 16$ & 2 \\
\hline$\# 17$ & 3 \\
\hline$\# 18$ & 2 \\
\hline$\# 19$ & 3 \\
\hline$\# 20$ & 4 \\
\hline$\# 21$ & 3 \\
\hline$\# 22$ & 4 \\
\hline$\# 23$ & 3 \\
\hline$\# 24$ & 4 \\
\hline$\# 25$ & 3 \\
\hline
\end{tabular}

\footnotetext{
${ }^{8}$ It was realised later during the survey that racers may not necessarily be more experienced with cycling in mixed traffic, hence respondents in this category were asked to select otherwise. Only 3 bicyclist were racers, and subsequently answered as expert riders.
} 
Exhibit [2]

\section{Survey: Bicycling Comfort on Shared Roads}

Years Biking: 16

Sex: female

Age: 22

Self-score on Experience Level: 3

\begin{tabular}{|l|l|l|l|l|}
\hline Novice -1 & A bit experienced -2 & Well Experienced -3 & Expert rider -4 & Racer -5 \\
\hline
\end{tabular}

Please score each video on a scale of 1 (dangerous) to 5 (very comfortable) assuming you are the cyclist in the given situation.

\begin{tabular}{|l|l|l|l|l|}
\hline Dangerous - 1 & Uncomfortable - 2 & tolerable- 3 & Comfortable - 4 & Very Comfortable - 5 \\
\hline
\end{tabular}

\begin{tabular}{|c|c|}
\hline Video Number & Score (1-5) \\
\hline$\# 1$ & 3 \\
\hline$\# 2$ & 3 \\
\hline$\# 3$ & 3 \\
\hline$\# 4$ & 4 \\
\hline$\# 5$ & 3 \\
\hline$\# 6$ & 4 \\
\hline$\# 7$ & 3 \\
\hline$\# 8$ & 2 \\
\hline$\# 9$ & 3 \\
\hline$\# 10$ & 3 \\
\hline$\# 11$ & 4 \\
\hline$\# 12$ & 4 \\
\hline$\# 13$ & 2 \\
\hline$\# 14$ & 4 \\
\hline$\# 15$ & 3 \\
\hline$\# 16$ & 3 \\
\hline$\# 17$ & 3 \\
\hline$\# 18$ & 2 \\
\hline$\# 19$ & 3 \\
\hline$\# 20$ & 4 \\
\hline$\# 21$ & 3 \\
\hline$\# 22$ & 4 \\
\hline$\# 23$ & 2 \\
\hline$\# 24$ & 2 \\
\hline$\# 25$ & 3 \\
\hline
\end{tabular}


Exhibit [3]

\section{Survey: Bicycling Comfort on Shared Roads}

Years Biking: 15

Sex: Male

Age: 21

Self-score on Experience Level: 4

\begin{tabular}{|l|l|l|l|l|}
\hline Novice -1 & A bit experienced -2 & Well Experienced -3 & Expert rider -4 & Racer -5 \\
\hline
\end{tabular}

Please score each video on a scale of 1 (dangerous) to 5 (very comfortable) assuming you are the cyclist in the given situation.

\begin{tabular}{|l|l|l|l|l|}
\hline Dangerous - 1 & Uncomfortable - 2 & tolerable- 3 & Comfortable - 4 & Very Comfortable - 5 \\
\hline
\end{tabular}

\begin{tabular}{|c|c|}
\hline Video Number & Score (1-5) \\
\hline$\# 1$ & 5 \\
\hline$\# 2$ & 3 \\
\hline$\# 3$ & 4 \\
\hline$\# 4$ & 5 \\
\hline$\# 5$ & 5 \\
\hline$\# 6$ & 4 \\
\hline$\# 7$ & 5 \\
\hline$\# 8$ & 4 \\
\hline$\# 9$ & 5 \\
\hline$\# 10$ & 4 \\
\hline$\# 11$ & 5 \\
\hline$\# 12$ & 5 \\
\hline$\# 13$ & 4 \\
\hline$\# 14$ & 4 \\
\hline$\# 15$ & 5 \\
\hline$\# 16$ & 3 \\
\hline$\# 17$ & 5 \\
\hline$\# 18$ & 5 \\
\hline$\# 19$ & 5 \\
\hline$\# 20$ & 3 \\
\hline$\# 21$ & 4 \\
\hline$\# 22$ & 3 \\
\hline$\# 23$ & 3 \\
\hline$\# 24$ & 3 \\
\hline$\# 25$ & 4 \\
\hline
\end{tabular}


Exhibit [4]

\section{Survey: Bicycling Comfort on Shared Roads}

Years Biking: 38 Sex: $F \quad$ Age: 44

Self-score on Experience Level:

\begin{tabular}{|l|l|l|l|l|}
\hline Novice - 1 & A bit experienced - 2 (Well Experienced - 3) & Expert rider - 4 & Racer - 5 \\
\hline
\end{tabular}

Please score each video on a scale of 1 (dangerous) to 5 (very comfortable) assuming you are the cyclist in the given situation.

\begin{tabular}{|l|l|l|l|l|}
\hline Dangerous - 1 & Uncomfortable - 2 & tolerable- 3 & Comfortable - 4 & Very Comfortable - 5 \\
\hline
\end{tabular}

\begin{tabular}{|c|c|}
\hline Video Number & Score (1-5) \\
\hline$\# 1$ & 3 \\
\hline$\# 2$ & 3 \\
\hline$\# 3$ & 3 \\
\hline \#4 & 3 \\
\hline H5 & 3 \\
\hline$\# 6$ & 3 \\
\hline$\# 7$ & 3 \\
\hline$\# 8$ & 3 \\
\hline$\# 9$ & 3 \\
\hline$\# 10$ & 3 \\
\hline$\# 11$ & 1 \\
\hline$\# 12$ & j \\
\hline$\# 13$ & 3 \\
\hline$\# 14$ & 2 \\
\hline$\# 15$ & 3 \\
\hline$\# 16$ & 3 \\
\hline$\# 17$ & 5 \\
\hline$\# 18$ & 4 \\
\hline$\# 19$ & 3 \\
\hline$\# 20$ & 3 \\
\hline$\# 21$ & 3 \\
\hline$\# 22$ & 3 \\
\hline$\# 23$ & 3 \\
\hline$\# 24$ & 2 \\
\hline$\# 25$ & 3 \\
\hline
\end{tabular}


Exhibit [5]

\section{Survey: Bicycling Comfort on Shared Roads}

Years Biking: 5

Sex: male

Age: 15

Self-score on Experience Level: 5

\begin{tabular}{|l|l|l|l|l|}
\hline Novice -1 & A bit experienced - 2 & Well Experienced -3 & Expert rider -4 & Racer -5 \\
\hline
\end{tabular}

Please score each video on a scale of 1 (dangerous) to 5 (very comfortable) assuming you are the cyclist in the given situation.

\begin{tabular}{|l|l|l|l|l|}
\hline Dangerous - 1 & Uncomfortable - 2 & tolerable- 3 & Comfortable - 4 & Very Comfortable - 5 \\
\hline
\end{tabular}

\begin{tabular}{|c|c|}
\hline Video Number & Score (1-5) \\
\hline$\# 1$ & 4 \\
\hline$\# 2$ & 3 \\
\hline$\# 3$ & 4 \\
\hline$\# 4$ & 5 \\
\hline \#5 & 2 \\
\hline$\# 6$ & 3 \\
\hline$\# 7$ & 2 \\
\hline$\# 8$ & 2 \\
\hline$\# 9$ & 2 \\
\hline$\# 10$ & 1 \\
\hline$\# 11$ & 2 \\
\hline$\# 12$ & 5 \\
\hline$\# 13$ & 4 \\
\hline$\# 14$ & 4 \\
\hline$\# 15$ & 3 \\
\hline$\# 16$ & 3 \\
\hline$\# 17$ & 4 \\
\hline$\# 18$ & 4 \\
\hline$\# 19$ & 4 \\
\hline$\# 20$ & 1 \\
\hline$\# 21$ & 3 \\
\hline$\# 22$ & 3 \\
\hline$\# 23$ & 1 \\
\hline$\# 24$ & 2 \\
\hline$\# 25$ & 5 \\
\hline
\end{tabular}


Appendix C: Base Models for PD and BCP

Summary Statistics of Passing Distance Base Model

\begin{tabular}{|c|c|c|c|c|c|c|}
\hline Variable & Coefficient & SE & t - stat. & $P>|t|$ & \multicolumn{2}{|c|}{ 95\% Conf. Interval } \\
\hline ATD & -0.00525 & 0.00180 & -2.91 & 0.004 & -0.00879 & -0.0017053 \\
\hline Bicycle Position & -0.12611 & 0.05642 & -2.24 & 0.026 & -0.23693 & -0.0152942 \\
\hline Lane Width & 0.51933 & 0.07328 & 7.09 & 0 & 0.375398 & 0.6632599 \\
\hline No. of Lanes & 0.30586 & 0.07686 & 3.98 & 0 & 0.154883 & 0.4568316 \\
\hline Bicycle Speed & -0.01875 & 0.00463 & -4.05 & 0 & -0.02783 & -0.0096598 \\
\hline Motor Speed & 0.01523 & 0.00200 & 7.62 & 0 & 0.011302 & 0.0191558 \\
\hline Grade & 0.20386 & 0.06823 & 2.99 & 0.003 & 0.069839 & 0.3378818 \\
\hline Parking & 0.34545 & 0.09398 & 3.68 & 0 & 0.160844 & 0.5300498 \\
\hline Intercept & -0.81105 & 0.46413 & -1.75 & 0.081 & -1.72273 & 0.1006234 \\
\hline \multicolumn{2}{|c|}{ R-squared: 0.2609} & \multicolumn{3}{|c|}{ RMSE: .44988 } & & \\
\hline \multicolumn{2}{|c|}{ Adjusted $R$-squared: 0.2503} & \multicolumn{3}{|c|}{$p$-value: $<1.8 e-15$} & & \\
\hline
\end{tabular}

Summary Statistics of Bicycle Comfort Perception Base Model

\begin{tabular}{|c|c|c|c|c|c|c|}
\hline Variable & Coefficient & SE & $\mathrm{t}$ - stat. & $P>|t|$ & \multicolumn{2}{|c|}{ 95\% Conf. Interval } \\
\hline ATD & -0.01898 & 0.00302 & -6.28 & 0.00 & -0.02 & -0.01 \\
\hline Passing Distance & 0.51228 & 0.06845 & 7.48 & 0.00 & 0.38 & 0.65 \\
\hline Bicycle Position & 0.10714 & 0.09215 & 1.16 & 0.25 & -0.07 & 0.29 \\
\hline Lane Width & -0.15168 & 0.11528 & -1.32 & 0.19 & -0.38 & 0.07 \\
\hline No. of Lanes & -0.71000 & 0.14331 & -4.95 & 0.00 & -0.99 & -0.43 \\
\hline Bicycle Speed & -0.01431 & 0.00759 & -1.89 & 0.06 & -0.03 & 0.00 \\
\hline Motor Speed & -0.00867 & 0.00365 & -2.38 & 0.02 & -0.02 & 0.00 \\
\hline Grade & -0.16356 & 0.13269 & -1.23 & 0.22 & -0.42 & 0.10 \\
\hline Parking & -0.75187 & 0.15134 & -4.97 & 0.00 & -1.05 & -0.45 \\
\hline Intercept & 5.17636 & 0.71123 & 7.28 & 0.00 & 3.78 & 6.57 \\
\hline \multicolumn{2}{|c|}{ R-squared: 0.3332} & \multicolumn{2}{|c|}{ RMSE: .67277 } & & & \\
\hline \multicolumn{2}{|c|}{ Adjusted R-squared: 0.3205} & \multicolumn{2}{|c|}{$p$-value: $<0.00001$} & & & \\
\hline
\end{tabular}

